Guidelines

\title{
Guidelines for the Surgical Management of Oral Cancer: Korean Society of Thyroid-Head and Neck Surgery
}

\author{
Korean Society of Thyroid-Head and Neck Surgery Guideline Task Force \\ Young-Hoon Joo ${ }^{1, *}$ (i) $\cdot$ Jae-Keun $\mathrm{Cho}^{2, \star} \cdot$ Bon Seok Koo ${ }^{3} \cdot$ Minsu Kwon $^{4} \cdot$ Seong Keun Kwon ${ }^{5} \cdot$ Soon Young Kwon ${ }^{6}$ \\ Min-Su Kim ${ }^{7} \cdot$ Jeong Kyu Kim ${ }^{8} \cdot$ Heejin Kim ${ }^{9} \cdot$ Innchul Nam$^{1} \cdot$ Jong-Lyel Roh ${ }^{10} \cdot$ Young Min Park $^{11} \cdot$ II-Seok Park ${ }^{9}$ \\ Jung Je Park ${ }^{12}$. Sung-Chan Shin ${ }^{13}$. Soon-Hyun Ahn ${ }^{5}$ Seongjun Won ${ }^{12}$. Chang Hwan Ryu ${ }^{14} \cdot$ Tae Mi Yoon $^{15}$ \\ Giljoon Lee ${ }^{16} \cdot$ Doh Young Lee ${ }^{5}$ Myung-Chul Lee ${ }^{17} \cdot$ Joon Kyoo Lee ${ }^{15} \cdot$ Jin Choon Lee ${ }^{13} \cdot$ Jae Yol Lim ${ }^{11}$ \\ Jae Won Chang ${ }^{3} \cdot$ Jeon Yeob Jang ${ }^{18} \cdot$ Man Ki Chung $^{19} \cdot$ Yuh-Seok Jung ${ }^{14} \cdot$ Jae-Gu Cho $^{6} \cdot$ Yoon Seok Choi20 \\ Jeong-Seok Choi $^{21} \cdot$ Guk Haeng Lee ${ }^{17}$ (B) Phil-Sang Chung ${ }^{22}$ (i) \\ Department of Otorhinolaryngology Head and Neck Surgery, ${ }^{\prime}$ College of Medicine, The Catholic University of Korea, Seoul, ${ }^{2}$ Inje University \\ College of Medicine, Busan; ${ }^{3}$ Chungnam National University School of Medicine, Daejeon; ${ }^{4} E u l j i$ University School of Medicine, Daejeon; ${ }^{5}$ Seoul \\ National University College of Medicine, Seoul; ${ }^{6}$ Korea University College of Medicine, Seoul; ${ }^{7}$ CHA University School of Medicine, Seongnam; \\ ${ }^{8}$ Catholic University of Daegu School of Medicine, Daegu; ${ }^{9}$ Hallym University College of Medicine, Seoul; ${ }^{10}$ Asan Medical Center, University of \\ Ulsan College of Medicine, Seoul; ${ }^{11}$ Yonsei University College of Medicine, Seoul; ${ }^{12}$ Gyeongsang National University School of Medicine, Jinju; \\ ${ }^{13}$ Pusan National University School of Medicine, Busan; ${ }^{14}$ National Cancer Center, Goyang; ${ }^{15}$ Chonnam National University Medical School, \\ Hwasun; ${ }^{16}$ School of Medicine, Kyungpook National University, Daegu; ${ }^{17}$ Korea Cancer Center Hospital, Seoul, ${ }^{18}$ Ajou University School of \\ Medicine, Suwon; ${ }^{19}$ Sungkyunkwan University School of Medicine, Seoul; ${ }^{20}$ Yeungnam University College of Medicine, Daegu; \\ ${ }^{21}$ Inha University School of Medicine, Incheon; ${ }^{22}$ Dankook University College of Medicine, Cheonan, Korea
}

\begin{abstract}
Korean Society of Thyroid-Head and Neck Surgery appointed a Task Force to provide guidance on the implementation of a surgical treatment of oral cancer. MEDLINE databases were searched for articles on subjects related to "surgical management of oral cancer" published in English. Results were restricted to systematic reviews, randomized control trials/controlled clinical trials, and observational studies. The quality of evidence was rated with use RoBANS (Risk of Bias Assessment Tool for Nonrandomized Studies) and AMSTAR (A Measurement Tool to Assess the Methodological Quality of Systematic Reviews). Evidence-based recommendations for practice were ranked according to the American College of Physicians grading system. Additional directives are provided as expert opinions and Delphi questionnaire when insufficient evidence existed. The Committee developed 68 evidence-based recommendations in 34 categories intended to assist clinicians and patients and counselors, and health policy-makers. Proper surgical treatment selection for oral cancer, which is directed by patient- and subsite-specific factors, remains the greatest predictor of successful treatment outcomes. These guidelines are intended for use in conjunction with the individual patient's treatment goals.
\end{abstract}

Keywords. Mouth Neoplasms; Squamous Cell Carcinoma; Surgery; Guideline; Republic of Korea

\footnotetext{
- Received December 6, 2018

Accepted December 14, 2018

- Corresponding author: Guk Haeng Lee

Department of Otorhinolaryngology Head and Neck Surgery,

Korea Cancer Center Hospital, 75 Nowon-ro, Nowon-gu,

Seoul 01812, Korea

Tel: +82-2-970-1272, Fax: +82-2-970-2450

E-mail: ghlee@kcch.re.kr
}

Copyright $\odot 2019$ by Korean Society of Otorhinolaryngology-Head and Neck Surgery.

This is an open-access article distributed under the terms of the Creative Commons Attribution Non-Commercial License (http://creativecommons.org/licenses/by-nc/4.0) which permits unrestricted non-commercial use, distribution, and reproduction in any medium, provided the original work is properly cited. 


\section{INTRODUCTION}

Oral cancer has a worldwide incidence of 300,400 cases and is responsible for 145,400 deaths annually [1]. Oral cancer has a 5 -year survival rate of $50 \%-60 \%$ [2]. The distribution of oral cancer is approximately $32 \%$ in the buccal mucosa, $22 \%$ in tongue, $11 \%$ in lower lip, $11 \%$ in palate, $8 \%$ in vestibule, $5 \%$ in alveolus, $5 \%$ in floor of the mouth (FOM), and 3\% in the gingiva [3]. Due to the heterogeneous nature of oral cancer, the functional and cosmetic results, and the coexistence of frequent medical comorbidities, treatment options should be evaluated through the multidisciplinary team and evaluated before reaching the final plan. In many countries, surgery remains the first option of treatment for oral cancer [2].

The effects of oral cancer surgery can have a serious impact on a patient's quality of life and can impair appearance and functional characteristics such as speech, mastication, and swallowing [4]. Therefore, these guidelines focus on oral cancer surgical treatment under the assumption that surgery is a chosen treatment after a multidisciplinary discussion under any circumstances. The Korean Society of Otorhinolaryngology-Head and Neck Surgery released guidelines for the standard management of oral cancer in 2011 and the Korean Society of Thyroid-Head and Neck Surgery (KSTHNS) published treatment guidelines for patients with laryngeal cancer in 2017 [5]. There have been many advances in oral cancer diagnosis and treatment over the past decades, but clinical debate exists in many areas. These guidelines summarize advances in the surgical management of oral cancer, including preoperative diagnostic techniques and postoperative management.

\section{Target population}

These guidelines apply to clinicians, patients, researchers, and health policy makers involved in diagnosis and treatment of oral cancer patients. These recommendations focus on diagnosis and work up, prevention, surgical treatment, postoperative care, and salvage surgery of oral cancer. Separate recommendations for initial surgical treatment are given for each subsite such as the oral tongue, maxillary gingiva and hard palate, mandibular gingiva, FOM, buccal mucosa, and the retromolar trigone (RMT).

\section{H I G H L I G G H T S}

- The Korean Society of Thyroid-Head and Neck Surgery (KSTHNS) developed the practice guideline about surgical treatment of oral cancer.

- These guidelines provide suitable treatment options following subsites of oral cavity and suggest proper reconstruction methods with considering defect site.

- Authors summarizes advances in the surgical management of oral cancer, including preoperative diagnostic methods and postoperative management.

\section{Intended users}

These guidelines are primarily for head and neck surgeons to treat oral cancer patients. These guidelines are comprehensive updates to the current surgical treatment methods for patients with oral cancer. All patients should have access to full support services and oral cancer care professionals for optimal treatment and follow-up. These guidelines provide general depth in the assessment and surgery of oral cancer and are intended for use by clinicians working in multidisciplinary team settings, including medical and radiation oncologists, plastic and reconstructive surgeons, specialized nurses, dentists, physical medicine and rehabilitation workers, speech and swallowing therapists, and counselors who provide patient support.

\section{MATERIALS AND METHODS}

\section{Organization of the committee}

The KSTHNS's guideline committee developed the clinical recommendations. Task Force Chairman (KHL) has been appointed by the PSTHNS President (PSJ) with the approval of the committee. A task force consisting of 31 experts with complementary expertise was appointed. The guideline committee had complete editorial independence from the KSTHNS. The clinical guideline committee participated in a conference call to review and evaluate the development of various recommendations and guidelines at regularly scheduled face-to-face meetings.

\section{Literature search and quality assessment}

This literature search was performed on November 12, 2017. A literature search was conducted with the support of four databases including MEDLINE, EMBASE, Cochrane Library, and KoreaMed.The search string used was: (oral OR mouth/exp OR mouth OR oris) OR (tongue* or gloss* or lingua*) OR ("mouth floor" or "floor of mouth" or sublingua* or "mouth floors" or "floors of mouth) OR (gingiva* or gum* or "interdental papilla" or "alveolar process" or "alveolar processes" or " alveolar ridge") OR ("hard palate" or "hard palates" or "palatine bone") OR ("buccal mucosa" or "mouth mucosa" or "oral mucosa" or bucca* or "buccal mucosal" or "mouth mucosal" or "oral mucosal") OR (retromola*) OR (neoplasms or cancer or carcinoma or malignant or malignancy or tumor or tumour). During the search, we applied the following limits: search fields:Title,Abstract, Key-words; publication type: article, review, article in press; species: humans. In order to obtain an adequate number of papers, the search was not limited by publication year. After reviewing the title, unrelated documents were excluded. The remaining selected documents were independently reviewed by two committee members who decided whether to exclude or include the documents. Key questions selected, the number of documents retrieved, and keywords used in the search results are shown in Supplementary Table 1. 
Table 1. Interpretation of American College of Physicians grading system

\begin{tabular}{|c|c|c|c|}
\hline Grade of recommendation & Benefit vs. risks and burdens & Interpretation & Implication \\
\hline \multicolumn{4}{|l|}{ Strong recommendation } \\
\hline $\begin{array}{l}\text { High-quality evidence } \\
\text { Moderate-quality evidence } \\
\text { Low-quality evidence }\end{array}$ & $\begin{array}{l}\text { Benefits clearly outweigh risks and } \\
\text { burden or vice versa. }\end{array}$ & $\begin{array}{l}\text { Strong recommendation, can apply } \\
\text { to most patients in most } \\
\text { circumstances without reservation. } \\
\text { Strong recommendation, but may } \\
\text { change when higher-quality } \\
\text { evidence becomes available. }\end{array}$ & $\begin{array}{l}\text { For patients: most would want the } \\
\text { recommended course and only a } \\
\text { small proportion would not. } \\
\text { For clinicians: most patients should } \\
\text { receive the recommended course } \\
\text { of action. }\end{array}$ \\
\hline \multicolumn{4}{|l|}{ Weak recommendation } \\
\hline $\begin{array}{l}\text { High-quality evidence } \\
\text { Moderate-quality evidence } \\
\text { Low-quality evidence }\end{array}$ & $\begin{array}{l}\text { Benefits closely balanced with risk } \\
\text { and burden. } \\
\text { Uncertainty in the estimates of } \\
\text { benefits, risks, and burden; } \\
\text { benefits, risks, and burden may } \\
\text { be closely balanced. }\end{array}$ & $\begin{array}{l}\text { Weak recommendation, best action } \\
\text { may differ depending on } \\
\text { circumstances or patients' or } \\
\text { societal values. } \\
\text { Very weak recommendation, other } \\
\text { alternatives may be reasonable. }\end{array}$ & $\begin{array}{l}\text { For patients: most would want the } \\
\text { recommended course of action but } \\
\text { some would not. A decision may } \\
\text { depend on an individual's } \\
\text { circumstances. } \\
\text { For clinicians: different choices will } \\
\text { be appropriate for different } \\
\text { patients, and a management } \\
\text { decision consistent with a patient's } \\
\text { values, preferences, and } \\
\text { circumstances should be reached. }\end{array}$ \\
\hline \multicolumn{4}{|l|}{ No recommendation } \\
\hline Insufficient evidence & $\begin{array}{l}\text { Balance of benefits and risks cannot } \\
\text { be determined. }\end{array}$ & $\begin{array}{l}\text { Insufficient evidence to recommend } \\
\text { for or against routinely providing } \\
\text { the service }\end{array}$ & $\begin{array}{l}\text { For patients: decisions based on } \\
\text { evidence from scientific studies } \\
\text { cannot be made. } \\
\text { For clinicians: decisions based on } \\
\text { evidence from scientific studies } \\
\text { cannot be made. }\end{array}$ \\
\hline
\end{tabular}

\section{Qualification of literature and evidence levels, and grades of recommendations}

Quality of evidence for use in these guidelines was evaluated by the American College of Physicians (ACP) guideline grading system, as related to critical appraisal and recommendations on therapeutic interventions (Table 1). The review of evidence under ACP guidance provides information on whether the studies included in the evidence review are reliable and accurate, and provides a reasonable assessment of potential adverse events. RoBANS (Risk of Bias Assessment Tool for Nonrandomized Study) was used to test non-critical control (non-randomized controlled trials [RCTs]) and to assess the quality of observational studies, and AMSTAR (A Measurement Tool to Assess the Methodological Quality of Systematic Reviews) was used for systematic review and metaanalysis evaluation [6,7]. Similar to our committee's previous guidelines, evidence levels were classified as high-quality, moderate-quality, or low-quality evidence (Table 2) [5]. This system provides the highest level of RCT, the lowest level of case series or expert opinion. The hierarchies rank studies according to the probability of bias. RCTs are placed at the highest level because they are not biased and have a low risk of systematic errors. The case series or expert opinion is often biased by the author's experience or opinion and cannot control the confounding factor. Evidence may be inconsistent, poor or insufficient, and thus cannot determine the balance of benefits and risks. Lack of evidence has resulted in a "no recommendation" decision. No recommen-
Table 2. Level of evidence

\begin{tabular}{lr}
\hline Term & \multicolumn{1}{c}{ Definition } \\
\hline High-quality evidence & $\begin{array}{r}\text { RCT without important limitations or } \\
\text { overwhelming evidence from } \\
\text { observational study }\end{array}$ \\
Moderate-quality evidence & RCT with important limitations or strong \\
& evidence from observational studies \\
Low-quality evidence & Observational studies/case studies \\
\hline
\end{tabular}

$\mathrm{RCT}$, randomized controlled trial.

dation does not mean that the committee opposes the action, only that it cannot decide for or against the matter.

A Delphi method was used to establish consensus. Head and neck surgeons with more than 10 years of experience were invited to participate as part of the panel of experts. In the first round, 67 best practice rec-ommendations were distributed to the panel. The panel members were asked to provide comments on each recommendation with "fully agree," "agree," "neither agree nor disagree," "disagree," or "totally disagree.” The recommendation was finally accepted if more than two-thirds of the panel members answered with "fully agree" or "agree." After the first round, 36 surgeons answered the first Delphi question. Consensus was achieved for 65 of the 67 recommendations (97\%) (Supplementary Table 2). Recommendations that failed to reach an agreement by two-thirds were modified according to feedback from expert panels and redistributed to second-round panels. In 
the second round, experts used the same voting methods described in the first round, but were aware of group scores and comments. The final response was analyzed as described in round one, and two recommendations were resolved by consensus on the entire panel of experts. The organization of the management guideline recommendations is shown in Table 3 .

Table 3. Organization of the KSTHNS guidelines of surgical treatment for oral cancer

\begin{tabular}{|c|c|c|}
\hline Location key & Section & Item \\
\hline & Guidelines for surgical treatment for oral cancer & $\mathrm{R} 1$ \\
\hline A & Diagnosis and work up of oral cancer & \\
\hline A1 & What is the role of a biopsy and physical examination in the diagnosis of oral cancer? & $\mathrm{R} 2$ \\
\hline A2 & What is the role of assessment of oral function in the treatment planning for oral cancer? & R3 \\
\hline $\mathrm{A} 3$ & How can we evaluate second primary malignancies in patients with oral cancer? & R4 \\
\hline A4 & What is the role of CT in the preoperative evaluation of oral cancer? & R5 \\
\hline A5 & What is the role of MRI in the preoperative evaluation of oral cancer? & R6 \\
\hline A6 & What is the role of PET/CT in the preoperative evaluation of oral cancer? & $\mathrm{R} 7$ \\
\hline A7 & What is the role of US in the preoperative evaluation of oral cancer? & $\mathrm{R} 8$ \\
\hline B & Prevention of oral cancer & \\
\hline B1 & What is the role of intervention for smoking and drinking cessation in preventing oral cancer? & R9 \\
\hline B2 & What is the role of oral care in preventing oral cancer? & $\mathrm{R} 10$ \\
\hline $\mathrm{C}$ & Surgical management of oral cancer according to subsites & \\
\hline $\mathrm{C} 1$ & Which approach is appropriate for oral cancer? & $\mathrm{R} 11$ \\
\hline $\mathrm{C} 2$ & Oral tongue cancer & \\
\hline $\mathrm{C} 2-1$ & What is the adequate resection margin for oral tongue cancer? & $\mathrm{R} 12$ \\
\hline $\mathrm{C} 2-2$ & What is the influence of tumor thickness on surgery-planning? & $\mathrm{R} 13$ \\
\hline C3 & Maxillary gingiva and hard palate cancer & $\mathrm{R} 14$ \\
\hline $\mathrm{C} 4$ & Mandibular gingival cancer & \\
\hline C4-1 & What is the adequate resection margin for mandibular gingival cancer? & $\mathrm{R} 15$ \\
\hline C4-2 & Is mandibulectomy mandatory when oral cancer abuts the periosteum of the mandible? & $\mathrm{R} 16$ \\
\hline C4-3 & What is the appropriate extent of mandibulectomy to be applied when oral cancer invades the marrow of the mandible? & $\mathrm{R} 17$ \\
\hline C5 & Floor of the mouth cancer & $\mathrm{R} 18$ \\
\hline C6 & Buccal mucosa cancer & R19 \\
\hline $\mathrm{C} 7$ & Retromolar trigone cancer & $\mathrm{R} 20$ \\
\hline C8 & $\begin{array}{l}\text { Neck management for oral cancer } \\
\text { What is the appropriate strategy for the management of cervical lymph nodes in oral cancer? }\end{array}$ & \\
\hline C8-1 & Management for clinically negative neck (N-) in patients with oral cancer & $\mathrm{R} 21$ \\
\hline C8-2 & Extent of neck dissection for clinically negative neck ( $\mathrm{N}-$-) in oral cancer & $\mathrm{R} 22$ \\
\hline C8-3 & Sentinel node biopsy for clinically negative neck ( $\mathrm{N}-$ ) in oral cancer & $\mathrm{R} 23$ \\
\hline C8-4 & Management of clinically positive neck $(\mathrm{N}+)$ in patients with oral cancer & $\mathrm{R} 24$ \\
\hline C9 & $\begin{array}{l}\text { Reconstruction for oral cancer defects } \\
\text { What are the appropriate reconstruction methods for oral cancer defects? }\end{array}$ & \\
\hline C9-1 & Soft tissue reconstruction for oral cancer defects & $\mathrm{R} 25$ \\
\hline C9-2 & Mandibular reconstruction for oral cancer defects & R26 \\
\hline $\mathrm{D}$ & $\begin{array}{l}\text { Postoperative follow-up } \\
\text { How can we postoperatively follow-up patients with oral cancer? }\end{array}$ & \\
\hline D1 & Long-term follow-up schedules & $\mathrm{R} 27$ \\
\hline D2 & Tests during the follow-up period & $\mathrm{R} 28$ \\
\hline D3 & Thyroid function evaluation & $\mathrm{R} 29$ \\
\hline$E$ & $\begin{array}{l}\text { Rehabilitation } \\
\text { What are the appropriate rehabilitation and supportive therapy options after anticancer treatment? }\end{array}$ & \\
\hline E1 & Speech therapy and swallowing rehabilitation & $\mathrm{R} 30$ \\
\hline E2 & Shoulder rehabilitation & R31 \\
\hline E3 & Lifestyle modification & R32 \\
\hline E4 & Psychiatric support & R33 \\
\hline $\mathrm{F}$ & Salvage surgery & \\
\hline $\mathrm{F} 1$ & What is role of salvage surgery in the recurrent oral cavity cancer? & R34 \\
\hline
\end{tabular}

KSTHNS, Korean Society of Thyroid-Head and Neck Surgery; CT, computed tomography; MRI, magnetic resonance imaging; PET/CT, positron emission tomography/computed tomography; US, ultrasonography. 


\section{GUIDELINES FOR SURGICALTREATMENT OF ORAL CANCER}

\section{Recommendation 1}

Decisions regarding treatment for oral cancer patients should be made as a result of discussion with the multidisciplinary team and sufficient information should be given to patients about the role of chemotherapy, radiation therapy and surgery (strong recommendation, high-quality evidence).

\section{A. Diagnosis and work up of oral cancer}

A1. What is the role of a biopsy and physical examination in the diagnosis of oral cancer?

\section{Recommendation 2}

(A) Tissue biopsy and histologic examination are essential for the diagnosis of oral cancer (strong recommendation, high-quality evidence).

(B) Adjunctive tests are useful but cannot replace traditional biopsy for the definitive diagnosis of oral cancer (weak recommendation, high-quality evidence).

(C) Population-based screening programs are necessary to reduce oral cancer mortality in high-risk individuals who use tobacco, alcohol, or both alcohol and tobacco (strong recommendation, high-quality evidence).

(D) Potentially malignant disorders (PMDs) should be carefully followed up (strong recommendation, moderatequality evidence).

Early recognition and diagnosis of PMDs (such as erythroplakia, leukoplakia, lichen planus, oral submucous fibrosis, discoid lupus erythematosus and actinic keratosis) and oral cancer can improve the survival rate and reduce treatment-related morbidity [8]. Advancements have been made in many technologies for the diagnosis of PMD and oral cancer, such vital staining, oral cytology, light-based detection, oral spectroscopy, and blood and saliva analysis; these details are summarized in Table $4[9,10]$. These advances in noninvasive technologies have been reported to show various degrees of sensitivity and specificity, and are promising for the future development of more effective methods for the diagnosis of oral cancer. However, sufficient evidence or crucial details were missing to rule out the risk of bias in the systematic reviews of these techniques. Therefore, further investigation with more extensive and exhaustive studies are warranted [9-11]. These advanced techniques may be helpful for use as adjunctive tests; however, none of these techniques can be recommended as replacements for definitive tissue biopsy.

All oral lesions should be considered for histologic examination and clinical impression is not an acceptable alternative to definitive biopsy. If this is not good, careful clinical surveillance is essential [12]. PMDs have the potential to develop into cancers, even though this may take time and the possibility may be small. Studies including a long-term follow-up provide evidence for the malignant transformation of PMDs. Therefore, it is essential for clinicians to perform regular observation and followup in patients with these conditions [13-15]. Oral cancer is an important global health problem with high mortality and morbidity rates. For accurate early detection and treatment, population-based screening programs have been introduced. A nation-wide RCT concluded that a visual examination as part of an opportunistic population-based screening can reduce the mortality rate and improve survival rate with a stage shift for high-risk groups who used tobacco, alcohol, or both alcohol and tobacco [16-20].

\section{A2. What is the role of assessment of oral function in the treat- ment planning for oral cancer?}

\section{Recommendation 3}

Oral functions such as mastication, speech, and swallowing may be assessed preoperatively (weak recommendation, moderate-quality evidence).

Table 4. List of the noninvasive technologies for the diagnosis of oral cavity cancer

\begin{tabular}{|c|c|}
\hline Diagnostic method & Content \\
\hline Vital staining & Toluidine blue, 5\% acetic acid, methylene blue, Lugol's iodine, rose bengal, iodine staining, Tolonium chloride \\
\hline Cytological techniques & Oral brush biopsy (Oral CDx), liquid based cytology, laser capture microdissection \\
\hline Light-based detection system & $\begin{array}{l}\text { Tissue fluorescence imaging (VELscope, identafi 3000), chemiluminiscence (ViziLite plus, Microlux/DL, } \\
\text { Orascoptic-DK), tissue fluorescence spectroscopy (NBI) }\end{array}$ \\
\hline Optical biopsy & $\begin{array}{l}\text { Tissue fluorescence spectroscopy, Raman spectroscopy, elastic scattering spectroscopy, differential path-length } \\
\text { spectroscopy, nuclear magnetic resonance spectroscopy, confocal reflectance microscopy, optical coherence } \\
\text { tomography, angle-resolved low coherence interferometry }\end{array}$ \\
\hline Saliva-based oral cancer diagnosis & Genomic substances, transcriptomic substances, proteomic substances \\
\hline Other techniques & $\begin{array}{l}\text { Molecular analyses (gene alterations, epigenetic alterations, loss of heterozygosity and microsatellite instability, } \\
\text { viral genome studies, proliferation index and AgNOR analysis, immunohistochemical identification of tumor } \\
\text { markers), Onco-chips }\end{array}$ \\
\hline
\end{tabular}

$\mathrm{NBI}$, narrow band imaging. 
Loss in tissue after oral cavity resection results in a decrease in speech, mastication, swallowing, and finally in the patient's quality of life. Assessment of these functions can help physicians measure the deterioration, and design a restoration plan. Examples of such assessments include analysis of tongue strength, range of motion of the jaw, and salivary production before tongue resection, or acoustic measurement before and after radial forearm free flap reconstruction for tongue defects [21,22]. There is a strong correlation between the extent of oral tongue and tongue base resection (especially the volume of resection of the tongue base) and decrease in swallowing and presence of aspiration [23]. Radiation further worsens oral functions such as masticatory performance, bite force, and dental state [24].

A prospective study demonstrated that the score significantly decreased at 3 months after surgery and gradually improved at 6 and 12 months. Majority of the patients showed preservation of normal or near-normal function at 1-year follow-up [25]. Performance including masticatory function markedly declined with mandibulectomy; however free flap mandibular reconstruction helped patients regain this function [25-27]. Furthermore, the group receiving mandibular reconstruction with prosthetic intervention had better individual functional outcomes $[26,28,29]$.

\section{A3. How can we evaluate second primary malignancies in patients with oral cancer?}

\section{Recommendation 4}

(A) The patient with oral cancer is carefully examined to detect second primary malignancies (strong recommendation, low-quality evidence).

(B) Additional modalities are recommended for second primary malignancy (SPM) screening, such as positron emission tomography/computed tomography (PET/CT), chest $\mathrm{CT}$, and panendoscopy (except bronchoscopy) (strong recommendation, moderate-quality evidence).

Head and neck squamous cell carcinoma (HNSCC) is associated with a high rate of SPM [30-33]. Tobacco smoking, alcohol use, betel nut chewing, human papilloma virus (HPV) infection, and several genetic predispositions contribute to increased risk of SPM in patients with HNSCC [34]. The reported annual incidence of SPM in HNSCC patients is approximately $3 \%$ to $7 \%$. In a pooled analysis of 13 cancer registries, the 20-year cumulative risk for SPM was 36\% [35]. These SPMs were predominantly located in the head and neck, lung, or esophagus. The incidence and location of SPMs varied with the subsite location of the primary HNSCC. SPMs occurred more frequently in patients with laryngeal or hypopharyngeal cancer than in those with oral or oropharyngeal cancer, in a Korea Central Cancer Registry [30]. Lung SPM was more common in laryngeal cancer, and head and neck SPM was more common in oral cancer, as per databases of the Memorial
Sloan-Kettering Cancer Center [36]. In addition, the risk of esophagus SPM was higher in oral or pharyngeal cancer than in laryngeal cancer, as per the Taiwan Cancer Registry [33].

SPMs have a significantly negative impact on the prognosis of HNSCC [37-39]. Overall survival (OS) in oral cancer patients with simultaneous SPM was significant lower than in those without simultaneous SPM (53\% vs. 69\%, 5-year OS) [38,39]. OS with head and neck SPMs was better than that with nonhead and neck SPMs in patients with tongue or laryngeal cancer (39\% vs. 29\% , 5-year OS) [40]. Early detection and proper treatment planning of SPMs has an important impact on prognosis [41,42]. The prognosis of HNSCC patients with early stage SPM of the esophagus was comparable to that in those without esophagus SPM, in contrast to the prognosis of patients with advanced stage SPM of esophagus [42]. Taken together, patients with HNSCC including oral cancer should undergo active surveillance for the early diagnosis of SPMs.

${ }^{18}$ F-labeled fluoro-2-deoxyglucose (FDG)-PET/CT has good diagnostic performance in detecting SPMs in patients with $\mathrm{HN}$ SCC. In a meta-analysis, PET/CT showed good sensitivity and specificity to detect distant metastases and SPMs for all other subsites of HNSCC [43]. Routine flexible or rigid panendoscopy of the upper aerodigestive tract including laryngopharyngoscopy, tracheobronchoscopy, and esophagoscopy for SPM surveillance has been supported by several studies [44-46]. In HNSCC, $6.4 \%$ of synchronous SPMs were clinically silent or were only revealed by panendoscopy [44]. There was a relatively high chance of detection of esophagus SPMs through panendoscopy in patients with oral, oropharyngeal, and hypopharyngeal cancer (odds ratio, 55.3) [45]. Whether PET/CT can replace panendoscopy is controversial. Regarding synchronous T1 and Tis superficial upper gastrointestinal cancers, PET or PET/CT detected only $9.3 \%$ of cancers, revealing the limitation of PET/CT for the detection of small or superficial mucosal cancers [47]. In contrast, Haerle et al. [48] reported that FDG/PET was superior to panendoscopy, especially for peripheral lung SPMs. Similarly, chest CT was superior to bronchoscopy and chest X-ray for the detection of lung SPMs $[49,50]$. Bronchoscopy was limited to the detection of most pulmonary parenchymal nodules diagnosed on chest CT. Importantly, screening with chest X-ray in asymptomatic patients did not improve survival in HNSCC patients who developed lung SPMs [51]. Therefore, concurrent evaluation of FDG-PET and/or chest CT, and panendoscopy except bronchoscopy may be the most sensitive strategy for detecting SPMs in patients with HNSCC.

\section{A4. What is the role of $\mathrm{CT}$ in the preoperative evaluation of oral cancer?}

\section{Recommendation 5}

Contrast-enhanced CT is recommended for the staging and 
pretreatment evaluation of oral cancer (strong recommendation, moderate-quality evidence).

CT with contrast enhancement is a one of the most commonly used cross-sectional imaging modalities in the staging of oral cancer. CT can provide information on primary tumor extent, cervical lymph node metastasis, and bone involvement with short scan times [52]. CT showed good sensitivity, specificity, and accuracy $(61 \%, 100 \%$, and $66 \%$, respectively) for detecting a primary tumor in oral cancer [53]. However, due to low soft tissue resolution of CT, magnetic resonance imaging (MRI) is regarded as more suitable for assessing primary tumor and soft tissue details, compared to conventional CT. Also, CT is more prone to metal artifacts and risk of radiation exposure [54]. CT generally showed high accuracy for detecting bony involvement [55-57]. Handschel et al. [57] reported that modern multislice (1-2 mm) CT was a valuable tool for surgical planning in oral cancer. In a systematic review, cone beam $\mathrm{CT}$ showed high accuracy $(95.7 \%)$ in detecting mandible invasion [58]. Therefore, $\mathrm{CT}$ is thought to be useful in RMT, gingiva, lip, and buccal cancer, which are more susceptible to bone invasion than other sites. Contrast enhanced CT showed similar efficacy in detecting metastatic lymph nodes compared to MRI [53,59-61]. In a recent meta-analysis, Liao et al. [60] reported that modern imaging modalities including CT, MRI, ultrasonography (US), and PET had similar high sensitivity and specificity. Also, they concluded that $\mathrm{CT}$ and MRI are recommended modalities for the staging of oral cancer, because CT and MRI can evaluate primary tumor and cervical nodal status concurrently.

\section{A5. What is the role of MRI in the preoperative evaluation of oral cancer?}

\section{Recommendation 6}

MRI is recommended for the staging and pretreatment evaluation of oral cancer (strong recommendation, moderatequality evidence).

MRI is widely accepted to provide excellent soft tissue resolution compared to conventional CT. Thus, in oral cancer where soft tissue involvement extent is important, MRI is more appropriate for accurate T-staging $[53,54,62,63]$. MRI has high sensitivity and specificity in assessing soft tissue involvement and bone invasion as well as in detecting lymph node metastasis $[8,64]$. Ng et al. [65] reported that PET is very sensitive to detecting primary tumors, but does not provide sufficient information for surgery planning. They further concluded that $\mathrm{CT}$ and MRI are methods of choice in staging oral cancer, though PET may be of value. In the evaluation of tumor thickness, preoperative MRI thickness tended to agree strongly with histologic thickness [66,67], but the preoperative MRI threshold was significantly higher than the histologic thickness [67]. In assessing bone invasion, MRI generally showed high sensitivity (58.3\% to $94 \%$ ), specificity $(97.1 \%$ to $100 \%$ ), and accuracy ( $86 \%$ to $87 \%)[58,68,69] \mathrm{CT}$ also showed good sensitivity $(47.1 \%$ to $83 \%)$, specificity ( $82 \%$ to $100 \%)$, and accuracy $(81 \%$ to $87 \%)$. In a systematic review, MRI, panoramic X-ray, PET-CT, and cone beam CT had high accuracy in detecting mandibular invasion $[54,58]$. In assessing cervical lymph node metastasis, CT and MRI showed equivalent ability to detect metastatic lymph nodes. In a study which analyzed 29 studies, both MRI and CT showed good sensitivity ( $24 \%$ to $79 \%$ ) and specificity (31\% to $89 \%$ ) [70]. In a meta-analysis by Liao et al. [60], MRI, CT, US, and PET were found to show similar sensitivities and specificities in detecting metastatic lymph nodes.

MRI provides excellent soft tissue detail without radiation exposure and is less affected by metal artifacts [54,70,71]. MRI has disadvantages related with motion artifacts due to relatively long scanning time; however, because it is less affected by metallic artifacts, MRI should be considered first for accurate Tstaging in cases where metal artifacts are expected $[52,54]$.

\section{A6. What is the role of PET/CT in the preoperative evaluation of oral cancer?}

\section{Recommendation 7}

$\mathrm{PET} / \mathrm{CT}$ is recommended for oral cancer assessment, especially at advanced stages, because it is superior to traditional $\mathrm{CT}$ or MRI in terms of accurate detection of regional/distant metastases and second primary cancers. It is useful to rule out mandibular marrow invasion (strong recommendation, moderate-quality evidence).

PET is a functional imaging technique which detects tumors with high metabolic activity. PET/CT is a fusion of functional imaging from PET and anatomic imaging from CT. Thus with $\mathrm{PET} / \mathrm{CT}$, functional information from PET can be more precisely correlated with anatomic details from CT.This technique is very sensitive in detecting primary and recurrent malignant tumors in the head and neck [72]. The National Comprehensive Cancer Network clinical practice guidelines for head and neck cancer recommend FDG-PET/CT in the preoperative staging of advanced (stage III and IV) oral cavity, oropharynx, hypopharynx, and larynx cancers. PET is known to have lower resolution compared to CT and MRI in outlining certain parameters essential for surgical planning such as anatomic details and the extent of a tumor. However, some studies have shown that PET has higher sensitivity than $\mathrm{CT}$ and MRI in the visualization of clinically proven primary tumors $[73,74] .{ }^{18} \mathrm{~F}$-FDG PET has higher sensitivity $(100 \%)$ than CT $(68.2 \%)$ in detecting primary tumors with high metabolic activity $[75,76]$. 
Stuckensen et al. [77] prospectively compared PET, US, CT, and MRI in assessing metastatic cervical lymph nodes of 106 patients with oral SCC. They found that PET showed the highest specificity $(82 \%)$ on the N stage, while US had the highest sensitivity (84\%). Ng et al. [65] compared PET with CT/MRI in the evaluation of primary tumors and metastatic cervical lymph nodes of 124 oral cancer patients. The sensitivity of PET (75\%) to assess nodal metastases by level was significantly higher than that of CT/MRI (53\%), while PET specificity $(93 \%)$ was similar to $\mathrm{CT} / \mathrm{MRI}(95 \%) .{ }^{18} \mathrm{~F}-\mathrm{FDG}$ PET/CT is a useful tool for staging and restaging head and neck cancers and can simultaneously detect regional recurrence, distant metastases, and possible second primary tumors with high sensitivity and specificity [78].

$\mathrm{PET} / \mathrm{CT}$ can be used in assessing mandibular invasion of oral cancer. Generally, CT has shown high accuracy for detecting cortical erosion of the mandible in oral cancer [55-57]. In assessing mandible or maxilla bone marrow involvement of oral cancer patients, PET/CT showed higher specificity than did MRI ( $83 \%$ vs. $61 \%$, respectively; $P=0.0015)$ but lower sensitivity (78\% vs. $97 \%$, respectively; $P=0.0391$ ) [79]. In another study, $\mathrm{PET} / \mathrm{CT}$ was comparable to CT and MRI in specificity for detecting mandibular invasion, and furthermore, by combining these imaging modalities, sensitivity was improved [68].

\section{A7. What is the role of US in the preoperative evaluation of oral cancer?}

\section{Recommendation 8}

US can be used to evaluate cervical nodal status for oral cancer staging (weak recommendation, low-quality evidence).

US is a reliable and valuable tool for evaluation of lymph node metastasis in head and neck cancer patients [80]. US has several advantages in head and neck cancer assessment over other imaging techniques, as it is widely available, well tolerated by patients, radiation-free and cost effective, and can be combined with a US-guided fine needle aspiration [81,82]. In particular, intraoral US has been found to be useful in oral tongue cancer. Vascularity assessment using intraoral US Doppler was found to be helpful in predicting pathologic grade of primary tumors and cervical node metastasis in oral tongue cancer patients [83].

When ${ }^{18} \mathrm{~F}$-FDG, US, CT, and MRI results in patients with proven oral cancer were compared with the postoperative histologic tissue evaluation, the US technique showed the highest sensitivity (84\%) and accuracy (76\%), but lowest specificity (68\%) [77]. Lodder et al. [84] have compared tumor thickness measured by intraoral US with histopathologic analysis. They found that when tumor thickness measured by intraoral US was less than $7 \mathrm{~mm}$, the risk of lymph node metastasis was $12 \%$. However, when tumor thickness as per intraoral US exceeded $7 \mathrm{~mm}$, the risk of lymph node metastasis was increased to $57 \%(P=0.001)$.

\section{B. Prevention of oral cancer}

B1. What is the role of intervention for smoking and drinking cessation in preventing oral cancer?

\section{Recommendation 9}

Intervention for smoking and drinking cessation should be recommended for high-risk populations (strong recommendation, high-quality evidence).

Various lifestyle, environmental, and host factors are implicated in oral carcinogenesis. The most important risk factor for oral cancer is smoking [62]. The association between oral cancer and smoking is dose-dependent. The risk for cancer development is proportional to the amount and duration of smoking. Smokers who do not have coexisting risk factors do not appear to be at higher oral cancer risk than are nonsmokers, while heavy smokers have a higher risk of oral cancer. The risk of oral cancer increases significantly when the smoking period is more than 20 years and the frequency of smoking is higher than 20 cigarettes per day [85].

Alcohol is another important cause of oral cancer and accounts for a large proportion of oral cancer deaths. It is known that about $7 \%-19 \%$ of oral cancer cases are caused by heavy alcohol drinking [86]. Alcohol consumption has been shown to act synergistically with smoking to increase the risk of development of oral cancer. Despite this strong association, the exact pathogenesis of alcohol for oral cancer is not completely understood. Malnutrition and the deficiency of vitamins and minerals due to chronic alcohol consumption may also influence carcinogenesis.

HPV is an important risk factor for the development of anogenital cancer. Recently HPV has been regarded as a cause of head and neck cancer, predominantly that of the oropharynx including the tonsils, the base of the tongue, and the other pharynx [87]. HPV-positive tumors have a risk factor associated with sexual behavior in contrast to HPV-negative cancer. HPV-negative cancers are associated with smoking and alcohol consumption [88]. HPV-positive tumors rarely occur in the oral cavity. The role of HPV in oral cancer has yet to be determined [89]. However, recent evidence suggested that the outcome for nonoropharyngeal HPV-positive patients is better compared to that of their HPV-negative counterparts; additional studies are needed to verify the correlation between HPV infection and the incidence of oral cancer. Vaccination for HPV is not recommended to prevent oral cancer due to little evidence.

\section{B2. What is the role of oral care in preventing oral cancer?}

\section{Recommendation 10}

Regular oral health maintenance and routine dental care are 
recommended to prevent oral cancer (strong recommendation, high-quality evidence).

Poor oral hygiene and dental status, and chronic oral ulceration have been suggested to promote neoplasms in patients with other risk factors such as smoking and consumption of alcohol. Evidence to evaluate the influence of dental factors on oral cancer development is challenging due to confounding effects of lifestyle, and socioeconomic and cultural characteristics. A 2-5 fold higher oral cancer risk has been reported for patients with periodontal disease, as compared to that for patients without periodontal disease [90]. Chronic inflammation caused by inflammatory cells and periodontal pathogens may add to the burden of oral cancer [91,92]. The risk of oral cancer was significantly lower in patients with oral health maintenance and dental care than in those without $[93,94]$. This further enhances the need for oral health education programs related to routine oral health care and routine dental care to prevent oral disease, including oral cancer.

\section{Surgical management of oral cancer according to subsites C1. Which approach is appropriate for oral cancer?}

\section{Recommendation 11}

(A) Surgeons should choose the appropriate surgical approach to achieve a clear surgical margin based on tumor size, depth location, degree of mouth opening, mandibular invasion, and the surgeon's experience (strong recommendation, low-quality evidence).

(B) For advanced oral cancers, mandibulotomy with or without lip-split can produce wide exposure, but may cause morbidities (weak recommendation, moderate-quality evidence).

Choosing the method of surgical approach is the first step in planning surgery for oral cancer. The goal should be to achieve adequate clear surgical margins and long-term survival. Therefore, parameters such as location and extent of invasion, depth of infiltration, and proximity to the mandible or maxilla should be used to guide surgical decisions. Oral cavity conditions such as trismus, dentition, tongue mobility, and the size of the oral aperture, and other factors such as dentition, size of the oral aperture, degree of mouth opening, and the size and mobility of the tongue should also considered while selecting the surgical method. Surgery for oral cancer often leads to unaesthetic patient appearance and functional problems, so surgery should also be aimed at preserving functions such as speech, swallowing, and deglutition, in addition to reducing scarring $[95,96]$.

A transoral (peroral) approach is recommended for small, anteriorly located, and easily accessible tumors which are located to the oral tongue, FOM, gum, cheek mucosa, and the hard pal- ate. However, this approach may not be useful for deeply infiltrating and/or posterior located cancers and/or in patients with trismus and/or obstructive dentition.

For advanced oral cancers, lip-splitting and/or mandibulotomy should be considered, to obtain a clear surgical margin. The lower cheek flap approach requires a midline lip-splitting incision which is continued laterally into the neck, for exposure and neck dissection (ND). Except for tumors of the upper gum and hard palate, this approach provides excellent exposure for nearly all tumors of the oral cavity. The upper cheek flap approach is optimal for the resection of larger tumors of the hard palate and the upper alveolus, particularly if located posteriorly. The mandibulotomy approach usually involves a lip-split, and has been preferred for advanced oral cancer because it can provide excellent exposure to the oral cavity and the oropharynx [97,98]. Compared to midline mandibulotomy, a paramedian mandibulotomy has merits for swallowing function since it preserves the geniohyoid and genioglossus muscles, and the anterior belly of the digastric muscle [99]. Paramedian mandibulotomy is an excellent surgical approach for access to large posteriorly located lesions of the oral cavity. However, mandibulotomy may lead to many unfavorable complications such as exposure of metal fixation plate, fistula formation, fixation failure, osteonecrosis after radiation treatment, and unsatisfying appearance $[100,101]$. Due to interruptions of the mandibular continuity, disturbances of oral functions and temporomandibular joint problems can occur $[102,103]$.

Therefore, to reduce such problems in cases without mandibular involvement, several methods of mandibular preservation such as the visor flap approach and the mandibular lingual release have been suggested. In a study comparing the mandibulotomy and mandibular lingual release approaches, no differences were observed in clinical outcomes and functions when the primary oral cancer was under $5.1 \mathrm{~cm}$, and was anteriorly located [96]. A recent meta-analysis comparing mandibulotomy and mandibular preservation methods concluded that mandibular sparing may provide a similar clinical outcome of surgical margins and survival [104]. However, the mandibular-sparing group showed a lower complication rate compared to the mandibulotomy group. The authors recommended the mandibulotomy approach over mandible-sparing in cases with involvement of the maxilla, upper gingiva, hard/soft palate, or a combination of multiple anatomic structures $[95,105,106]$.

\section{C2. Oral tongue cancer}

$\mathrm{C} 2-1$. What is the adequate resection margin for oral tongue cancer?

\section{Recommendation 12}

(A) The macroscopic and palpable margin should be at least $10 \mathrm{~mm}$ from the edge of the tumor (weak recommendation, low-quality evidence). 
(B) When a microscopic residual tumor or a close margin is identified, re-resection or adjuvant treatment should be considered (strong recommendation, low-quality evidence).

Surgical margin was an independent prognostic factor that affected disease-free survival and local recurrence [107-112]. Obtaining adequate margin during surgical excision may improve these outcomes. The 5 -year and 10 -year OS rates were $72 \%$ and $64 \%$, respectively, in patients with clear surgical margins, compared with $21 \%$ and 0 , respectively, in those with involved margins [108]. Traditionally, a 1-cm margin is taken in all planes around a macroscopic or palpable oral tongue cancer [107,109112]. Pathologists and clinicians have agreed to define involved margins as less than $1 \mathrm{~mm}$ and close margins as $5 \mathrm{~mm}$ or less, and to designate margins greater than $5 \mathrm{~mm}$ as clear $[107,108$, $111,112]$. The pathological margins were reported to be much smaller than those expected by the surgeons; this is largely due to margin shrinkage by about $20 \%-25 \%$ following resection, and further loss of about $10 \%$ on formalin fixation [113]. So, formalin fixation and slide preparation reduced mucous margin by approximately $30 \%-50 \%$. This results in a final pathological margin of approximately $5 \mathrm{~mm}$ for tumors with surgeon-measured margins of $1 \mathrm{~cm}$. The tumor resection margin was an important predictor for recurrence, with statistically significant higher recurrence rate for resection margins $<5 \mathrm{~mm}$ as compared to that for margins $>5 \mathrm{~mm}$. The significance was maintained for resection margins $<10 \mathrm{~mm}$. On multivariate analysis, lower recurrence rates was noted for margins $>5 \mathrm{~mm}$ compared to those for margins $<5 \mathrm{~mm}$. This has led to improved diseasespecific survival rates in patients with margins $>5 \mathrm{~mm}$ [107]. However, several studies have reported that the surgical margin was not related patient prognosis $[3,114]$. Ganly et al. [114] reported that the surgical margin involved by the tumor did not affect the OS of patients in multivariate analysis. Surgical margin status was related to disease-specific survival and recurrencefree survival in univariate analysis. Other studies have reported that the recurrence of oral tongue cancer with an epithelial positive margin was seen only at the primary lesion, and that not all cases showed local recurrence; furthermore, the time for the recurrence was considerably longer, all of the recurrence cases could be treated with additional resection, and there was no prognostic difference [3]. Intraoral intraoperative US was found to be an accurate and reliable tool for assessing tumor-free deep margin during surgery [115].

C2-2. What is the influence of tumor thickness on surgery-planning?

\section{Recommendation 13}

(A) Tumor thickness should be considered when determining the extent of surgery because it is closely related to local recurrence of the primary tumor and to cervical lymph node metastasis (strong recommendation, moderatequality evidence).

(B) Tumor thickness should be assessed to ensure adequate deep resection margin of oral tongue cancer, and the evaluation of tumor thickness can be made through palpation, preoperative imaging studies, and intraoperative US (strong recommendation, moderate-quality evidence).

Because the oral tongue is mainly composed of muscle tissue and there is no anatomic boundary to prevent the tumor spread, oral tongue tumors spread more easily than do tumors at other oral cavity subsites. Thus, it is difficult to accurately evaluate the extent of tumor thickness before surgery. Completion of surgical resection with adequate safety margins has a substantial effect on treatment outcome and prognosis $[116,117]$. However, in the case of oral tongue cancer, it is very difficult to predict the degree of tumor thickness by gross inspection and palpation before surgery. The most challenging area to obtain adequate safety margins during surgical resection of oral tongue cancer is the basal area of the tongue.

In general, since surgical resection of the oral tongue starts from the surface of the oral tongue cancer, insufficient or close resection margins are commonly confirmed in the basal area of oral tongue cancer on pathologic specimen. Inadequate safety margins at this site and the thickness of the tumor are closely related to local relapse of the primary tumor and to cervical lymph node metastasis $[118,119]$. In a study comparing tumor thickness and the frequency of lymph node metastasis in oral tongue cancer, a $26 \%$ occult lymph node metastasis rate was reported in patients with a tumor thickness of $2 \mathrm{~mm}$ or more. A similar study reported that there was a significant difference in lymph node metastasis as per the criterion of $4-7.5 \mathrm{~mm}$, and the authors insisted that a prophylactic ND was needed in all the cases except superficial cancer cases [120-123].

In the newly revised American Joint Committee on Cancer (AJCC) 8th edition, the concept of depth of invasion (DOI) was introduced in the T classification method, and T1 was defined as $<5 \mathrm{~mm}, \mathrm{~T} 2$ was defined $>5 \mathrm{~mm}$, and T3 was defined $>10 \mathrm{~mm}$ [124]. DOI is histologically the distance from the basement membrane of the surrounding normal tissue to the deepest part of the tumor. However, as it is difficult to evaluate DOI intraoperatively, tumor thickness should be assessed by palpation, preoperative imaging studies, or by intraoperative US [115]. If postoperative histopathologic examination shows a significant DOI or insufficient deep safe resection margin, additional treatment such as additional resection, prophylactic cervical lymphadenectomy, and radiation therapy should be considered. 


\section{C3. Maxillary gingiva and hard palate cancer}

\section{Recommendation 14}

(A) Mucosal/periosteal resection is recommended primarily for lesions without bone invasion (strong recommendation, low-quality evidence).

(B) Partial resection of the maxillary bone is recommended primarily for lesions with bone invasion (strong recommendation, low-quality evidence).

Many studies have revealed the importance of margin status as an outcome predictor in oral cancer. Such studies have suggested that a margin of $\geq 5 \mathrm{~mm}$ on final pathology was adequate [125]. However, cancers in the maxillary gingiva and hard palate regions are rare compared to cancers at other oral cavity subsites; this has led to a paucity of evidence regarding the management and outcome for cancers occurring at these subsites. Data on treatment guidelines in this patient population are limited [126].

Superficial erosion of the bone or tooth socket in gingival cancer is not sufficient to classify the tumor as T4, but gingival cancer that invades the underlying bone is designated as T4. Since bone is close to the musculoskeletal, gingival cancer tends to invade bone early, so it should be classified as T4 in the presentation. As a result, most operations for gingival cancer involve removal of bone structures [127]. However, one systematic review suggested that small lesions without bone invasion are rare, but can be treated with only mucosal or periosteal resection [128].

Attachment of the hard palate mucosa to the underlying periosteum is different from that of the gingival mucosa. The hard palate is a unique anatomic site because it has an abundance of minor salivary glands. Consequently, hard palate cancer tends to invade the bone later than does gingival cancer. Surgery of hard palate cancer frequently does not include removal of the underlying bone [129]. However, management guidelines specifically pertaining to hard palate cancer are based on expert opinion owing to scant evidence [130]. Enucleation is avoided for hard palate cancer because it is associated with a high risk of recurrence whether enucleation is safe for hard palate cancer remains unknown [131].

The extent of maxillary gingival and hard palate surgery is dependent on the size and growth of the tumor. There are various types of partial resection modes used for the maxillary bone, i.e., alveolectomy, infrastructure maxillectomy, and palatectomy. Among them, infrastructure maxillectomy involves the resection of the maxillary floor below the level of the infraorbital nerve, gingiva arch, hard palate, and the lower lateral nasal wall [132]. However, maxillectomy may induce functional discomfort. Due to the proximity of the maxillary sinuses, the surgery of upper gingival cancer often leads to oroantral fistulas, which may require subsequent surgical or nonsurgical recon- struction. Some studies have reported that margins of $<5 \mathrm{~mm}$ are associated with significantly higher local recurrence rates than are margins of $\geq 5 \mathrm{~mm}$ in oral cancer. However, no study has focused on the gingiva or the hard palate. Nevertheless, the effects of 5-mm margins were similar across all oral cavity subsites in many studies [125].

\section{C4. Mandibular gingival cancer}

C4-1. What is the adequate resection margin for mandibular gingival cancer?

\section{Recommendation 15}

(A) Mucosal/periosteal resection is recommended primarily for lesions without bone invasion (strong recommendation, low-quality evidence).

(B) Maintenance of a bone margin of at least $10 \mathrm{~mm}$ is necessary in mandibulectomy (weak recommendation, low quality evidence).

In case of the mandibular gingival cancer, selection of the surgical resection depends on the stage of disease, the need for mandibular resection or ND, and the method of reconstruction. Recent trends in treatment focus on preservation of mandibular function due to its critical involvement in maintaining aesthetic and psychological aspects of the patient [133]. There are several resection approaches available. Similar to the maxillary gingiva, mandibular gingival cancer without bone invasion is rare, but the tumor is usually removed by gingival mucosal resection [128]. Studies of mandibular gingiva are mainly either retrospective or case reports, and the mandibular gingiva is often studied together with the other oral cancer subsites; thus mandibular gingival subsite-specific analysis is difficult. In the future, studies focused on gingival cancer will help provide a better basis for conclusions of treatment and outcomes. Even if the study evaluates a broader oral cancer population, gingival subsite analysis is needed to better understand this separate disease entity.

Although more than $5 \mathrm{~mm}$ of histopathologically uninvolved tissue margin from the resected tumor is usually regarded as a negative margin in oral cancer, most studies of "margin tissue" have included an evaluation of bone tissue. Soft tissues including mucosa shrink to varying extents once removed from the original sites; however, due to the hardness of this tissue type, planning the placement of $5-\mathrm{mm}$ resection margins in bone is not a tenable option. Furthermore, the exact location of the tumor in the bone may be unclear and lead to ambiguity in the application of bone margin.

McGregor and MacDonald [134] recommended a resection of 5 to $10 \mathrm{~mm}$ of uninvolved bone around the tumor, and other researchers have suggested removal of at least $10 \mathrm{~mm}$ of unaffected bone in the case of macroscopic tumors with suspected bone involvement [135-137]. Intraoperative histologic evalua- 
tion of bone margins by frozen section analysis may provide critical information during mandibulectomy, but it is presently not practical in real-world settings because of the necessity of decalcification procedures before identification of the bone margin. Some authors have suggested intraoperative cytologic scrapings of the mandibular bone marrow to estimate the bone margin, and have demonstrated excellent correlations with the actual pathologic status of the bone margin [135,138].

In principle, a positive bone margin involved by cancer increases risk of morbidity; this may influence postoperative additional treatment plans, and lead to an unfavorable prognosis. However, as previously discussed, low impact of the pathologic status of a bone margin on local disease control and survival outcomes may not justify implementation of such a safety margin on mandibular resection. A subsequent question pertaining to safety margins in mandibulectomy concerns the extent to which the buttress of the remnant mandible should be preserved in the case of marginal mandibulectomy. Barttelbort and Ariyan [139] compared the amount of residual bone necessary to withstand fracture in marginal mandibulectomy. The authors performed incremental osteotomies on fresh cadaver mandibles by applying incremental weights. They proved that at least $1 \mathrm{~cm}$ of bone at the inferior border of the mandible should be kept to reduce the risk of fracture in marginal mandibulectomy. According to the report, surgeons may reinforce the remaining mandible with reconstruction plates if the height of nonviolent bones is less than $10 \mathrm{~mm}[140]$.

C4-2. Is mandibulectomy mandatory when oral cancer abuts the periosteum of the mandible?

\section{Recommendation 16}

(A) Mandibulectomy can be waived if the tumor abuts the periosteum of the mandible (weak recommendation, low quality evidence).

(B) Mucosal/periosteal resection can be considered for lesions without bone invasion (weak recommendation, low quality evidence).

Mandibular invasion in oral cancer is an important determinant of the manner of reconstruction as well as the extent of resection. Management of the mandible is a very important part of oral cancer surgery in terms of complete tumor removal and limiting aesthetic and functional deficits (such as chewing and phonation).

Prior to mandibulectomy, it should be determined whether the mandible is actually invaded or if it merely abutted by the tumor. If violation of the mandible by the tumor is obvious, it is important to determine whether only the cortex is invaded or if the medulla or an alveolar nerve are involved as well. In addition, in cases of recurrence, it is necessary to grasp the status of the adjacent tooth and that of previous treatment including surgery or radiotherapy (RT), prior to performing mandibulectomy and reconstruction.

The judgement of the extent (marginal versus segmental) of surgery and the plan to include safety margins are important for oncological safety during mandibulectomy. Finally, reconstruction considering both aesthetic and functional aspects is critical to the patient's quality of life. For this reason, choice of graft materials should be made with caution, and preoperative simulation of reconstruction should be performed using computeraided design and manufacturing systems. This section addresses recommendations about resection and reconstruction of the mandible in oral cancer.

Accurate preoperative assessment along with the comprehension of the spreading pattern and invasion routes is essential to determine the optimal level and extent of mandibulectomy in oral cancer. Clinical evaluation of mandibular invasion is performed by bimanual assessment of the cortical thickening or fixity of the tumor mass in relation to the mandible. Inferior alveolar nerve paresthesia or pathological fractures are also highly suspicious signs of mandible invasion. According to a recent review article, clinical evaluation carries a sensitivity ranging from $32 \%$ to $96 \%$ [141]. There is no consensus regarding the most reliable imaging modality for the identification of mandibular involvement in oral cancer. There have been no investigations into methods for predicting mandible invasion with $100 \%$ reliability. Various imaging techniques including plain radiography, $\mathrm{CT}$, MRI, bone scans, single photon emission CT, and PET/CT have been used with varying degrees of sensitivity and specificity (Table 5) [140-142].

Another point for consideration in the assessment of mandible invasion is the pattern of tumor infiltration to the bone. It has been known that there are two invasion patterns of oral cancer to the mandible. In the infiltrative pattern, digits and islands of tumor advance independently into the cancellous spaces. In the erosive pattern, the tumor propagates on a broad front with a connective tissue layer and active osteoclasts can be seen separating the tumor from the bone [143]. Wong et al. [144]

Table 5. Summary and comparison of the imaging techniques in detecting mandible invasion of oral cavity cancer

\begin{tabular}{lll}
\hline Imaging modality & Sensitivity (\%) & Specificity (\%) \\
\hline Plan radiography & $79.0(57-97)$ & $80.6(64-97)$ \\
CT & $75.8(50-100)$ & $95.7(57-97)$ \\
MRI & $80.1(39-100)$ & $79.1(50-96)$ \\
Bone scintigraphy & $93.4(71-100)$ & $70.5(41-88)$ \\
SPECT & $98.2(97-100)$ & $63.2(29-92)$ \\
PET/CT & $93.3(80-100)$ & $61.0(14-85)$ \\
\hline
\end{tabular}

Values are presented as mean (range).

CT, computed tomography; MRI, magnetic resonance imaging; SPECT, single photon emission computed tomography; PET/CT, positron emission tomography/computed tomography. 
studied survival in relation to cancer invasion patterns and found that the 3-year recurrence-free survival in the infiltrative pattern group was $30 \%$, compared with $73 \%$ in the erosive pattern group. Shaw et al. [145] demonstrated that the infiltrative pattern was related to significantly higher local recurrence rates and lower cancer-specific survival rates compared to erosive patterns. Intriguingly, the authors identified no statistical difference in local recurrence or survival compared to patients with the erosive pattern regardless of bony involvement histologically. Therefore, in the assessment of tumor invasion to the mandible with subsequent decision-making on mandibulectomy, tumor invasion patterns should also be considered.

The management of a mandible which is not definitely invaded but is just abutted by oral cancer is usually subjected to resection rather than to preservation or stripping. Shaha [146] insisted that whenever the tumor is close to the mandible or is adherent to the periosteum, marginal mandibulectomy should be considered. Muscatello et al. [147] in their reports about 56 patients who underwent marginal mandibulectomy also concluded that whenever the tumor was close to the mandible or adhered to the alveolar periosteum, marginal mandibulectomy could be an oncological sound procedure, although infiltration of the resected bone was detected in only one patient $(1.8 \%)$.

It is relevant to evaluate the actual correlation between the number of clinically suspicious cases of mandible invasion and that of cases with real pathologic involvement. Pandey et al. [148] performed a prospective study of 51 patients with oral cancer with suspicious mandibular bone involvement and who subsequently underwent segmental- or hemimandibulectomy. After resection, the mandible was decalcified and sectioned serially at $0.5-\mathrm{cm}$ intervals to determine bone invasion, and mandibular invasion was identified in 25 of 51 patients (49\%). Surgeons are often inclined to perform mandibulectomy to avoid under-treatment (i.e., positive margin) even in cases of tumor abutment to the mandible; however, a review article demonstrated relatively high percentages $(35 \%-78 \%)$ of cases with no evidence of mandibular invasion in the resected mandibles; such surgeries often result in considerable cosmetic and functional defects [141]. Additionally, the prognostic impact of mandibular invasion by oral cancer is controversial, and there have been reports of decreased survival rates and increased recurrence with bone invasion as well as reports of decreased survival rates independent of bone invasion [141].

To clearly prove the validity of mandibulectomy in abutment cases, a RCT comparing the local control rate of oral cancer between mandibulectomized and mandible-preserved patients is needed; however, neither clinical trial reports nor reports of active surveillance have been published in literature. In summary, it is necessary to identify mandibular involvement in the management of oral cancer by combined physical exam and imaging modalities. Additionally, tumor invasion patterns should also be considered with subsequent planning on mandibulectomy. How- ever, in cases where the periosteum of the mandible is abutted by the oral tumor, the necessity and validity of mandibulectomy is unclear.

C4-3. What is the appropriate extent of mandibulectomy to be applied when oral cancer invades the marrow of the mandible?

\section{Recommendation 17}

(A) Marginal mandibulectomy is recommended if the cancer has not deeply invaded into the cancellous bone, and if a resection margin is obtainable. Segmental mandibulectomy should be performed for patients with extensive bone invasion (strong recommendation, high-quality evidence).

(B) Segmental mandibulectomy can be considered for those with an irradiated or edentulous thin mandible (weak recommendation, low-quality evidence).

While it is generally accepted that surgery should be performed to treat patients with obvious mandibular invasion, the extent of mandibular resection required is not always clear. Most surgeons may agree that marginal mandibulectomy is the best choice to preserve mandibular contour and function when the tumor encroaches or superficially invades the cortex, unless the cancellous bone is extensively invaded. However, for cases in which the medullary bone is definitely involved, the decision is more problematic, and such cases may be subjected to segmental resection; despite subsequent severe morbidities, segmental resection may help in avoiding positive margins associated with marginal mandibulectomy.

Petrovic et al. [133] reported the results of marginal mandibulectomy with a large number $(n=362)$ of patients with oral cancer and demonstrated that microscopic bone involvement was identified in $15 \%$ of patients; positive bony margins were significantly associated with medullary bone invasion, primary sites of FOM and buccal mucosa, and with positive soft tissue margins after marginal mandibulectomy. But the locoregional recurrence-free and cancer-specific survivals were similar in patients without or with bone invasion, and local disease control rates were not different between patients with microscopically positive versus negative bone margins. A recent systematic review concluded that a marginal mandibulectomy would be an appropriate choice for oral cancers adherent to or superficially invading the cortex of mandible, since no statistically significant difference in 2- and 5-year local control rates and survivals was found between marginal and segmental resections in a metaanalyses [149].

However, a segmental mandibulectomy is required to obtain the oncological safety margins of soft tissue in patients with extensive medullary invasion. If the inferior alveolar nerve canal is involved, a segmental mandibulectomy beyond the mandibular 
and mental foramen is needed. It has been generally accepted that once the inferior alveolar canal is destroyed by invasive tumors, anterior and posterior perineural extension takes place in both the edentulous and the dentate mandible. Thus, segmental mandibulectomy would be a better choice for these patients [150]. In addition, cases with previous irradiation to the mandible require further attention. Wax et al. [151] reported that irradiation may alter the bone's resistance to tumor spread and insisted that a segmental mandibulectomy is indicated for such cases. In addition, they opposed a marginal resection in the edentulous or in a previously irradiated mandible because of the risk of bony fracture or of osteoradionecrosis.

On the other hand, other researchers have reported that there was no statistically significant difference between marginal and segmental mandibulectomies in the rate of positive margins; the survival rate was found to be significantly related to positive soft tissue margins, and not to bone invasion or the type of mandibulectomy. The authors suggested that local recurrence is usually a result of positive soft tissue margins and does not correlate with the type of mandibulectomy [152]. Wolff et al. [153] also suggested that mandible-sparing surgery is oncologically safe in cases where the primary tumor does not erode the mandible even though in adjacency or where there is no indication of bone destruction. Accordingly, it would be relevant to evaluate whether a safety margin must be acquired in mandibulectomy despite the lack of benefit on disease control or survival, considering that segmental resection compromises the patient's quality of life. Therefore, it could be concluded that marginal mandibulectomy is an oncologically sound procedure if the tumor is not compromising soft tissue margins, when there is no radiographic evidence of extensive medullary or bony canal involvement in oral cancers. However, the final decision of the method of mandibulectomy should be based on case-by-case clinical judgment by the surgeon.

\section{C5. FOM cancer}

\section{Recommendation 18}

(A) Macroscopic and palpable margins including deep margin should be at least $10 \mathrm{~mm}$ from the tumor for FOM cancer (strong recommendation, moderate-quality evidence).

(B) Submandibular ducts and/or sublingual glands may be sacrificed (weak recommendation, low-quality evidence).

In FOM cancer, like in cancers of other sub-sites of the oral cavity, the most important thing is to resect the tumor with an appropriate margin considering anatomy. Generally, "margin" refers to the distance from the tumor edge to the cut edge of the specimen. Histopathologically, a margin greater than $5 \mathrm{~mm}$ is designated as a "clear margin." A margin less than $5 \mathrm{~mm}$ is con- sidered to be a "closed margin," and that less than $1 \mathrm{~mm}$ is defined as an "involved margin" [154]. The optimal resection margin of oral cavity cancer to achieve clear margins histopathologically is still a controversial issue. It is well known that shrinkage of tissue occurs during tissue processing like fixation, embedding, cutting, and mounting $[155,156]$. Because of tissue shrinkage in oral cavity cancer, the pathological margins are much smaller than the preresection margins [113]. The extent of tissue shrinkage is variable depending on the type and site of cancer [157-159]. In a previous report by Johnson et al. [160], the postresection tissue shrinkage or contracture values were $24.8 \%$ and $20.9 \%$ for the mucosa and tongue, respectively. Contracture of $41 \%$ to $47.5 \%$ were reported for a lip specimen by Egemen et al. [161]. Considering the pathologic clear margin and tissue shrinkage values, the clinical resection margins should be at least $10 \mathrm{~mm}$ in oral cancer including FOM cancer.

In FOM cancer, a macroscopic and palpable margin including a deep margin should be at least $10 \mathrm{~mm}$. However, considering anatomical features like a mandible near the tumor, it may be difficult to resect the tumor with an appropriate margin. In such cases, widest margins are indicated, if possible. In the case of tumors involving FOM that show abutment or invasion of the mandibular periosteum, it is necessary to consider marginal or segmental mandibulectomy to obtain adequate margins [142, 162]. Additionally, sublingual glands and/or submandibular ducts may be sacrificed when they are included in the deep resection margins $[163,164]$. Sublingual lymph nodes may also be removed with the sublingual glands in cases of sublingual lymph node metastasis $[165,166]$.

\section{C6. Buccal mucosa cancer}

\section{Recommendation 19}

(A) For buccal cancer within the sumucosal layer, sufficient deep resection margins should be achieved by composite resection including the buccinators (strong recommendation, moderate-quality evidence).

(B) If the tumor invades the buccinator muscles, ideally, surgical resection may be extended to the fat pads of the buccal space (strong recommendation, moderate-quality evidence).

(C) If the tumor penetrates or involves to the skin, resection of 1 to $2 \mathrm{~cm}$ of normal skin around the tumor is required (strong recommendation, moderate-quality evidence).

The rate of local recurrence in SCC of the buccal mucosa is relatively high because there is no anatomical barrier to spread in the buccal space $[167,168]$. The buccinator muscle and its overlying fascia are the only barriers preventing the spread of buccal cancer. Once the tumor penetrates beyond the buccinator muscle and s encroaches on the buccal fat, there is no solid anatomic 
barrier to limit the spread [169]. There is no consensus on the issue of including the buccinator in the primary surgical resection specimen of a tumor within the submucosal layer. Ota et al. [170] proposed a surgical resection classification method based on the presence or absence of buccinator invasion. They recommended that when the tumor was confined within submucosal layer, the buccinator muscle was to be spared, and if the tumor extended to the buccinator, the tumor was to be resected to include the buccinator muscle with the overlying fascia. They reported a $73.7 \%$ disease-specific survival rate and an $89.5 \%$ local control rate during treatment based on this classification. However, others argue that sufficient deep resection margins including the buccinator should be resected together even if the tumor is confined within the submucosal layer [171]. Surgical margin status is an important prognosticator in oral SCC. Studies have shown that exclusive reliance on surgical margins on the tumor bed is strongly associated with local control. The primary aim of surgical resection is to achieve a microscopically complete surgical resection at the time of initial surgery [172175]. Oral cancer frequently shows microscopic spread beyond gross resection margins, which alters the margin status [175, 176]. Intraoperative frozen section could help in assessing the margin status, but some may argue that frozen sections do not alter surgical margin status [177-179]. Narrow band imaging may be a useful adjunctive technique for acquiring free resection margins, but further research is required regarding this aspect $[180,181]$. In the minimum, a resection margin of more than $5 \mathrm{~mm}$ is now acceptable in oral SCC [125,182]. Given this, en bloc resection including the buccinator with its overlying fascia even for tumors confined within the submucosal layer has potential benefit to achieve clear deep resection margins. If the tumor invades the buccinator muscles, the optimal surgical resection may be extended to the fat pads of the buccal space.

The issue of resection of the overlying skin along with tumor should be considered carefully. Skin resection may result in facial and mastication defects. Liao et al. [183] reported that additional skin resection may not impact OS. Therefore, if enough surgical resection margin $(>10 \mathrm{~mm})$ is secured, it is better to preserve the overlying skin. Preoperative CT/MRI is helpful to decide on additional skin resection. If the distance between the overlying skin and deep resection margin is more than $13 \mathrm{~mm}$ (skin thickness, $3 \mathrm{~mm}$ ), the skin may be preserved. If the tumor is either invading towards or involving the skin, resection of 1 to $2 \mathrm{~cm}$ of normal skin around the tumor is required [183]. In cases of T4b buccal cancers with invasion to the masticator space (posterolateral extension), en bloc removal of all soft-tissues in the masticator space is advocated to safely remove tumor contained within the masticator compartment. This compartment surgery provides an opportunity to acquire safe margin for cancers actually invading into the masticator space. In general, it is not appropriate to club all patients with masticator space involvement into one group [184].

\section{C7. RMT cancer}

\section{Recommendation 20}

(A) RMT cancer frequently invades to the mandible and is underestimated. Careful preoperative evaluation should be made regarding adjacent bone invasion, because of the limited space between the mucosa and the mandible (strong recommendation, moderate-quality evidence).

(B) Trismus-releasing procedures including coronoidectomy and myotomy of the masticator muscles may be considered simultaneously for patients undergoing mandibulectomy (weak recommendation, low-quality evidence).

In many cases of SCC of RMT, the invasion of the mandible is an important factor for decisions regarding dissection extent. Cancer clinically localized to superficial layers of the RMT is rare, and tumors in most cases penetrate into the submucosal layer and invade into the mandible. The mandible located posterior to the third molar has a large surface with abundant pores on the cortex, which makes it easy to infiltrate the marrow as well as the cortex. When the tumor reaches the marrow, it may progress horizontally through the inferior alveolar canals and nerves. The incidence of pathologically-proven mandibular involvement in surgical specimens was reported to be about $12 \%-53 \%$ [185-188].

Because invasion of the inferior alveolar nerve occurs after invasion of the inferior alveolar canal, this nerve could be spared in cases with a grossly intact inferior alveolar canal. But if the inferior alveolar canals are invaded, sufficient resection including the inferior alveolar nerve should be performed, due to the possibility of perineural spread [189]. If there is inadequate amount of normal tissue between the mandible and the tumor, the surgeon should consider including part of the mandible in the resection extent [190].

Trismus refers to the restriction of opening of the mouth. Currently, an interincisal distance of $35 \mathrm{~mm}$ or less is the accepted cutoff point for trismus [191]. Patients with trismus show compromised oral hygiene, swallowing, and conversation, which severely impacts quality of life [192-194]. Studies show that $55 \%-80 \%$ of oral cancer patients have preoperative or postoperative trismus [195-197]. Advanced T stages and postoperative RT are associated with the development of trismus after surgery [197,198].

The recommendations for simultaneous trismus-releasing procedures including myotomy of masticator muscles and coronoidectomy during resection are unclear because of lack of sufficient evidence. The potential benefit of these additional procedures is that these procedures may help avoid revision surgery requiring general anesthesia. Fibrosis of the surgical field needs to destruct greater tissue destruction to achieve the purpose. The potential risk of these procedures includes increase in the oper- 
ating time, which may result in surgical complications. However, these procedures may concomitantly be performed for patients undergoing wide excision including marginal mandibulectomy with acceptable increase in surgery time (less than 1 hour) and surgical complications [197].

\section{C8. Neck management for oral cancer \\ What is the appropriate strategy for the management of cervical lymph nodes in oral cancer?}

C8-1. Management for clinically negative neck $(\mathrm{N}-)$ in patients with oral cancer

\section{Recommendation 21}

(A) ND can be considered in T2-4 oral cancer (weak recommendation, low-quality evidence).

(B) DOI can be used as a predictive parameter of neck metastasis for ND of oral cancer (strong recommendation, moderate-quality evidence).

Because of the variety of subsites in the oral cavity, it is difficult to uniformly categorize patients with oral cancer for elective neck dissection (END). Rates of regional metastatic spread differ by subsites, and sufficient evidence is lacking for making recommendations on END in early stage cancer for most of the subsites excluding the oral tongue and FOM. The tongue is a wellstudied subsite of the oral cavity for SCC. Although several studies reported that early-stage tongue carcinomas have higher rates of metastatic spread than do FOM carcinomas, there is limited comparison with other oral cavity subsites [199,200].

In several studies on END in early oral cancer, the probability of occult nodal disease based on the clinical T stage was estimated [201,202]. It is difficult to estimate the prevalence of occult nodal metastasis due to differences in patient populations, subsite distributions, extent of dissection, and the method of histologic node analysis between these studies. In the END series, in which elective neck treatment was universally applied, the prevalence of occult positive nodes was between $6 \%$ and $25 \%$ for $\mathrm{T} 1$ oral cancer and $20 \%$ to $32 \%$ for T2 oral cancer. When studies comparing observation and ND were included, the prevalence of occult node disease in early oral cancer approached $40 \%$ to $50 \%$, but these numbers can be inflated due to the selection bias of clinical parameters associated with a higher chance of occult neck metastasis [203-206]. These data should be interpreted carefully because there is insufficient high-quality evidence surrounding $20 \%$ of the treatment threshold for END determination [203]. However, it can be proposed that most cases with oral cancer higher than $\mathrm{T} 2$ should be candidates for END.

The DOI of the primary tumor was reported to have a significant effect on the spread of occult node, particularly in the case of oral tongue cancer. A DOI greater than $4 \mathrm{~mm}$ is associated with an increased risk of occult node metastasis [207]. In the multivariate analysis, only the DOI predicted cervical node metastases with a relative risk ratio of 9.4 (95\% confidence interval [CI], 1.5 to 57.7 ) for lesions $4 \mathrm{~mm}$ or greater thickness [201]. An additional retrospective study showed a relationship between increased tumor thickness and an increased risk of occult node metastasis [208]. The significance of more than $4 \mathrm{~mm}$ of tumor depth was identified as an important predictor of occult node metastasis in the RCT, which assessed END relative to observations for early oral cancer [205,209]. Future studies have shown similar trends in early oral cancer compared to resection alone and resection with selective ND (level I-III). Researchers observed an increase in occult node metastasis for tumors with a depth of $4 \mathrm{~mm}$ or more.

Because of these findings, we recommend END when the DOI exceeds $4 \mathrm{~mm}$. Recently, the newly revised AJCC staging system reported that tumors with a DOI of over $5 \mathrm{~mm}$ are now categorized into T2. Considering this T stage criterion for END, the cutoff value of DOI can be modified with the surgeon's experience. However, the biggest limitation on the use of DOI cutoffs is that it is difficult to obtain this information before it is necessary.

\section{C8-2. Extent of ND for clinically negative neck $(\mathrm{N}-)$ in oral cancer}

\section{Recommendation 22}

(A) Selective ND (level I-III) can be applied as END in oral cancer (weak recommendation, moderate-quality evidence).

(B) Level IIb can be omitted in END in oral cancer (strong recommendation, high-quality evidence).

(C) Perivascular lymph node dissection should be included in END in oral cancer (strong recommendation, moderate-quality evidence).

When the surgeon decides to perform END on patients with N0 oral cancer, it is important to decide the extent of surgery. Several studies have compared selective ND (level I-III) and modified radical ND.

Previous reports showed that OS did not differ among patients with selective ND (level I-III) and modified radical ND, and therefore selective ND (level I-III) can be considered as the standard elective treatment for oral cancer [210]. Other studies have also reported that selective ND (level I-III) has been identified as an appropriate staging procedure to provide valuable pathologic cervical node information for patients with oral cancer [211-213]. Byers [214] reported that Level III lymph nodes were observed in five cases without involvement in level I and/ or II in the modified radical ND of oral cancer. Also, two out of 76 people had positive nodes at level IV without involvement of the upper lymph nodes. 
In the last 20 years, quality of life has been assessed as an essential secondary outcome along with survival rates. Thus, an assessment of the quality of life for oral cancer patients has become an important aspect of postoperative care and even a target of therapeutic approaches [215]. Selective ND (level I-III) are associated with lower rates of complications and faster recovery [216]. Therefore, due to the minor morbidity associated with high efficiency, a selective ND (level I-III) is recommended as a definitive therapeutic approach in N0 oral cancer.

In terms of level IIb lymph node metastasis, there have been two meta-analysis studies. One study found that level IIb had a low rate of metastasis $(6 \%)$ and little isolated level IIb metastases was found [217]. Therefore, it was suggested that level IIb lymph nodes need not always be dissected in oral cancer patients. Another meta-analysis reported that the nodal metastasis rate to level IIb in previously untreated oral cancer was $6.0 \%$ (95\% CI, 3.5 to 8.6) [218]. Pantvaidya et al. [219] found that level IIb metastases were associated with level IIa metastases in $68.1 \%$ of ND, while only $11.3 \%$ of all level IIa metastases had positive nodes at level IIb. Bhattacharya et al. [220] also reported that the positive nodes of level IIa were always observed in patients with a positive level IIb nodes. Therefore, we propose that the assessment of level IIa should be performed during ND, and that level IIb dissection is unnecessary if there is no suspicious lymph node at level IIa.

The perivascular lymph node is one of the subunits of the level Ib. These perivascular lymph nodes may be the major metastatic reservoirs in oral cancer [221]. Lim et al. [222] studied tongue cancer and FOM cancer patients with N0, and concluded that four out of 72 with tongue cancer and two out of 27 FOM cancers had perivascular lymph nodes. Agarwal et al. [223] analyzed oral cancer with N0 and reported that $19(8.22 \%)$ of the 231 cases were found to have isolated perivascular nodal metastasis.

\section{C8-3. Sentinel node biopsy for clinically negative neck (N-) in oral cancer}

\section{Recommendation 23}

Sentinel node biopsy can be an alternative to selective ND (weak recommendation, low-quality evidence).

Increased evidence of the effects of sentinel node biopsies on early stage oral cancer has been released over the past decade. A meta-analysis of the available studies on a total of 301 patients with oral cancer showed that the sensitivity of sentinel node biopsy ranged from 0.75 to 1 , and pooled sensitivity using the random effects model was 0.926 (95\% CI, 0.852 to 0.964$)$ [224]. Since that time, results of the American College of Surgeons Oncology Group examined the accuracy of sentinel node biopsy in 140 patients of oral cancer in the early-stage (T1-
T2N0) [225]. Results revealed a 94\%-negative predictive value with routine hematoxylin and eosin stain, while the value improved to $96 \%$ with additional sectioning of the sentinel node and immunohistochemical analysis. In addition, improved performance was noted for $\mathrm{T} 1$ vs. T2 lesions (negative predictive value, $100 \%$ vs. $94 \%$ ), and for experienced (in sentinel node biopsy) versus novice surgeons (negative predictive value, $100 \%$ vs. $95 \%)$.

In principle, the sentinel node biopsy should be associated with a reduced morbidity rate compared to END, but the data supporting this contention for oral cancer is sparse [226]. In a study comparing outcomes after sentinel node biopsy and END, authors reported that there were no differences in the European Organization for Research and Treatment of Cancer Quality of Life Questionnaire Core 30 (EORTC QLQ-30) [227]. Overall, the evidence so far suggests that for experienced clinicians, the sentinel node biopsy is a reliable method for staging N0 necks to early oral cancer patients. However, there is a lack of conclusive data showing a reduction in morbidity compared to END.

\section{C8-4. Management of clinically positive neck $(\mathrm{N}+)$ in patients with oral cancer}

\section{Recommendation 24}

(A) Therapeutic ND should be performed for $\mathrm{N}+$ in patients with oral cancer. The extent of ND should include at least level I, II, and III (strong recommendation, low-quality evidence).

(B) Elective contralateral ND is not routinely recommended for ipsilateral $\mathrm{N}+$ oral cancer (weak-recommendation, low-quality evidence).

Cervical lymph node metastasis has been identified as one of the most important prognostic factors for patients with oral cancer $[228,229]$. Metastasis to the lymph node occurs in about half of the oral cancer patients at the initial stage of diagnosis [230]. It has been found that lymph node metastasis predicates a $50 \%$ decrease in survival rates [231]. Moreover, recent studies have shown that a higher lymph node density was associated with a worse survival rate $[232,233]$. Eliminating the metastatic lymph node is one of the most important procedures in oral cancer patients who have positive lymph nodes.

Treatment of metastatic lymph nodes should be performed according to the involved level of clinically positive neck nodes. Comprehensive ND such as radical or modified radical ND should be considered according to the status of lymph nodes metastasis [234]. Recently, several studies have reported that selective ND performed in a select group of patients with positive lymph nodes resulted in excellent regional control. The key learning from these trials is that cervical lymph node metastasis occurs in a predictive pattern. According to a study by Shah et 
al. [235], ipsilateral levels I, II, and III are the most frequently involved sites in cervical metastasis of advanced oral cancers. Levels IV $(4.7 \%)$ and V (3.8\%) are rarely involved in oral cancers $[219,236]$. However, several factors such as advanced T stage, multiple clinically positive nodes, and extracapsular spread were associated with neck failure in patients treated with selective ND due to metastasis to level IV and V, or due to higher regional recurrence rates [237-241]. Therefore, dissection of neck at level IV orV should be added to a dissection of level I, II, and III according to the individual patient status.

Several studies have evaluated the effect of contralateral ND for ipsilateral $\mathrm{N}+$ oral cancer. According to a report, the occult rate of contralateral lymph node metastasis was $11 \%$ [242]. The occult rate dropped to $2.9 \%$ when primary tumors close to the midline were excluded [243]. Contralateral lymph node metastasis was associated with multiple positive nodes (two or more) rather than with a single positive node [244], and with level IV/ $\mathrm{V}$ involvement rather than with other level involvement [245]. Oral cancers are associated with a low incidence of contralateral metastases; therefore, contralateral ND my not be routinely considered.

\section{C9. Reconstruction for oral cancer defects What are the appropriate reconstruction methods for oral cancer defects?}

C9-1. Soft tissue reconstruction for oral cancer defects

\section{Recommendation 25}

(A) Flap reconstruction is recommended to preserve adequate speech and swallowing in patients with considerable defects after oral cancer surgery (strong recommendation, moderate-quality evidence).

(B) Flap reconstruction is recommended for the partial glossectomy defect approaching half of the tongue or more, to provide better swallowing function (strong recommendation, low-quality evidence).

(C) Flap reconstruction and postoperative rehabilitation should be performed for patients who underwent subtotal or total glossectomy to preserve functional speech and swallowing (strong recommendation, low-quality evidence).

(D) Flap reconstruction is recommended for FOM defects to prevent communication between neck and oral cavity and to preserve mobility of the tongue for adequate speech and swallowing (strong recommendation, lowquality evidence).

(E) Flap reconstruction is recommended for considerable buccal defects to preserve mouth-opening ability and for structural cosmesis (weak recommendation, low-quality evidence).

(F) The radial forearm and the anterolateral thigh free flaps are the preferred reconstructive methods for oral soft tissue defects while other types of reconstructive surgery may be performed depending upon the extent of primary resection, patient's morbidity, and surgeon's preference (strong recommendation, low-quality evidence).

Reconstructive surgery is important in the multidisciplinary management of oral cancer; this surgery is usually determined based on the location and extent of surgical resection. Patient morbidity and survival could be critically influenced by the quality of reconstruction. Microvascular free flap is the primarily recommended reconstructive method for most of the oral soft tissue defects that need tissue transfer, while local or regional flap methods may be indicated in specific situations [246]. Although many studies have investigated functional outcomes following treatment of oral soft tissue reconstruction, high-quality level I evidence is still lacking due to a limitation of the standardized approach, pertaining to functional assessment [247]. To date, there have been several systematic reviews and prospective cohort studies that have addressed these issues.

Oral soft tissues include tongue, FOM, buccal mucosa, and the retro-molar trigone. The objectives of soft tissue flap reconstruction for tongue defects after tumor resection are to preserve mobility of the residual tongue and to restore tongue bulk for proper speech and swallowing functions [248]. Flap reconstruction is usually required if more than $50 \%$ of the tongue is resected [247]. There are two retrospective case-control studies directly comparing the functional outcomes between free flap reconstructions and primary closure after hemiglossectomy [249,250]. In terms of swallowing, better functional outcomes were reported in patients with flap reconstruction compared to those with primary closure following hemiglossectomy of the oral tongue, while speech intelligibility appeared to be not superior in the flap reconstruction group as compared to the primary closure group [249,250]. However, the above mentioned studies were retrospective case-control studies with small sample sizes; thus the level of evidence is low. Uwiera et al. [251] prospectively evaluated functional outcomes after hemiglossectomy with bilobed radial forearm free flap reconstruction, and reported functional speech and excellent swallowing outcomes. A recent prospective study indicated that the preservation of the tip of the tongue is important for speech outcomes [252]. However, additional well-designed prospective studies are indicated [247].

Although current data generally support the use of flap reconstruction for hemiglossectomy defects, whether flap reconstruction is helpful for partial glossectomy defects involving less than $1 / 2$ of the anterior tongue is controversial, and there is a lack of adequate evidence. Alternative reconstructive options including primary closure, secondary intention, skin grafts, and skin graft substitutes (e.g.,AlloDerm) may also provide relatively good functional outcomes for defects involving less than $1 / 2$ of the mobile 
tongue. For defects involving less than $1 / 3$ of the mobile tongue, soft tissue flap reconstruction is not usually recommended.

For reconstruction of subtotal or total glossectomy, a bulkier flap is required to reconstruct the greater volume of the resection, and flaps such as the anterolateral thigh are commonly used [253]. Because it is quite evident that soft tissue flap reconstruction is required for subtotal or total glossectomy defects, there is no study that directly compares functional results between flap reconstruction and primary closure/secondary healing. Recent systematic reviews have indicated relatively favorable swallowing outcomes, and report that $82 \%$ to $97 \%$ of patients resumed oral feeding at 1 year after flap reconstruction for subtotal or total glossectomy defects [254,255]. Also, patients who attended postoperative swallowing and speech rehabilitation sessions demonstrated superior functional outcomes and improved quality of life scores [254-256].

The purpose of the FOM reconstruction is to close defects communicating with the neck to prevent blood vessel rupture due to salivary contamination [253]. Appropriate flap width is required not to tie the tip of the tongue to the FOM. Fasciocutaneous radial forearm free flaps are popular reconstructive options for FOM defects. Recently, pedicled flaps such as facial artery musculomucosal flaps have been increasingly used for small or modest defects of the FOM, providing excellent functional and aesthetic outcomes [257].

The goal of buccal defect reconstruction is to prevent limitation of mouth-opening or even trismus, and to preserve structural cosmesis $[253,258]$. If muscle loss is noticeable or buccal defect is observed after resection of a T2 tumor or more, soft tissue flap reconstruction is recommended, while skin graft is mainly performed for superficial defects of the buccal mucosa [259]. The radial forearm fasciocutaneous flap is a preferable reconstructive option for buccal mucosal defects as it was shown to achieve excellent functional outcomes in preserving the original open-mouth width $[258,260]$. For reconstruction of throughand-through buccal defects, folded fasciocutaneous free flaps or flaps with dual perforating skin paddles should be used to restore oral functions as well as to maintain acceptable cosmetic outcomes [261,262].

\section{C9-2. Mandibular reconstruction for oral cancer defects}

\section{Recommendation 26}

(A) The osteocutaneous free flap, especially the fibular free flap, is regarded as the primary method of mandibular reconstruction (weak recommendation, low-quality evidence).

(B) Mandibular reconstruction using computer-aided design (CAD) and manufacturing (CAM) can be considered for reducing trial and error and surgical time (weak recommendation, low-quality evidence).
Reconstruction is difficult but inevitable for functional and cosmetic outcomes in cases which result in mandibular defects due to treatment of oral malignancies, especially in those cases including the condyle. For the planning of mandibular reconstruction, a generally accepted classification of the mandibular defect could guide further understanding of the optimal options for reconstruction. However, the choice of reconstruction has been usually based on the individual surgeon's preference of or experience with a particular option. Therefore, it will be necessary to establish a standardized classification of the size and types of defects not only describing the pictorial records of the defect but also demonstrating the different complexities of defects, while suggesting the best methods of reconstruction.

Brown et al. [263] recently suggested a new classification system for mandibular defects after oral cancer surgery. They analyzed 49 studies of mandibular defects and consequently proposed a new classification based on the four corners of the mandible (two angles and two canines) with further subclasses (Ic, IIc, and IVc) contingent on the condylectomy. They also demonstrated that the increasing defect class was related to the size of the defect, osteotomy rate, and functional and aesthetic outcomes, and accordingly insisted that this system could guide method selection for mandibular reconstruction.

The mandible is important for speech, deglutition, mastication, and lower face shape, and the goals of mandibular reconstruction are restoration of form and function while considering impact on quality of life of the patient. Mandibular defects after oral cancer surgery usually involve the skin, mucosa, nerve, or a combination of these; hence, the plans for restoration of form involve various combinations of these tissues. When planning autologous bone grafting, it is necessary to choose the area that matches with the thickness and angulation of the mandible; at the same time, the donor site morbidity should also be considered based on the patient's individual condition including vascular status. Dentition can be predictably restored using osseointegrated implants, consequently improving mastication and other functions. Soft tissue including the oral mucosa and/or skin replacements need to be thin and pliable enough so as not to inhibit the mobility of the remaining oral structures in terms of functional recovery.

The osteocutaneous free flap is considered the main method for the primary method of mandibular reconstruction, because it has consistently provided the best functional and aesthetic results in patients. This technique, performed simultaneously with cancer ablation, is the fastest surgery for patients and provides the most successful rehabilitation [264]. The advantages and disadvantages of the currently well-known osteocutaneous freeflap options for mandibular defects are summarized in Table 6 . Moubayed et al. [265] recently reviewed the frequency of use of osteocutaneous free flaps for mandibular reconstruction and reported on a preliminary comparison of quality of life according to the flap methods used. In their analyses, the fibular free flap 
Table 6. Advantages and disadvantages of the osteocutaneous free flaps for mandibular reconstruction

\begin{tabular}{lcccc}
\hline Parameter & Fibula & Radial forearm & lliac crest & Scapula \\
\hline Bone length $(\mathrm{cm})$ & Up to 25 & Up to 12 & Up to 15 & Up to 20 \\
Skin paddle & 2 & 1 & 1 & 2 \\
Pedicle length & Short & Very long & Short & Long \\
Dental restoration & Possible & Impossible & Best & Limited \\
Donor site morbidity & Minimal & Fracture & LOM & LOM \\
Two-team approach & Possible & Possible & Possible & Limited \\
Quality of life & Best & Intermediate & NA & Worst \\
\hline
\end{tabular}

LOM, limitation of motion; NA, not assessable.

$(72.6 \%)$ was the most frequently used mandibular reconstruction method followed by the radial forearm $(14.9 \%)$, iliac crest $(8.4 \%)$ and the subscapular system free flaps $(3.7 \%)$. They also showed a trend towards better quality of life and depression alleviation in the fibula free flap group; however, these findings did not reach statistical significance because of heterogeneity in patient age, follow-up times, and defect types, and thus cannot be used to draw firm conclusions. Another study by Zavalishina et al. [266] about the patients' quality of life after mandibular resection and reconstruction with the free fibula flap demonstrated that most patients reported satisfaction with their overall quality of life.

Although vascularized bone grafting is the preferred method of mandibular reconstruction, this technique can increase surgical time and blood loss, which may be associated with increased morbidity and mortality. Bridging plates can be used to select segmental mandibular reconstruction. Okura et al. [267] inspected the plate survival and factors influencing the occurrence of complications, and reported a 5-year plate survival rate with no complications of $62.2 \%$; anterolateral defects and preoperative RT were identified as independent risk factors for plate survival. They concluded that the use of bridging plates may be an option for lateral mandibular reconstruction in cases without previous irradiation. Relatively short mandibular defects with sufficient vascularity could possibly be treated with particulate cancellous bone marrow combined with a titanium mesh (PCBM-MESH). Miyamoto et al. [268] introduced the use of the PCBM-MESH for mandibular reconstruction and demonstrated a $90 \%$ (nine of 10 patients) success rate; they suggested PCBMMESH as an attractive reconstruction option, if sufficient alveolar ridge with good oral membrane. However, this is in sharp contrast to the use of alloplastic supports of nonvascularized cancellous bone grafts wrapped in pedicled musculocutaneous flaps [264].

It is often accepted that reconstruction with composite free flaps promises better functional and aesthetic outcomes than does bridging the paucity with reconstruction plates. van Gemert et al. [269] compared health-related quality of life using the EORTC questionnaires in patients who received free fibula flaps versus reconstruction plates after segmental mandibulecto- my on the lateral mandible. They demonstrated that reconstruction with a fibula free flap did not offer obvious further benefit on quality of life compared to bridging plates. The authors concluded that plate reconstruction with sufficient soft tissue remains a suitable technique for the reconstruction of segmental defects of the lateral mandible, unless dental rehabilitation using implants would be expected in the fibula free flap.

Besides bone grafting, transport disk distraction osteogenesis is an alternative method that can be applied for the reconstruction of lateral mandibular defects after oral cancer surgery $[270,271]$. Furthermore, the recent introduction of a three-dimensional CAD software and additive manufacturing technology can enable patient-specific scaffold and matrix manufacturing; this includes biocompatible patient-specific scaffolds and matrices, osteogenic cells, and osteoinductive and angioinductive growth factors [272]. Studies evaluating the efficacy and validity of these new tissue engineering technologies are currently ongoing.

In the past, the utility of an osteocutaneous free flap during mandibular reconstruction greatly depended on the surgeon's expertise and decision-making. To overcome this problem, computer-aided surgery was introduced in the late 2000s, and has been applied to the reconstruction of segmental mandibular defects that occur after oral cancer surgery. Computer-aided surgical technology includes virtual surgical planning, CAD, CAM, rapid prototyping, and intraoperative navigation-assists in the planning of reconstructive surgery.

Reconstruction using CAD/CAM proceeds through four phases: planning, modeling, surgery, and evaluation. This technique can surmount a number of trial-and-error issues which may happen in the surgical field and may also reduce operating time. Traditional methods (i.e., intraoperative planning), involve repeated trial and error, and require significant time investment in perfecting procedures such as those for the alignment of the folded angle of the reconstruction plate. Since CAD/CAM facilitates the performance of these tasks using a stereolithographic model, this method significantly lowers ischemic and operating time. According to a literature review, the accuracy of intraoperative $\mathrm{CAD} / \mathrm{CAM}$ use and subsequent plate designing reached $92 \%$, and this technique was efficacious in elevating the accuracy of dental occlusion and the orthognathic relationship [273, 274]. Furthermore, the stereolithographic model-assisted reconstruction is also useful in the rebuilding of the mandibular condyle with a fibular free flap with satisfactory esthetical and functional outcomes [275].

However, the most important limitation of CAD/CAM in oral cancer surgery is that it does not allow for an exact estimation of the tumor margin in the mandible. Therefore, surgeons should consider the likelihood that in the operating room, more tissue will be sacrificed than planned. There are reports that the likelihood of achieving a negative resection margin when performing tumor surgery using CAD/CAM is only about $5 \%[276,277]$. 
Additionally, recipient vessels, pedicle length, oral alignment and overlying dermal amount, location and type of perforating vessels supplying the osteocutaneous fibula flap skin paddle, and volumetric restoration in mandible reconstruction are critical components; however, it is difficult to evaluate and apply these variables in the CAD/CAM system [274]. Additionally, $\mathrm{CAD} / \mathrm{CAM}$ use leads to higher operating time; thus, taking into account the risk of tumor progression during that time, patients are required to undergo surgery within a maximum of 3 weeks [274]. If the above mentioned problems are resolved, applications of $\mathrm{CAD} / \mathrm{CAM}$ in mandibular reconstruction can be greatly extended in the future.

\section{Postoperative follow-up How can we postoperatively follow-up patients with oral cancer?}

\section{D1. Long-term follow-up schedules}

\section{Recommendation 27}

(A) Patients should be regularly examined for at least 5 years after treatment (strong recommendation, high-quality evidence).

(B) Because of the high risk of locoregional recurrence, patients must be inspected frequently for the first 2 years; this schedule requires patients to be examined every 1 to 3 months during year 1 , and every 2 to 6 months during year 2 (strong recommendation, low-quality evidence).

Follow-up schedules for each patient should be devised individually. The survey of quality of life, nutritional status, speech and swallowing function, dental status, and investigation of complications after treatment including thyroid function, smoking and alcohol consumption habits, etc., should be examined periodically. There are several reasons to regard posttreatment followup in patients with oral cancer as important, including the early identification of locoregional recurrence, monitoring and management of complications, optimization of rehabilitation, encouraging cessation of smoking and excessive alcohol consumption, providing emotional support to patients and their families, and patient counseling and education.

It is recommended that patients with oral cancer visit frequently after treatment, especially during the first 2 years, since the risk of locoregional recurrence is high during this time. If there is no evidence of recurrence, the frequency of visits may be reduced later and follow-up measures should be completed by year 5 . Patients with advanced stage of disease or specific tumors, those who require continuous special rehabilitation, and those who need a longer period of follow-up may be examined for a longer time period, and maybe even for the rest of their lives [278-286]. The European Journal of Surgical Oncology recommends that the follow-up schedule in patients with head and neck cancer should include visits every 4 to 6 weeks during the first 2 years, every 3 months during year 3, twice yearly in year 4 and 5, and then once every year [287]. Members of the American Society for Head and Neck Surgery reported a $73 \%$ of the agreements in their consensus report, in response to a schedule comprising monthly follow-up visits during the first year after surgical treatment, visits every 2 to 3 months during year 2 , and visits every 4 to 6 months during years 3 to 5 [288]. Many studies have revealed that the follow-up protocol should be planned such that the first 2-year follow-up generally occurs between week 4 and week 8 postoperatively, and subsequent visits occur every 3 to 6 months [278-281].

\section{D2. Tests during the follow-up period}

\section{Recommendation 28}

(A)To provide reference images, repeating pretreatment baseline imaging studies (CT or MRI) is recommended within 6 months after treatment (strong recommendation, low-quality evidence).

(B) PET-CT is recommended for the detection of distant metastasis, recurrence, and second primary tumors (strong recommendation, moderate-quality evidence).

(C) A chest radiography or CT study is recommended for the detection of lung metastasis and second primary tumors in the lung (strong recommendation, moderate-quality evidence).

(D) US can be considered for the detection of cervical lymph node recurrence (weak recommendation, low-quality evidence).

The first step of the follow-up protocol in patients with oral cancer should include a patient education program related to the potential symptoms and signs of recurrence. Tobacco smoking and alcohol cessation programs should also be included in these education sessions $[278,289,290]$. During the follow-up period, physical examination including laryngoscope or fiberscope examination should be conducted for oral cavity inspection, and the palpation of the primary site and the neck including cervical lymph nodes should be performed.

Baseline images of CT or MRI implemented between 3 to 6 months after the surgical, radiological, or combined treatment for advanced oral cancer can be used for comparing with subsequent images for the early detection of abnormalities [291]. Patients with oral cancer require careful follow-up including thorough clinical examinations and imaging studies at 3- to 4-month intervals for a period of 2 years after definitive treatment.

PET-CT exhibits superior performance for detecting recurrences or second primary malignancies. In addition, PET-CT has the advantage of allowing for a systemic evaluation; a sensitivity of up to $93 \%$ has been reported for this technique, for detecting 
recurrent oral cancer. PET-CT shows nearly $100 \%$ accuracy in diagnosing distant metastasis in cancer patients [292,293].

Chest radiography should be performed as a part of the routine protocol for head and neck cancer follow-up to detect lung metastasis and second primary malignancies in the lung. At times, it is more appropriate to use chest CT rather than chest radiography for evaluating patients with advanced oral cancer [294,295].

Several studies have evaluated the efficiency of US and physical examination including manual palpation during follow-up, and have revealed that US showed $97.5 \%$ accuracy in detecting lymph node enlargement. Other studies have also reported that US and US-guided fine needle aspiration cytology provide important information for detecting recurrence of cervical lymph node [294-298].

In patients who were treated with radiation therapy, CT, MRI, and US could not specifically differentiate postradiation edema from recurrence. Therefore, CT, MRI, or PET-CT should be performed within 3 to 6 months after treatment to obtain reference image [293]. Although the optimal follow-up strategy after surgical treatment still remains under debate, a careful clinical examination should be performed, if the results are positive, followed by contrast CT [278]. PET-CT are applied to the screen for metastasis in patients undergoing surgery with RT or chemoradiotherapy (CRT) [293,299-301]. Patients treated with definitive chemoradiation therapy should be evaluated with PET-CT at 3 months after the completion of therapy; the primary and neck disease should be assessed to evaluate treatment response and to plan salvage neck surgery if required [293,299-301]. Tumor markers and gene expression profiling are known to be less sensitive and have low cost-effectiveness, are thus not recommended as useful markers for the follow-up of oral cancer [302,303].

\section{D3. Thyroid function evaluation}

\section{Recommendation 29}

(A) A thyroid function test is recommended to identify the presence of hypothyroidism in patients with oral cancer treated with RT in the head and neck area (strong recommendation, low-quality evidence).

(B) Thyroid function should be examined twice yearly during the first 5 years after treatment, and annually thereafter. Periodic thyroid function tests may be conducted to follow-up thyroid function for 10 years (weak recommendation, low-quality evidence).

At least $50 \%$ of patients who had undergone radiation therapy in the head and neck area were prone to hypothyroidism resulting in biochemical injury. Previous reports revealed that $10 \%$ to $70 \%$ of patients suffer from thyroid dysfunction after head and neck cancer treatment [304-306]. Thyroid function is evaluated to measure the serum levels of thyroid stimulating hormone (TSH) and free thyroxine (fT4).

Damaged vascular supply is one of the pathophysiologic causes of hypothyroidism. During neck lymphatic dissection, the vascularity around the thyroid gland may be iatrogenically damaged or intentionally sacrificed. These procedures distract the vascularities of the thyroid gland and eventually affect thyroid function. In addition, radiation-induced fibrosis may lead to decreased thyroid function not only due to impaired vascularity but also due to fibrosis of the entire gland. Increased TSH levels have been found in $20 \%$ to $25 \%$ of patients who have undergone radiation therapy in the head and neck area, and these patients have an increased risk of hypothyroidism [306]. Several studies have shown that regular evaluation of thyroid function is needed for a period of at least 10 years after receiving treatment for oral cancer. Thyroid dysfunction is a common complication in up to $25 \%$ of patients with radiation therapy in the head and neck area, and this condition is not easily recognized [306,307]. Therefore, regular thyroid function tests are recommended in patients with oral cancer, especially in those treated with radiation therapy. For patients treated with radiation therapy in the head and neck area, the recommended follow-up protocol should include an assessment of thyroid function.

\section{E. Rehabilitation}

What are the appropriate rehabilitation and supportive therapy options after anticancer treatment?

\section{E1. Speech therapy and swallowing rehabilitation}

\section{Recommendation 30}

(A) Swallowing evaluation and rehabilitation should be offered to all patients with locally advanced oral cancer treated with postoperative concurrent chemoradiation therapy, within 3 months posttreatment (strong recommendation, moderate-quality evidence).

(B) Speech evaluation and rehabilitation should be considered for all patients and oral cancer survivors within 3 months posttreatment (strong recommendation, moderate-quality evidence).

Chronic dysphagia is more prevalent after multimodality treatment for advanced disease than after low dose/small field irradiation or a single modality treatment. Even with advancements in medicine, surgical techniques, and technologies such as intensity-modulated radiation therapy or transoral robotic surgery, about half of the patients treated with multimodal therapy for locally advanced disease suffer chronic dysphagia [308]. Psychosocial factors including depression, cognitive dysfunction, deficiency of caregiver support, and sensory changes, may also relate to poor oral intake in oral cancer survivors. 
Although many clinicians believe that swallowing rehabilitation favorably affects not only posttreatment function but also quality of life and overall treatment outcome, there are few randomized prospective studies of oral cancer survivors [309]. However, increasing data support the finding that swallowing evaluation and rehabilitation should be recommended to patients with locally advanced oral cancer undergoing concurrent chemoradiation therapy [309]. While it is difficult to recover from persistent dysphagia, patients can benefit from swallowing therapy (compensations, exercise, biofeedback) [310-313].

The optimal timing of swallowing rehabilitation has not been established. However, limited data suggest that early intervention is more advantageous than delayed intervention [309]. Furthermore, increasing evidence suggests that a "window of opportunity" may exist, and may be associated with fibrosis. A study reported that the greatest increase in swallowing dysfunction was noted at three months after treatment, without obvious improvement in many of the observed disorders by the end of the study [314]. Furthermore, a few retrospective cross-sectional or small prospective studies have suggested that pretreatment swallowing exercises had favorable effects on posttreatment swallowing function.

Voice and speech therapies and related rehabilitation using a prosthesis should also be considered. According to two RCTs and various non-RCT-based studies, oral cancer survivors should be referred to a speech-language therapist for assessment and management of voice, speech, and disturbance in resonance $[315,316]$. Early evaluation and treatment are preferred. Use of a prosthesis is supported by numerous non-RCT-based studies [317]. For instance, obturators fabricated by prosthodontists can help speech resonance in patients with oral and oropharyngeal defects, and palatal drop prostheses can help proper articulation after radical resection of oral cavity structures such as after subtotal or total glossectomy [318].

\section{E2. Shoulder rehabilitation}

\section{Recommendation 31}

Shoulder function should be assessed as part of a regular follow-up in patients who underwent ND and/or postoperative radiation therapy; early rehabilitation should be considered where shoulder morbidity exists (strong recommendation, high-quality evidence).

Shoulder dysfunction and pain are present in almost $70 \%$ of patients who undergo lymph node dissection of the lateral neck. The primary cause of shoulder problems is damage to the spinal accessory nerve (SAN) due to surgical procedures. Radiation therapy can also cause injury to the SAN and other neuromuscular structures related to shoulder movement. All the above factors may induce rotator cuff tendonitis, adhesive capsulitis, myofas- cial pain, and other similar conditions. The onset of clinical symptoms may take months or even years; therefore caregivers should assess shoulder function after treatment by not only directed history-taking but also by physical examination to periodically evaluate patients for shoulder pain or functional impairment.

Oral cancer survivors with shoulder dysfunction and pain should be referred for shoulder rehabilitation. A small RCT has reported that progressive resistance training (PRT) was better than standard physical therapy for oral cancer patients with SAN-related shoulder dysfunction [319]. Oral cancer survivors with shoulder dysfunction who underwent a PRT program reported obvious reduction in pain and disability in addition to improvement of upper extremity strength and endurance [320]. A Cochrane review also reported that PRT was more effective than standard physical therapy for shoulder dysfunction in patients treated for head and neck cancer; while PRT improved pain, disability, and ROM of shoulder joint, the effect on quality of life of head and neck cancer survivors was unclear [319-322].

\section{E3. Lifestyle modification}

\section{Recommendation 32}

(A) Regular physical activity (at least 150 minutes of moderate or 75 minutes of vigorous aerobic exercise per week, include strength training exercise at least 2 days per week should be targeted) is recommended for oral cancer survivors (strong recommendation, high-quality evidence).

(B) Patients and survivors should avoid alcohol/tobacco product consumption (strong recommendation, highquality evidence).

(C) Patients and survivors are encouraged eat a healthy diet high in vegetables, fruits, and whole grains, low in saturated fats, and with adequate dietary fiber (strong recommendation, lower-quality evidence).

(D) Regular dental care, early interventions for oral/dental complications, and fastidious oral hygiene are important for oral cancer survivors (strong recommendation, lowquality evidence).

Oral cancer survivors should be advised avoid inactivity and to return to normal daily activities as soon as possible after treatment $[323,324]$. Additionally, as recommended for the general population by the American Cancer Society, head and neck cancer survivors should try to exercise for at least 150 minutes moderately or 75 minutes vigorously a week and the reinforcement exercise should include at least 2 days a week [323]. Preliminary evidence with head and neck cancer survivors [325] suggests that an individual-tailored exercise regimen can increase functional capacity and quality of life (QoL) of head and neck cancer survivors undergoing concurrent chemoradiation therapy 
[326]. Although evidence is inadequate, generally, performing any exercise is better than not exercising, and there is consensus about the value of specific exercises appropriate for this patient population [327]. If specific impairments are identified such as shoulder dysfunction and cervical radiculopathy, oral cancer survivors should be referred to a rehabilitation specialist [327].

According to rigorous evidence, more than $75 \%$ of head and neck cancers are related to tobacco and alcohol abuse [328]. Thus, in addition to encouraging healthful eating, it is critical to emphasize abstinence from tobacco and alcohol consumption. A prospective study reported that consuming more than three drinks per day was associated with an increased risk of head and neck cancer in both men (hazard ratio, 1.48) and women (hazard ratio, 2.52) [329]. Alcohol was identified in the 1980s as a carcinogen of the upper digestive tract including the oral cavity, pharynx, and larynx [330], and numerous studies have confirmed this finding [331]. It has been noted that compared to non-drinkers, alcohol-drinkers who consume about $50 \mathrm{~g}$ of alcohol per day (more than three drinks) have a 2-3 fold higher risk of upper digestive tract cancers. Furthermore, a synergistic effect of alcohol consumption and smoking has been implicated in head and neck cancer carcinogenesis [332].

Oral cancer patients who continued to consume alcohol tobacco after diagnosis have been reported to have poorer survival rates compared to those who abstained [333]. Furthermore, even in HPV-related head and neck cancer, the overall prognosis was worse among current or the former smokers; current and former smokers also showed an increased rate of recurrence compared with HPV-related survivors who never smoked [334]. Increasing evidence suggests that about $48 \%$ of oral cavity [335] and pharynx cancer deaths [336] are caused by smoking. Most head and neck cancer patients try to quit smoking before or during treatment [337], 14\%-60\% will relapse [338-340]. Continued smoking is associated with the following negative outcomes: (1) risk of smoking-associated diseases other than cancers (e.g., coronary artery disease); (2) higher rates of second primary cancers and recurrence of the original primary cancer [341-343]; (3) reduced treatment efficacy [344,345], worsened treatment side effects [346,347]; (4) subsequent negative impacts on QoL, morbidity, and mortality [341,348]. Because of the numerous benefits of quitting smoking, clinicians should strongly encourage and support patients to stop smoking and maintain their abstinence.

Fastidious dental hygiene practices and regularly scheduled dental visits are important for oral cancer survivors, and especially for those received radiation therapy with or without chemotherapy $[349,350]$. Oral complications may be influenced by several factors. One of the most controllable factors is dental and oral hygiene prior to treatment initiation. Commodities that can potentially increase the severity of oral side effects should consider malnutrition, diabetes, alcohol and tobacco abuse, and poor general hygiene.
The following issues should be assessed during evaluation of oral complications: dental caries, gingival status, periodontal abnormalities, oral mucosal health, taste perception, production of saliva, pain, and swallowing. Long-term oral side effects by treatment include neurosensory dysfunction, loss of saliva and taste, and other functional changes [350]. If the patient is totally or partially edentulous and wears dentures, proper and regular fitting should always be recommended [350]. Many oral cancer survivors with edentulous areas will experience a remodeling of the supportive ridge for the appliance, causing the denture to become loose and ill-fitting; the denture may rub the gums, tongue, or oral mucosa to the point of ulceration. The device must be removed overnight to rest the oral tissue and prevent nocturnal bruxing. The dentures should be kept moist while out of the patient's mouth [350].

In addition, patients should be advised to avoid mouth-breathing and nasal respiration should be recommended. Mouth-breathing can lead to xerostomia, recurrent oral mucositis, oral infections, and cause desiccation of the teeth and rapid advancement of dental caries [350]. Patients who use a continuous positive airway pressure to treat sleep apnea should know that careful dental and oral health is most important to avoid caries; caries and associated abscesses may increase risks of osteoradionecrosis [350].

\section{E4. Psychiatric support}

\section{Recommendation 33}

Patients and survivors should be assessed for distress, depression, and anxiety periodically ( 3 months posttreatment and at least annually) using a validated assessment tool. Counseling and/or pharmacotherapy should be offered (strong recommendation, high-quality evidence).

Many cancer survivors have difficulties in returning to "regular life" after treatment [351,352]. Many head and neck cancer survivors have fear of recurrence [353], which impacts mental

Table 7. General psychosocial long-term and late effects

\begin{tabular}{l}
\hline Depression, depressive symptoms \\
Distress_multifactorial unpleasant experience of psychological, social, \\
and/or spiritual nature \\
Worry, anxiety \\
Fear of recurrence \\
Pain-related concerns \\
End-of-life concerns: death and dying \\
Changes in sexual function and/or desire \\
Challenges with body image (secondary to surgery, laryngectomy, radiation) \\
Challenges with self-image \\
Relationship and other social role difficulties \\
Return to work concerns and financial challenges
\end{tabular}


health. Additionally, such patients have an increased risk of depression and anxiety $[354,355]$. Although the estimated prevalence of mental problems in cancer survivors is variable, among cancer survivors in general, the estimated prevalence of anxiety and depression is $17.9 \%$ and $11.6 \%$, respectively [356].

Distress for head and neck cancer patients includes worry, anxiety, sadness, emotional concerns [357], social disruption [358], fear of recurrence, and posttraumatic distress disorder (Table 7) [353,359]. One study reported that the incidence of depressive disorders was $15 \%$ to $50 \%$ in head and neck cancer patients, in contrast to $15 \%$ to $25 \%$ in cancer patients in general [360]. An analysis of 89 head and neck cancer patients revealed that $75 \%$ of head and neck cancer patients reported emotional concerns and over 50\% acknowledged feelings of worry [357]. In a larger cohort study, the most common psychological distress factors included interpersonal relationships, uncertainty, and interference in activities [361].

It is important to monitor the psychological health of the survivors, caregivers, and the survivor's family members. The survivor's financial status, family responsibilities, and access to support impact the posttreatment psychological status. To provide timely and appropriate support for patients, clinicians should be familiar with the mental health problems commonly incident after cancer treatment, the tools to screen for and assess these problems, and the resources to provide care (Table 8). A recent American Society of Clinical Oncology guideline provides comprehensive description of the screening, assessment, and management of anxiety and depressive symptoms in patients with cancer [362].

\section{F. Salvage surgery}

F1. What is role of salvage surgery in the recurrent oral cavity cancer?

\section{Recommendation 34}

(A) Salvage surgery should be considered for recurrent oral cavity cancer, if resection is feasible (strong recommendation, moderate-quality evidence).

(B) END can be considered for T2-4 recurrent oral cavity cancer (weak recommendation, low-quality evidence).

(C) Comprehensive ND should be considered for $\mathrm{rN}+$ recurrent oral cavity cancer (strong recommendation, lowquality evidence).

Overall recurrence rate from a meta-analysis of 1,692 oral cavity cancer patients was $26 \%$, with a mean local recurrence rate of $47.3 \%$, regional recurrence rate of $35.1 \%$, and locoregional recurrence rate of $10.9 \%$; the 5 -year OS after salvage surgery was $37.5 \%-42.9 \%$ [363]. Patients treated with salvage surgery showed better survival than did those treated with chemotherapy and/or RT [364]. Patients with previous treatment to the neck presented a poorer survival after recurrence than did those without previous treatment [365]. Patients with early clinical stage such as a small tumor size (less than $4 \mathrm{~cm}$ ), or a tumor without evidence of bone invasion showed better survival than did those with late clinical stage [366]. Patients with late relapse or with a disease free-interval of more than 1 year showed significantly better survival than did those with early recurrence or a disease-free period of less than 1 year [367]. Patients treated with surgery alone showed better survival than did those treated with surgery followed by RT or with RT alone $[368,369]$. Extracapsular spread was reported as an important prognostic factor for salvage surgery $[364,366]$.

Overall complications from salvage surgery have been reported in $37 \%-60.7 \%$ of cases, which is higher compared to that from primary surgery. Commonly reported complications include wound infection, orocutaneous fistula, and wound dehiscence and/or flap necrosis [366,368]. Even with free flap reconstruction, permanent gastrotomy may be required in $25 \%-50 \%$ of the patients $[366,370]$. Therefore, morbidity should be considered before salvage surgery is to be performed, especially in advanced recurrences.

Among patients with oral cavity cancer with negative neck who are treated with RT or CRT initially, some show local recurrence without obvious neck recurrence. Currently, there is no clear consensus on the optimal treatment for a node-negative neck during the salvage surgery of locally recurrent oral cavity cancer. Generally, the risk of occult neck nodal metastasis in a

Table 8. Validated tools to assess for distress/depression/anxiety

\begin{tabular}{|c|c|c|}
\hline Tool & Intended use & How it works \\
\hline Beck Anxiety Inventory (BAI) & Screen for anxiety & 21 Items, 0 (not problematic)-3 (problematic) \\
\hline $\begin{array}{l}\text { Center for Epidemiological Studies Depression Scale } \\
\text { (CES-D) }\end{array}$ & Screen for depression & 0-3 Scoring ( $\geq 16$ suggests clinical depression) \\
\hline Generalized Anxiety Disorder (GAD)-7 & Screen for anxiety & 0-3 Scoring for 7 items ( $\geq 15$ suggests severe anxiety) \\
\hline Hospital Anxiety and Depression Scale (HADS) & Screen for depression and anxiety & 0-3 Scoring for 14 items ( $\geq 9$ suggests clinical significance) \\
\hline NCCN Distress Thermometer & Screen for distress & $\begin{array}{l}0 \text { (No distress)-10 (extreme distress), } \geq 14 \text { suggests clinical } \\
\text { significance) }\end{array}$ \\
\hline Patient Health Questionnaire (PHQ)-9 & Screen for depression & 0-3 Scoring for 9 items ( $\geq 20$ suggests severe depression) \\
\hline
\end{tabular}

NCCN, National Comprehensive Cancer Network. 
clinically N0 oral cavity cancer depends on (1) the primary cancer site and (2) T stage classification [371]. END is generally recommended after evaluation of the characteristics of the primary tumor. The likelihood of occult metastasis may be over $20 \%$, depending on tumor characteristics such as T stage, site of the primary tumor, tumor thickness, etc. [206,372]. In oral cavity cancer, it is accepted that a tumor with a DOI of over $4 \mathrm{~mm}$ or with advanced T stage has over a $20 \%$ risk of occult neck metastasis [372,373]. In these cases, END in combination with resection of the locally recurred primary tumor has shown promising results [206,209,372-375]. However, there is no consensus regarding management of the N0 neck in patients with locally recurrent head and neck cancers. Some authors suggest END with the removal of the recurrent primary tumor based on the following assumptions: (1) biologic behavior of the recurrent tumor implies a higher risk of lymph node metastasis, and (2) there may be residual microscopic tumor in the neck after initial RT or CRT. In addition, complex (free flap) reconstruction may be necessary after resection of a local recurrence with advanced $\mathrm{T}$ stage, making neck exposure mandatory for finding and dissecting the vessels. Finally, the success rate of a second salvage surgery in the neck after a regional recurrence is poor [376378]. Some authors suggest a "wait and see" policy, since there is a risk of injuring the nerves and vessels, and there is lack of evidence to suggest that ND is superior with reference to longterm prognosis and regional recurrence [379,380].

Yirmibesoglu et al. [380] analyzed 44 patients with locally recurrent HNSCC; the patients were originally classified as N0, and were initially treated with RT or CRT prior to disease recurrence. Of the 44 patients, 30 received END, depending on the surgeon's preference. Positive nodes were found in $10 \%$ of the patients (3/30). However, the survival rate between ND and observation groups showed no difference. Solares et al. [381] reviewed 69 patients initially treated with RT or CRT, and who later developed local recurrence and received salvage surgery and ND. Multiple primary sites were as follows: larynx, 37/69 (53\%); oropharynx, 15/69 (22\%); hypopharynx, 7/69 (10\%); and oral cavity, $10 / 69(15 \%)$. While 17 of 69 patients $(24 \%)$ had nodal metastasis, 7 of 17 (41\%) showed more than two positive nodes, and 3 of 17 (17\%) showed extracapsular invasion. Regarding the frequency of metastasis, supraglottic cancers had the highest frequency (55\%), followed by hypopharynx $(43 \%)$, oral/oropharynx $(20 \%)$, and glottis $(12 \%)$ cancers. Second recurrence was observed in 28 of 69 patients $(40 \%)$. There were no neck recurrences when the primary site was controlled. Lee et al. [382] analyzed 149 patients with oral cavity, oropharynx, larynx, and hypopharynx cancers who later showed isolated local recurrence with an N0 neck, and were submitted to salvage surgery. Data showed that 50 of 149 patients $(33 \%)$ had laryngeal cancers (of them, 35 of 50 [70\%] showed glottic cancer), 47 of 149 (31\%) had oral cavity cancers (of them, 27 of 47 [57\%] showed tongue cancer), 23 of 149 (15\%) had oropharyn- geal cancers, and 29 of 149 (19\%) had hypopharyngeal cancers. The observation group showed 74 hemi-necks and the ND group showed 80 hemi-necks. Within the ND group, more heminecks were treated with CRT initially ( 21 vs. 8 ) than with exclusive RT (5 vs. 18), while showing more advanced recurrences (44 vs. 22). Regional recurrence was seen in 19 patients (10 of 19 [52\%] in the observation group, compared to 9 of 19 [47\%] in the ND group). Occult lymph node metastasis was found in six of $80(7.5 \%)$ of the dissected hemi-necks. In a multivariate analysis, the authors found a relationship between ND and better regional control and cause-specific survival [382]. However, these studies did not analyze oral cavity cancer exclusively, and due to the small number of patients, it is not feasible to gauge the accuracy of the results. Therefore, it is difficult to draw conclusions regarding the need for END. However, in locally recurrent oral cavity cancer with a clinically N0 Neck, the risk of occult neck node metastasis is about $7.5 \%-17 \%$. Most studies suggest ND for patients with more advanced primary or recurrent tumor stage and a "wait and see" approach for less advanced cases. END can be considered in patients with advanced locally recurrent oral cavity cancer (rT2-4). In the future, diagnostic modalities with enhanced accuracy in finding or excluding occult metastasis will be developed. However, the final decision rests with the surgeon, while taking into consideration the status of the patient.

A few studies have focused exclusively on regional or locoregional recurrence in oral cavity cancer. In a study of recurrent oral cavity cancer with regional recurrence, Wong et al. [383] reported that patients with ipsilateral recurrence in a previously undissected neck had a surgical salvage rate of $56 \%$, with a 5 -year survival of $32 \%$. However, within the previous ND group, these figures fell to $32.5 \%$ and $18 \%$, respectively. RT or chemotherapy showed no successful salvage $(0 \%)$. Kowalski [365] reported that in a series of 513 patients with oral cancer, 82 patients $(16 \%)$ had regional recurrence. Only 51 patients $(62 \%)$ were eligible for salvage treatment. Among 82 regional recurrences, 44 were ipsilateral, 31 contralateral, and 7 bilateral. Only five of 46 patients $(10.8 \%)$ who had recurrence in an undissected neck survived. Factors with prognostic significance after salvage ND were (1) previous ND type, (2) previous RT history, and (3) recurrence within 6 months (these patients showed a statistically better survival than did those with recurrence after 24 months). Sun et al. [384] reported on 233 cases of tongue cancer, 45 of which showed regional recurrence $(19.3 \%)$. The salvage rate was at $26 \%$. In univariate analysis, neck relapse had a significantly worse prognosis compared to local recurrence. Patients who showed recurrence within 6 months had a worse prognosis and surgery showed better results as a method of salvage treatment. In study by Gleich et al. [385], all 18 patients with initially advanced oral cavity cancer (T3/4) showed regional recurrence. While four of them were treated with RT alone and showed persisting tumors or recurrence within 6 months, 
14 received ND, and showed a mean survival time of 31.1 months. Six of the ND patients had a prolonged survival duration. Ord et al. [386] reported on a series of 354 patients with oral cancer, and observed that 30 patients showed regional recurrences $(8.5 \%)$. They reported that in previous studies, the highest success rate of salvage in previously untreated necks was $63.3 \%$ (19/30). The success rate dropped in patients with previous surgery or RT to the neck. All patients received surgery as a mode of salvage treatment, and modified radical ND plus RT showed best results. Koo et al. [370] emphasized that in patients with recurrent neck disease, aggressive treatment with surgery and adjuvant therapy was very important. They concluded that surgery was superior to chemotherapy with or without radiation therapy at controlling the disease. These studies suggest that the prognosis of ipsilateral neck recurrence is better than that of bilateral neck recurrence, and that radical ND improves the survival rate in patients with regional recurrence in a previous undissected neck. In addition, Jones et al. [376] reviewed 699 head and neck cancer patients with primary radical ND. Most of the patients receiving primary radical ND suffered no recurrence in the neck, and the study reported a cure rate of $56 \%$. Those with a recurrence received a second ND, with a cure rate of $31 \%$. Those who had no curative treatment to the neck showed a median survival time of 7 months, with no long-term survivors. Based on the results of several studies, comprehensive ND should be considered for recurrent oral cavity cancer with regional recurrence. While regional recurrence is one of most important prognostic factors in oral cavity cancer, the optimal management of recurrent lymph node metastasis is worthy of more study.

\section{CONFLICT OF INTEREST}

No potential conflict of interest relevant to this article was reported.

\section{ENDORSEMENT FROM OTHER SOCIETIES}

The final draft was approved by the boards of executives of the Korean Society for Head Neck Oncology (KSHNO), Korean Society for Radiation Oncology (KOSRO), Korean Society of Medical Oncology (KSMO), and Korean Society of Otorhinolaryngology-Head and Neck Surgery (KORL).

\section{SUPPLEMENTARY MATERIALS}

Supplementary materials can be found via https://doi.org/10. 21053/ceo.2018.01816.

\section{ORCID}

Young-Hoon Joo https://orcid.org/0000-0002-1158-0974

Guk Haeng Lee https://orcid.org/0000-0003-4766-9556

Phil-Sang Chung https://orcid.org/0000-0003-4591-2276

\section{REFERENCES}

1. Torre LA, Bray F, Siegel RL, Ferlay J, Lortet-Tieulent J, Jemal A. Global cancer statistics, 2012. CA Cancer J Clin. 2015 Mar;65(2): 87-108.

2. Chi AC, Day TA, Neville BW. Oral cavity and oropharyngeal squamous cell carcinoma: an update. CA Cancer J Clin. 2015 Sep-Oct; 65(5):401-21.

3. Tahir A, Nagi AH, Ullah E, Janjua OS. The role of mast cells and angiogenesis in well-differentiated oral squamous cell carcinoma. J Cancer ResTher. 2013 Jul-Sep;9(3):387-91.

4. Rogers SN, Brown JS, Woolgar JA, Lowe D, Magennis P, Shaw RJ, et al. Survival following primary surgery for oral cancer. Oral Oncol. 2009 Mar;45(3):201-11.

5. Korean Society of Thyroid-Head and Neck Surgery Guideline Task Force, Ahn SH, Hong HJ, Kwon SY, Kwon KH, Roh JL, et al. Guidelines for the surgical management of laryngeal cancer: Korean Society of Thyroid-Head and Neck Surgery. Clin Exp Otorhinolaryngol. 2017 Mar;10(1):1-43.

6. Kim SY, Park JE, Lee YJ, Seo HJ, Sheen SS, Hahn S, et al. Testing a tool for assessing the risk of bias for nonrandomized studies showed moderate reliability and promising validity. J Clin Epidemiol. 2013 Apr;66(4):408-14.

7. Shea BJ, Grimshaw JM,Wells GA, Boers M,Andersson N, Hamel C, et al. Development of AMSTAR: a measurement tool to assess the methodological quality of systematic reviews. BMC Med Res Methodol. 2007 Feb; $7: 10$.

8. Warnakulasuriya S, Johnson NW, van derWaal I. Nomenclature and classification of potentially malignant disorders of the oral mucosa. J Oral Pathol Med. 2007 Nov;36(10):575-80.

9. Carreras-Torras C, Gay-Escoda C.Techniques for early diagnosis of oral squamous cell carcinoma: systematic review. Med Oral Patol Oral Cir Bucal. 2015 May;20(3):e305-15.

10. Omar E. Current concepts and future of noninvasive procedures for diagnosing oral squamous cell carcinoma: a systematic review. Head Face Med. 2015 Mar;11:6.

11. Macey R, Walsh T, Brocklehurst P, Kerr AR, Liu JL, Lingen MW, et al. Diagnostic tests for oral cancer and potentially malignant disorders in patients presenting with clinically evident lesions. Cochrane Database Syst Rev. 2015 May;(5):CD010276.

12. Forman MS, Chuang SK, August M. The accuracy of clinical diagnosis of oral lesions and patient-specific risk factors that affect diagnosis. J Oral Maxillofac Surg. 2015 Oct;73(10):1932-7.

13. Wang YY,Tail YH, Wang WC, Chen CY, Kao YH, Chen YK, et al. Malignant transformation in 5071 southern Taiwanese patients with potentially malignant oral mucosal disorders. BMC Oral Health. 2014 Aug;14:99.

14. Fitzpatrick SG, Hirsch SA, Gordon SC. The malignant transformation of oral lichen planus and oral lichenoid lesions: a systematic review. J Am Dent Assoc. 2014 Jan;145(1):45-56.

15. Warnakulasuriya S, Kovacevic T, Madden P, CouplandVH, Sperandio $\mathrm{M}$, Odell E, et al. Factors predicting malignant transformation in oral potentially malignant disorders among patients accrued over a 10-year period in South East England. J Oral Pathol Med. 2011 Oct;40(9):677-83. 
16. Brocklehurst P, Kujan O, O’Malley LA, Ogden G, Shepherd S, Glenny AM. Screening programmes for the early detection and prevention of oral cancer. Cochrane Database Syst Rev. 2013 Nov;(11): CD004150.

17. Sankaranarayanan R, Ramadas K, Thomas G, Muwonge R, Thara S, Mathew B, et al. Effect of screening on oral cancer mortality in Kerala, India: a cluster-randomised controlled trial. Lancet. 2005 Jun;365(9475):1927-33.

18. Ramadas K, Sankaranarayanan R, Jacob BJ, Thomas G, Somanathan $\mathrm{T}$, Mahe $\mathrm{C}$, et al. Interim results from a cluster randomized controlled oral cancer screening trial in Kerala, India. Oral Oncol. 2003 Sep;39(6):580-8.

19. Sankaranarayanan R, Ramadas K, Thara S, Muwonge R, Thomas G, Anju G, et al. Long term effect of visual screening on oral cancer incidence and mortality in a randomized trial in Kerala, India. Oral Oncol. 2013 Apr;49(4):314-21.

20. Sankaranarayanan R, Mathew B, Jacob BJ,Thomas G, Somanathan T, Pisani P, et al. Early findings from a community-based, clusterrandomized, controlled oral cancer screening trial in Kerala, India. The Trivandrum Oral Cancer Screening Study Group. Cancer. 2000 Feb;88(3):664-73.

21. Lazarus CL, Husaini H, Anand SM, Jacobson AS, Mojica JK, Buchbinder $\mathrm{D}$, et al.Tongue strength as a predictor of functional outcomes and quality of life after tongue cancer surgery. Ann Otol Rhinol Laryngol. 2013 Jun;122(6):386-97.

22. Laaksonen JP, Rieger J, Happonen RP, Harris J, Seikaly H. Speech after radial forearm free flap reconstruction of the tongue: a longitudinal acoustic study of vowel and diphthong sounds. Clin Linguist Phon. 2010 Jan;24(1):41-54.

23. Hartl DM, Dauchy S, Escande C, Bretagne E, Janot F, Kolb F. Quality of life after free-flap tongue reconstruction. J Laryngol Otol. 2009 May;123(5):550-4.

24. Speksnijder CM, van der Bilt A, Abbink JH, Merkx MA, Koole R. Mastication in patients treated for malignancies in tongue and/or floor of mouth: a 1-year prospective study. Head Neck. 2011 Jul; 33(7):1013-20.

25. Villaret AB, Cappiello J, Piazza C, Pedruzzi B, Nicolai P. Quality of life in patients treated for cancer of the oral cavity requiring reconstruction: a prospective study. Acta Otorhinolaryngol Ital. 2008 Jun; 28(3):120-5.

26. Roumanas ED, Garrett N, Blackwell KE, Freymiller E, Abemayor E, Wong WK, et al. Masticatory and swallowing threshold performances with conventional and implant-supported prostheses after mandibular fibula free-flap reconstruction. J Prosthet Dent. 2006 Oct; 96(4):289-97.

27. Curtis DA, Plesh O, Miller AJ, Curtis TA, Sharma A, Schweitzer R, et al. A comparison of masticatory function in patients with or without reconstruction of the mandible. Head Neck. 1997 Jul;19(4): 287-96.

28. Teoh KH, Patel S, Hwang F, Huryn JM, Verbel D, Zlotolow IM. Prosthetic intervention in the era of microvascular reconstruction of the mandible: a retrospective analysis of functional outcome. Int J Prosthodont. 2005 Jan-Feb;18(1):42-54.

29. MatsuiY, Neukam FW, Schmelzeisen R, Ohno K. Masticatory function of postoperative tumor patients rehabilitated with osseointegrated implants. J Oral Maxillofac Surg. 1996 Apr;54(4):441-7.

30. Jung YS, Lim J, Jung KW, Ryu J,Won YJ. Metachronous second primary malignancies after head and neck cancer in a Korean cohort (1993-2010). PLoS One. 2015 Jul;10(7):e0134160.

31. Tiwana MS, Hay J, Wu J, Wong F, Cheung W, Olson RA. Incidence of second metachronous head and neck cancers: population-based outcomes over 25 years. Laryngoscope. 2014 Oct;124(10):2287-91.

32. Gan SJ, Dahlstrom KR, Peck BW, Caywood W, Li G, Wei Q, et al. Incidence and pattern of second primary malignancies in patients with index oropharyngeal cancers versus index nonoropharyngeal head and neck cancers. Cancer. 2013 Jul;119(14):2593-601.

33. Chen MC, Chen PT, Chan CH, Yang CT, Chen CC, Huang CE, et al. Second primary esophageal or lung cancer in patients with head and neck carcinoma in Taiwan: incidence and risk in relation to primary index tumor site. J Cancer Res Clin Oncol. 2011 Jan;137(1): 115-23.

34. Atienza JA, Dasanu CA. Incidence of second primary malignancies in patients with treated head and neck cancer: a comprehensive review of literature. Curr Med Res Opin. 2012 Dec;28(12):1899-909.

35. Chuang SC, Scelo G, Tonita JM, Tamaro S, Jonasson JG, Kliewer $\mathrm{EV}$, et al. Risk of second primary cancer among patients with head and neck cancers: a pooled analysis of 13 cancer registries. Int $\mathrm{J}$ Cancer. 2008 Nov;123(10):2390-6.

36. Lin K, Patel SG, Chu PY, Matsuo JM, Singh B, Wong RJ, et al. Second primary malignancy of the aerodigestive tract in patients treated for cancer of the oral cavity and larynx. Head Neck. 2005 Dec; 27(12):1042-8.

37. van der Waal I, de Bree R. Second primary tumours in oral cancer. Oral Oncol. 2010 Jun;46(6):426-8.

38. Hsu SH, Wong YK, Wang CP, Wang CC, Jiang RS, Chen FJ, et al. Survival analysis of patients with oral squamous cell carcinoma with simultaneous second primary tumors. Head Neck. 2013 Dec;35(12): 1801-7.

39. Liao CT, Fan KH, Kang CJ, Lin CY, Chang JT,Tsang NM, et al. Clinical outcomes of patients with resected oral cavity cancer and simultaneous second primary malignancies. PLoS One. 2015 Sep; 10(9): 0136918.

40. Hsu YB, Chang SY, Lan MC, Huang JL, Tai SK, Chu PY. Second primary malignancies in squamous cell carcinomas of the tongue and larynx: an analysis of incidence, pattern, and outcome. J Chin Med Assoc. 2008 Feb;71(2):86-91.

41. Griffioen GH, Louie AV, de Bree R, Smit EF, Paul MA, Slotman BJ, et al. Second primary lung cancers following a diagnosis of primary head and neck cancer. Lung Cancer. 2015 Apr;88(1):94-9.

42. Lim H, Kim DH, Jung HY, Gong EJ, Na HK, Ahn JY, et al. Clinical significance of early detection of esophageal cancer in patients with head and neck cancer. Gut Liver. 2015 Mar;9(2):159-65.

43. Xu GZ, Guan DJ, He ZY. (18)FDG-PET/CT for detecting distant metastases and second primary cancers in patients with head and neck cancer: a meta-analysis. Oral Oncol. 2011 Jul;47(7):560-5.

44. Stoeckli SJ, Zimmermann R, Schmid S. Role of routine panendoscopy in cancer of the upper aerodigestive tract. Otolaryngol Head Neck Surg. 2001 Feb;124(2):208-12.

45. Hung SH,Tsai MC, Liu TC, Lin HC, Chung SD. Routine endoscopy for esophageal cancer is suggestive for patients with oral, oropharyngeal and hypopharyngeal cancer. PLoS One. 2013 Aug;8(8): e72097.

46. SuYY, Chen WC, Chuang HC, Guo CS, Lin YT, Luo SD, et al. Effect of routine esophageal screening in patients with head and neck cancer. JAMA Otolaryngol Head Neck Surg. 2013 Apr;139(4):350-4.

47. Yabuki K, Kubota A, Horiuchi C, Taguchi T, Nishimura G, Inamori M. Limitations of PET and PET/CT in detecting upper gastrointestinal synchronous cancer in patients with head and neck carcinoma. Eur Arch Otorhinolaryngol. 2013 Feb;270(2):727-33.

48. Haerle SK, Strobel K, Hany TF, Sidler D, Stoeckli SJ. (18)F-FDGPET/CT versus panendoscopy for the detection of synchronous second primary tumors in patients with head and neck squamous cell carcinoma. Head Neck. 2010 Mar;32(3):319-25.

49. Page C, Lucas-Gourdet E, Biet-Hornstein A, Strunski V. Initial staging of head and neck squamous cell carcinoma: what is the place of bronchoscopy and upper GI endoscopy? Eur Arch Otorhinolaryngol. 2015 Mar;272(3):705-9.

50. McLeod NM, Jess A,Anand R, Tilley E, Higgins B, Brennan PA. Role 
of chest $\mathrm{CT}$ in staging of oropharyngeal cancer: a systematic review. Head Neck. 2009 Apr;31(4):548-55.

51. Ritoe SC, Krabbe PF, Jansen MM, Festen J, Joosten FB, Kaanders $\mathrm{JH}$, et al. Screening for second primary lung cancer after treatment of laryngeal cancer. Laryngoscope. 2002 Nov;112(11):2002-8.

52. Kerawala C, Roques T, Jeannon JP, Bisase B. Oral cavity and lip cancer: United Kingdom National Multidisciplinary Guidelines. J Laryngol Otol. 2016 May;130(S2):S83-9.

53. Dammann F, Horger M, Mueller-Berg M, Schlemmer H, Claussen $\mathrm{CD}$, Hoffman J, et al. Rational diagnosis of squamous cell carcinoma of the head and neck region: comparative evaluation of CT, MRI, and 18FDG PET. AJR Am J Roentgenol. 2005 Apr;184(4): 1326-31.

54. Blatt S, Ziebart T, Kruger M, Pabst AM. Diagnosing oral squamous cell carcinoma: how much imaging do we really need? A review of the current literature. J Craniomaxillofac Surg. 2016 May;44(5): 538-49.

55. Arya S, Rane P, Deshmukh A. Oral cavity squamous cell carcinoma: role of pretreatment imaging and its influence on management. Clin Radiol. 2014 Sep;69(9):916-30.

56. Arya S, Rane P, Sable N, Juvekar S, Bal M, Chaukar D. Retromolar trigone squamous cell cancers: a reappraisal of 16 section MDCT for assessing mandibular invasion. Clin Radiol. 2013 Dec;68(12): e680-8.

57. Handschel J, Naujoks C, Depprich RA, Kubler NR, Kropil P, Kuhlemann J, et al. CT-scan is a valuable tool to detect mandibular involvement in oral cancer patients. Oral Oncol. 2012 Apr;48(4):361-6.

58. Uribe S, Rojas LA, Rosas CF. Accuracy of imaging methods for detection of bone tissue invasion in patients with oral squamous cell carcinoma. Dentomaxillofac Radiol. 2013;42(6):20120346.

59. Kyzas PA, Evangelou E, Denaxa-Kyza D, Ioannidis JP. 18F-fluorodeoxyglucose positron emission tomography to evaluate cervical node metastases in patients with head and neck squamous cell carcinoma: a meta-analysis. J Natl Cancer Inst. 2008 May;100(10): 712-20.

60. Liao CT, Chang JT,Wang HM, Ng SH, Hsueh C, Lee LY, et al. Analysis of risk factors of predictive local tumor control in oral cavity cancer. Ann Surg Oncol. 2008 Mar;15(3):915-22.

61. Yoon DY, Hwang HS, Chang SK, Rho YS, Ahn HY, Kim JH, et al. CT, MR, US, 18F-FDG PET/CT, and their combined use for the assessment of cervical lymph node metastases in squamous cell carcinoma of the head and neck. Eur Radiol. 2009 Mar;19(3):634-42.

62. Park S, Jee SH, Shin HR, Park EH, Shin A, Jung KW, et al. Attributable fraction of tobacco smoking on cancer using population-based nationwide cancer incidence and mortality data in Korea. BMC Cancer. 2014 Jun;14:406.

63. Park JO, Jung SL, Joo YH, Jung CK, Cho KJ, Kim MS. Diagnostic accuracy of magnetic resonance imaging (MRI) in the assessment of tumor invasion depth in oral/oropharyngeal cancer. Oral Oncol. 2011 May;47(5):381-6.

64. Seitz O, Chambron-Pinho N, Middendorp M, Sader R, Mack M, VoglTJ, et al. 18F-Fluorodeoxyglucose-PET/CT to evaluate tumor, nodal disease, and gross tumor volume of oropharyngeal and oral cavity cancer: comparison with MR imaging and validation with surgical specimen. Neuroradiology. 2009 Oct;51(10):677-86.

65. Ng SH, Yen TC, Liao CT, Chang JT, Chan SC, Ko SF, et al. 18F-FDG PET and CT/MRI in oral cavity squamous cell carcinoma: a prospective study of 124 patients with histologic correlation. J Nucl Med. 2005 Jul;46(7):1136-43.

66. Lam P, Au-Yeung KM, Cheng PW,Wei WI, Yuen AP, Trendell-Smith $\mathrm{N}$, et al. Correlating MRI and histologic tumor thickness in the assessment of oral tongue cancer. AJR Am J Roentgenol. 2004 Mar; 182(3):803-8.

67. Preda L, Chiesa F, Calabrese L, Latronico A, Bruschini R, Leon ME, et al. Relationship between histologic thickness of tongue carcinoma and thickness estimated from preoperative MRI. Eur Radiol. 2006 Oct;16(10):2242-8.

68. Gu DH, Yoon DY, Park CH, Chang SK, Lim KJ, Seo YL, et al. CT, MR, (18)F-FDG PET/CT, and their combined use for the assessment of mandibular invasion by squamous cell carcinomas of the oral cavity. Acta Radiol. 2010 Dec;51(10):1111-9.

69. Vidiri A, Guerrisi A, Pellini R, Manciocco V, Covello R, Mattioni O, et al. Multi-detector row computed tomography (MDCT) and magnetic resonance imaging (MRI) in the evaluation of the mandibular invasion by squamous cell carcinomas (SCC) of the oral cavity: correlation with pathological data. J Exp Clin Cancer Res. 2010 Jun;29:73.

70. Sarrion Perez MG, Bagan JV, Jimenez Y, Margaix M, Marzal C. Utility of imaging techniques in the diagnosis of oral cancer. J Craniomaxillofac Surg. 2015 Nov;43(9):1880-94.

71. Wolff KD, Follmann M, Nast A.The diagnosis and treatment of oral cavity cancer. Dtsch Arztebl Int. 2012 Nov;109(48):829-35.

72. Rege S, Maass A, Chaiken L, Hoh CK, Choi Y, Lufkin R, et al. Use of positron emission tomography with fluorodeoxyglucose in patients with extracranial head and neck cancers. Cancer. 1994 Jun; 73(12):3047-58.

73. Schoder H,Yeung HW. Positron emission imaging of head and neck cancer, including thyroid carcinoma. Semin Nucl Med. 2004 Jul; 34(3):180-97.

74. Hannah A, Scott AM, Tochon-Danguy H, Chan JG, Akhurst T, Berlangieri S, et al. Evaluation of 18 F-fluorodeoxyglucose positron emission tomography and computed tomography with histopathologic correlation in the initial staging of head and neck cancer.Ann Surg. 2002 Aug;236(2):208-17.

75. Higashi K, Clavo AC, Wahl RL. Does FDG uptake measure proliferative activity of human cancer cells? In vitro comparison with DNA flow cytometry and tritiated thymidine uptake. J Nucl Med. 1993 Mar;34(3):414-9.

76. Haberkorn U, Strauss LG, Reisser C, Haag D, Dimitrakopoulou A, Ziegler S, et al. Glucose uptake, perfusion, and cell proliferation in head and neck tumors: relation of positron emission tomography to flow cytometry. J Nucl Med. 1991 Aug;32(8):1548-55.

77. Stuckensen T, Kovacs AF, Adams S, Baum RP. Staging of the neck in patients with oral cavity squamous cell carcinomas: a prospective comparison of PET, ultrasound, CT and MRI. J Craniomaxillofac Surg. 2000 Dec;28(6):319-24.

78. Bakhshayesh Karam M, Doroudinia A, Safavi Nainee A, Kaghazchi F, Yousefi Koma A, Mehrian P, et al. Role of FDG PET/CT scan in head and neck cancer patients. Arch Iran Med. 2017 Jul;20(7):452-8.

79. Abd El-Hafez YG, Chen CC, Ng SH, Lin CY, Wang HM, Chan SC, et al. Comparison of PET/CT and MRI for the detection of bone marrow invasion in patients with squamous cell carcinoma of the oral cavity. Oral Oncol. 2011Apr;47(4):288-95.

80. Sureshkannan P, Vijayprabhu, John R. Role of ultrasound in detection of metastatic neck nodes in patients with oral cancer. Indian $\mathrm{J}$ Dent Res. 2011 May-Jun;22(3):419-23.

81. Geetha NT, Hallur N, Goudar G, Sikkerimath BC, Gudi SS. Cervical lymph node metastasis in oral squamous carcinoma preoperative assessment and histopathology after neck dissection. J Maxillofac Oral Surg. 2010 Mar;9(1):42-7.

82. Haberal I, Celik H, Gocmen H,Akmansu H,Yoruk M, Ozeri C.Which is important in the evaluation of metastatic lymph nodes in head and neck cancer: palpation, ultrasonography, or computed tomography? Otolaryngol Head Neck Surg. 2004 Feb;130(2):197-201.

83. Yamamoto C, Yuasa K, Okamura K, ShiraishiT, Miwa K.Vascularity as assessed by Doppler intraoral ultrasound around the invasion front of tongue cancer is a predictor of pathological grade of malignancy and cervical lymph node metastasis. Dentomaxillofac Radi- 
ol. 2016;45(3):20150372.

84. Lodder WL, Teertstra HJ, Tan IB, Pameijer FA, Smeele LE, van Velthuysen ML, et al. Tumour thickness in oral cancer using an intra-oral ultrasound probe. Eur Radiol. 2011 Jan;21(1):98-106.

85. Hashibe M, Brennan P, Benhamou S, Castellsague X, Chen C, Curado $\mathrm{MP}$, et al. Alcohol drinking in never users of tobacco, cigarette smoking in never drinkers, and the risk of head and neck cancer: pooled analysis in the International Head and Neck Cancer Epidemiology Consortium. J Natl Cancer Inst. 2007 May;99(10):777-89.

86. Room R, BaborT, Rehm J.Alcohol and public health. Lancet. 2005 Feb;365(9458):519-30.

87. Gillison ML, KochWM, Capone RB, Spafford M,WestraWH,Wu L, et al. Evidence for a causal association between human papillomavirus and a subset of head and neck cancers. J Natl Cancer Inst. 2000 May;92(9):709-20.

88. Schwartz SM, Daling JR, Doody DR, Wipf GC, Carter JJ, Madeleine $\mathrm{MM}$, et al. Oral cancer risk in relation to sexual history and evidence of human papillomavirus infection. J Natl Cancer Inst. 1998 Nov;90(21):1626-36.

89. Lingen MW, XiaoW, Schmitt A, Jiang B, Pickard R, Kreinbrink P, et al. Low etiologic fraction for high-risk human papillomavirus in oral cavity squamous cell carcinomas. Oral Oncol. 2013 Jan;49(1): 1-8.

90. Javed F, Warnakulasuriya S. Is there a relationship between periodontal disease and oral cancer? A systematic review of currently available evidence. Crit Rev Oncol Hematol. 2016 Jan;97:197-205.

91. Mantovani A, Allavena P, Sica A, Balkwill F. Cancer-related inflammation. Nature. 2008 Jul;454(7203):436-44.

92. Mager DL, Haffajee AD, Devlin PM, Norris CM, Posner MR, Goodson JM. The salivary microbiota as a diagnostic indicator of oral cancer: a descriptive, non-randomized study of cancer-free and oral squamous cell carcinoma subjects. JTransl Med. 2005 Jul;3:27.

93. Hwang IM, Sun LM, Lin CL, Lee CF, Kao CH. Periodontal disease with treatment reduces subsequent cancer risks. QJM. 2014 Oct; 107(10):805-12.

94. Gupta B, Johnson NW. Emerging and established global life-style risk factors for cancer of the upper aero-digestive tract. Asian Pac J Cancer Prev. 2014;15(15):5983-91.

95. Song M, Li QL, Li FJ, Chen SW, Zhuang SM, Wang LP, et al. Mandibular lingual release approach: an appropriate approach for total or subtotal glossectomy. Head Neck Oncol. 2013 Feb;5(2):11.

96. Devine JC, Rogers SN, McNally D, Brown JS, Vaughan ED. A comparison of aesthetic, functional and patient subjective outcomes following lip-split mandibulotomy and mandibular lingual releasing access procedures. Int J Oral Maxillofac Surg. 2001 Jun;30(3): 199-204.

97. Na HY, Choi EJ, Choi EC, Kim HJ, Cha IH, NamW. Modified mandibulotomy technique to reduce postoperative complications: 5-year results. Yonsei Med J. 2013 Sep;54(5):1248-52.

98. Satpathy S, Dam A, Hossain MA, Chatterjee J. Double mandibular osteotomy with segmental mandibular swing approach to parapharyngeal space. Natl J Maxillofac Surg. 2014 Jul-Dec;5(2):213-6.

99. Shah JP, Kumaraswamy SV, Kulkarni V. Comparative evaluation of fixation methods after mandibulotomy for oropharyngeal tumors. Am J Surg. 1993 Oct;166(4):431-4.

100. Dziegielewski PT, Mlynarek AM, Dimitry J, Harris JR, Seikaly H. The mandibulotomy: friend or foe? Safety outcomes and literature review. Laryngoscope. 2009 Dec;119(12):2369-75.

101. Dziegielewski PT, O'Connell DA, Rieger J, Harris JR, Seikaly H. The lip-splitting mandibulotomy: aesthetic and functional outcomes. Oral Oncol. 2010 Aug;46(8):612-7.

102. Marchetta FC. Function and appearance following surgery for intraoral cancer. Clin Plast Surg. 1976 Jul;3(3):471-9.

103. Al-Saleh MA, Armijo-Olivo S, Thie N, Seikaly H, Boulanger P,Wol- faardt J, et al. Morphologic and functional changes in the temporomandibular joint and stomatognathic system after transmandibular surgery in oral and oropharyngeal cancers: systematic review. J Otolaryngol Head Neck Surg. 2012 Oct;41(5):345-60.

104. Pang P, Li RW, Shi JP, Xu ZF, DuanWY, Liu FY, et al.A comparison of mandible preservation method and mandibulotomy approach in oral and oropharyngeal cancer: a meta-analysis. Oral Oncol. 2016 Dec;63:52-60.

105. Li H, Li J, Yang B, Su M, Xing R, Han Z. Mandibular lingual release versus mandibular lip-split approach for expanded resection of middle-late tongue cancer: a case-control study. J Craniomaxillofac Surg. 2015 Sep;43(7):1054-8.

106. Masuda M, Fukushima J, Kadota H, Kamizono K, Ejima M, Taura M. Mandible preserving pull-through oropharyngectomy for advanced oropharyngeal cancer: a pilot study. Auris Nasus Larynx. 2011 Jun;38(3):392-7.

107. Al-Rajhi N, Khafaga Y, El-Husseiny J, Saleem M, MouradW,Al-Otieschan A, et al. Early stage carcinoma of oral tongue: prognostic factors for local control and survival. Oral Oncol. 2000 Nov;36(6): 508-14.

108. El-Husseiny G, Kandil A, Jamshed A, Khafaga Y, Saleem M,Allam A, et al. Squamous cell carcinoma of the oral tongue: an analysis of prognostic factors. Br J Oral Maxillofac Surg. 2000 Jun;38(3):193-9.

109. Ling W, Mijiti A, Moming A. Survival pattern and prognostic factors of patients with squamous cell carcinoma of the tongue: a retrospective analysis of 210 cases. J Oral Maxillofac Surg. 2013 Apr; 71(4):775-85.

110. Sharma P, Shah SV, Taneja C, Patel AM, Patel MD. A prospective study of prognostic factors for recurrence in early oral tongue cancer. J Clin Diagn Res. 2013 Nov;7(11):2559-62.

111. Vered M, Dayan D, Dobriyan A, Yahalom R, Shalmon B, Barshack I, et al. Oral tongue squamous cell carcinoma: recurrent disease is associated with histopathologic risk score and young age. J Cancer Res Clin Oncol. 2010 Jul;136(7):1039-48.

112. Yuen PW, Lam KY, Chan AC, WeiWI, Lam LK. Clinicopathological analysis of local spread of carcinoma of the tongue. Am J Surg. 1998 Mar;175(3):242-4.

113. Mistry RC, Qureshi SS, Kumaran C. Post-resection mucosal margin shrinkage in oral cancer: quantification and significance. J Surg Oncol. 2005 Aug;91(2):131-3.

114. Ganly I, Patel S, Shah J. Early stage squamous cell cancer of the oral tongue: clinicopathologic features affecting outcome. Cancer. 2012 Jan;118(1):101-11.

115. Baek CH, Son YI, Jeong HS, Chung MK, Park KN, Ko YH, et al. Intraoral sonography-assisted resection of T1-2 tongue cancer for adequate deep resection. Otolaryngol Head Neck Surg. 2008 Dec; 139(6):805-10.

116. Campana JP, Meyers AD. The surgical management of oral cancer. Otolaryngol Clin North Am. 2006 Apr;39(2):331-48.

117. Wolfensberger M, Zbaeren P, Dulguerov P, Muller W, Arnoux A, Schmid S. Surgical treatment of early oral carcinoma: results of a prospective controlled multicenter study. Head Neck. 2001 Jul; 23(7):525-30.

118. Larsen SR, Johansen J, Sorensen JA, Krogdahl A. The prognostic significance of histological features in oral squamous cell carcinoma. J Oral Pathol Med. 2009 Sep;38(8):657-62.

119. Woolgar JA, Triantafyllou A. A histopathological appraisal of surgical margins in oral and oropharyngeal cancer resection specimens. Oral Oncol. 2005 Nov;41(10):1034-43.

120. Alkureishi LW, Ross GL, Shoaib T, Soutar DS, Robertson AG, Sorensen JA, et al. Does tumor depth affect nodal upstaging in squamous cell carcinoma of the head and neck? Laryngoscope. 2008 Apr;118(4):629-34.

121. Mark Taylor S, Drover C, Maceachern R, Bullock M, Hart R, Psooy 
$\mathrm{B}$, et al. Is preoperative ultrasonography accurate in measuring tumor thickness and predicting the incidence of cervical metastasis in oral cancer? Oral Oncol. 2010 Jan;46(1):38-41.

122. O'Brien CJ, Lauer CS, Fredricks S, Clifford AR, McNeil EB, Bagia JS, et al. Tumor thickness influences prognosis of T1 and T2 oral cavity cancer: but what thickness? Head Neck. 2003 Nov;25(11): 937-45.

123. Wallwork BD, Anderson SR, Coman WB. Squamous cell carcinoma of the floor of the mouth: tumour thickness and the rate of cervical metastasis. ANZ J Surg. 2007 Sep;77(9):761-4.

124. Dirven R, Ebrahimi A, Moeckelmann N, Palme CE, Gupta R, Clark J.Tumor thickness versus depth of invasion: analysis of the 8th edition American Joint Committee on Cancer Staging for oral cancer. Oral Oncol. 2017 Nov;74:30-3.

125. Anderson CR, Sisson K, Moncrieff M. A meta-analysis of margin size and local recurrence in oral squamous cell carcinoma. Oral Oncol. 2015 May;51(5):464-9.

126. Eskander A, Givi B, Gullane PJ, Irish J, Brown D, Gilbert RW, et al. Outcome predictors in squamous cell carcinoma of the maxillary alveolus and hard palate. Laryngoscope. 2013 Oct;123(10):2453-8.

127. Seoane J,Varela-Centelles PI, Walsh TF, Lopez-Cedrun JL, Vazquez I. Gingival squamous cell carcinoma: diagnostic delay or rapid invasion? J Periodontol. 2006 Jul;77(7):1229-33.

128. Bark R, Mercke C, Munck-Wikland E, Wisniewski NA, Hammarstedt-Nordenvall L. Cancer of the gingiva. Eur Arch Otorhinolaryngol. 2016 Jun;273(6):1335-45.

129. Yang Z, Deng R, Sun G, Huang X, Tang E. Cervical metastases from squamous cell carcinoma of hard palate and maxillary alveolus: a retrospective study of 10 years. Head Neck. 2014 Jul;36(7):969-75.

130. Alonso JE, Han AY, Kuan EC, Strohl M, Clair JM, St John MA, et al. The survival impact of surgical therapy in squamous cell carcinoma of the hard palate. Laryngoscope. 2018 Sep;128(9):2050-5.

131. Aydil U, Kizil Y, Bakkal FK, Koybasioglu A, Uslu S. Neoplasms of the hard palate. J Oral Maxillofac Surg. 2014 Mar;72(3):619-26.

132. Stern SJ, GS H, Clayman G, Byers R, Ang KK, el-Naggar AK, et al. Squamous cell carcinoma of the maxillary sinus. Arch Otolaryngol Head Neck Surg. 1993 Sep;119(9):964-9.

133. Petrovic I, Montero PH, Migliacci JC, Palmer FL, Ganly I, Patel SG, et al. Influence of bone invasion on outcomes after marginal mandibulectomy in squamous cell carcinoma of the oral cavity. J Craniomaxillofac Surg. 2017 Feb;45(2):252-7.

134. McGregor AD, MacDonald DG. Routes of entry of squamous cell carcinoma to the mandible. Head Neck Surg. 1988 May-Jun;10(5): 294-301.

135. Namin AW, Bruggers SD, Panuganti BA, Christopher KM, Walker RJ, Varvares MA. Efficacy of bone marrow cytologic evaluations in detecting occult cancellous invasion. Laryngoscope. 2015 May; 125(5):E173-9.

136. Wysluch A, Stricker I, Holzle F, Wolff KD, Maurer P. Intraoperative evaluation of bony margins with frozen-section analysis and trephine drill extraction technique: a preliminary study. Head Neck. 2010 Nov;32(11):1473-8.

137. Weitz J, Pautke C,Wolff KD, KolkA. Can the inferior alveolar nerve be used as a marker in frozen section for free margin control after segmental mandibulectomy in tumour ablation? Int J Oral Maxillofac Surg. 2016 Nov;45(11):1366-71.

138. Nieberler M, Haussler P, Kesting MR, Kolk A, Deppe H, Weirich G, et al. Clinical impact of intraoperative cytological assessment of bone resection margins in patients with head and neck carcinoma. Ann Surg Oncol. 2016 Oct;23(11):3579-86.

139. Barttelbort SW, Ariyan S. Mandible preservation with oral cavity carcinoma: rim mandibulectomy versus sagittal mandibulectomy. Am J Surg. 1993 Oct;166(4):411-5.

140. Lubek JE, Magliocca KR. Evaluation of the bone margin in oral squamous cell carcinoma. Oral Maxillofac Surg Clin North Am. 2017 Aug;29(3):281-92.

141. Rao LP, Shukla M, Sharma V, Pandey M. Mandibular conservation in oral cancer. Surg Oncol. 2012 Jun;21(2):109-18.

142. Brown J. Mechanisms of cancer invasion of the mandible. Curr Opin Otolaryngol Head Neck Surg. 2003 Apr;11(2):96-102.

143. Brown JS, Browne RM. Factors influencing the patterns of invasion of the mandible by oral squamous cell carcinoma. Int J Oral Maxillofac Surg. 1995 Dec;24(6):417-26.

144. Wong RJ, Keel SB, Glynn RJ, Varvares MA. Histological pattern of mandibular invasion by oral squamous cell carcinoma. Laryngoscope. 2000 Jan;110(1):65-72.

145. Shaw RJ, Brown JS, Woolgar JA, Lowe D, Rogers SN, Vaughan ED. The influence of the pattern of mandibular invasion on recurrence and survival in oral squamous cell carcinoma. Head Neck. 2004 Oct;26(10):861-9.

146. Shaha AR. Marginal mandibulectomy for carcinoma of the floor of the mouth. J Surg Oncol. 1992 Feb;49(2):116-9.

147. Muscatello L, Lenzi R, Pellini R, Giudice M, Spriano G. Marginal mandibulectomy in oral cancer surgery: a 13-year experience. Eur Arch Otorhinolaryngol. 2010 May;267(5):759-64.

148. Pandey M, Rao LP, Das SR. Predictors of mandibular involvement in cancers of the oromandibular region. J Oral Maxillofac Surg. 2009 May;67(5):1069-73.

149. Gou L, Yang W, Qiao X, Ye L, Yan K, Li L, et al. Marginal or segmental mandibulectomy: treatment modality selection for oral cancer: a systematic review and meta-analysis. Int J Oral Maxillofac Surg. 2018 Jan;47(1):1-10.

150. Shah JP, Gil Z. Current concepts in management of oral cancer: surgery. Oral Oncol. 2009 Apr-May;45(4-5):394-401.

151. Wax MK, Bascom DA, Myers LL. Marginal mandibulectomy vs segmental mandibulectomy: indications and controversies. Arch Otolaryngol Head Neck Surg. 2002 May;128(5):600-3.

152. O’Brien CJ,Adams JR, McNeil EB, Taylor P, Laniewski P, Clifford A, et al. Influence of bone invasion and extent of mandibular resection on local control of cancers of the oral cavity and oropharynx. Int J Oral Maxillofac Surg. 2003 Oct;32(5):492-7.

153. Wolff D, Hassfeld S, Hofele C. Influence of marginal and segmental mandibular resection on the survival rate in patients with squamous cell carcinoma of the inferior parts of the oral cavity. J Craniomaxillofac Surg. 2004 Oct;32(5):318-23.

154. Priya SR, D'Cruz AK, Pai PS. Cut margins and disease control in oral cancers. J Cancer Res Ther. 2012 Jan-Mar;8(1):74-9.

155. Boonstra H, Oosterhuis JW, Oosterhuis AM, Fleuren GJ. Cervical tissue shrinkage by formaldehyde fixation, paraffin wax embedding, section cutting and mounting. Virchows Arch A Pathol Anat Histopathol. 1983;402(2):195-201.

156. Chen CH, Hsu MY, Jiang RS, Wu SH, Chen FJ, Liu SA. Shrinkage of head and neck cancer specimens after formalin fixation. J Chin Med Assoc. 2012 Mar;75(3):109-13.

157. Park HS, Lee S, Haam S, Lee GD. Effect of formalin fixation and tumour size in small-sized non-small-cell lung cancer: a prospective, single-centre study. Histopathology. 2017 Sep;71(3):437-45.

158. Silverman MK, Golomb FM, Kopf AW, Grin-Jorgensen CM, Vossaert KA, Doyle JP, et al. Verification of a formula for determination of preexcision surgical margins from fixed-tissue melanoma specimens. J Am Acad Dermatol. 1992 Aug;27(2 Pt 1):214-9.

159. Siu KF, Cheung HC, Wong J. Shrinkage of the esophagus after resection for carcinoma. Ann Surg. 1986 Feb;203(2):173-6.

160. Johnson RE, Sigman JD, Funk GF, Robinson RA, Hoffman HT. Quantification of surgical margin shrinkage in the oral cavity. Head Neck. 1997 Jul;19(4):281-6.

161. Egemen O, Bingol D, Orman C, Sayilgan AT, Ozkaya O, Akan M. Quantification of the surgical margin shrinkage in lip cancer: deter- 
mining the relation between the surgical and histopathologic margins. J Craniofac Surg. 2014 Nov;25(6):2152-5.

162. Chen YL, Kuo SW, Fang KH, Hao SP. Prognostic impact of marginal mandibulectomy in the presence of superficial bone invasion and the nononcologic outcome. Head Neck. 2011 May;33(5):708-13.

163. Clark JR, Franklin JH, Naranjo N, Odell MJ, Gullane PJ. Sublingual gland resection in squamous cell carcinoma of the floor of mouth: is it necessary? Laryngoscope. 2006 Mar;116(3):382-6.

164. Nason RW, Sako K, BeecroftWA, Razack MS, BakamjianVY, Shedd DP. Surgical management of squamous cell carcinoma of the floor of the mouth. Am J Surg. 1989 Oct;158(4):292-6.

165. Kaya I, Ozturk K, Turhal G. Sublingual lymph node metastasis in early-stage floor of the mouth carcinoma. Turk Arch Otorhinolaryngol. 2017 Dec;55(4):177-9.

166. Umeda M, Minamikawa T, Shigeta T, Oguni A, Kataoka T, Takahashi $\mathrm{H}$, et al. Metastasis to the lingual lymph node in patients with squamous cell carcinoma of the floor of the mouth: a report of two cases. Kobe J Med Sci. 2010 Feb;55(3):E67-72.

167. Rodgers GK, Myers EN. Surgical management of the mass in the buccal space. Laryngoscope. 1988 Jul;98(7):749-53.

168. Lubek JE, Dyalram D, Perera EH, Liu X, Ord RA. A retrospective analysis of squamous carcinoma of the buccal mucosa: an aggressive subsite within the oral cavity. J Oral Maxillofac Surg. 2013 Jun; 71(6):1126-31.

169. Diaz EM Jr, Holsinger FC, Zuniga ER, Roberts DB, Sorensen DM. Squamous cell carcinoma of the buccal mucosa: one institution's experience with 119 previously untreated patients. Head Neck. 2003 Apr;25(4):267-73.

170. Ota Y, Aoki T, Karakida K, Otsuru M, Kurabayashi H, Sasaki M, et al. Determination of deep surgical margin based on anatomical architecture for local control of squamous cell carcinoma of the buccal mucosa. Oral Oncol. 2009 Jul;45(7):605-9.

171. Lore JM, Medina JE. An atlas of head and neck surgery. 4th ed. Philadelphia (PA): Elsevier; 2006.

172. Farah CS, Dalley AJ, Nguyen P, Batstone M, Kordbacheh F, PerryKeene J, et al. Improved surgical margin definition by narrow band imaging for resection of oral squamous cell carcinoma: a prospective gene expression profiling study. Head Neck. 2016 Jun;38(6): 832-9.

173. Jan JC, HsuWH, Liu SA, Wong YK, Poon CK, Jiang RS, et al. Prognostic factors in patients with buccal squamous cell carcinoma: 10year experience. J Oral Maxillofac Surg. 2011 Feb;69(2):396-404.

174. Luryi AL, Chen MM, Mehra S, Roman SA, Sosa JA, Judson BL. Treatment factors associated with survival in early-stage oral cavity cancer: analysis of 6,830 cases from the National Cancer Data Base. JAMA Otolaryngol Head Neck Surg. 2015 Jul;141(7):593-8.

175. Mishra A, Datta S, Malik A, Garg A, Nair D, Nair S, et al. Role of microscopic spread beyond gross disease as an adverse prognostic factor in oral squamous cell carcinoma. Eur J Surg Oncol. 2017 Aug; 43(8):1503-8.

176. Lin HY, Huang TT, Lee MS, Hung SK, Lin RI, Tseng CE, et al. Unexpected close surgical margin in resected buccal cancer: very close margin and DAPK promoter hypermethylation predict poor clinical outcomes. Oral Oncol. 2013 Apr;49(4):336-44.

177. Buchakjian MR, Tasche KK, Robinson RA, Pagedar NA, Sperry SM. Association of main specimen and tumor bed margin status with local recurrence and survival in oral cancer surgery. JAMA Otolaryngol Head Neck Surg. 2016 Dec;142(12):1191-8.

178. Gokavarapu S, Rao LM, Mahajan M, Parvataneni N, Raju KV, Chander R. Revision of margins under frozen section in oral cancer: a retrospective study of involved margins in pT1 and pT2 oral cancers. Br J Oral Maxillofac Surg. 2015 Nov;53(9):875-9.

179. Mair M, Nair D, Nair S, Dutta S, Garg A, Malik A, et al. Intraoperative gross examination vs frozen section for achievement of ade- quate margin in oral cancer surgery. Oral Surg Oral Med Oral Pathol Oral Radiol. 2017 May;123(5):544-9.

180. Tirelli G, Piovesana M, Gatto A, Tofanelli M, Biasotto M, Boscolo Nata F. Narrow band imaging in the intra-operative definition of resection margins in oral cavity and oropharyngeal cancer. Oral Oncol. 2015 Oct;51(10):908-13.

181. Tirelli G, Piovesana M, Gatto A, Torelli L, Boscolo Nata F. Is NBIguided resection a breakthrough for achieving adequate resection margins in oral and oropharyngeal squamous cell carcinoma? Ann Otol Rhinol Laryngol. 2016 Jul;125(7):596-601.

182. Chen TC, Wang CP, Ko JY, Yang TL, Lou PJ. The impact of pathologic close margin on the survival of patients with early stage oral squamous cell carcinoma. Oral Oncol. 2012 Jul;48(7):623-8.

183. Liao CT, Huang SF, Chen IH, Chang JT, Wang HM, Ng SH, et al. When does skin excision allow the achievement of an adequate local control rate in patients with squamous cell carcinoma involving the buccal mucosa? Ann Surg Oncol. 2008 Aug;15(8):2187-94.

184. Trivedi NP, Kekatpure VD, Shetkar G, Gangoli A, Kuriakose MA. Pathology of advanced buccal mucosa cancer involving masticator space (T4b). Indian J Cancer. 2015 Oct-Dec;52(4):611-5.

185. Antoniades K, Lazaridis N, Vahtsevanos K, Hadjipetrou L, Antoniades V, Karakasis D. Treatment of squamous cell carcinoma of the anterior faucial pillar-retromolar trigone. Oral Oncol. 2003 Oct; 39(7):680-6.

186. Byers RM, Anderson B, Schwarz EA, Fields RS, Meoz R. Treatment of squamous carcinoma of the retromolar trigone. Am J Clin Oncol. 1984 Dec;7(6):647-52.

187. Hao SP, Tsang NM, Chang KP, Chen CK, Huang SS. Treatment of squamous cell carcinoma of the retromolar trigone. Laryngoscope. 2006 Jun;116(6):916-20.

188. Lane AP, Buckmire RA, Mukherji SK, Pillsbury HC 3rd, Meredith SD. Use of computed tomography in the assessment of mandibular invasion in carcinoma of the retromolar trigone. Otolaryngol Head Neck Surg. 2000 May;122(5):673-7.

189. Lam KH, Lam LK, Ho CM, Wei WI. Mandibular invasion in carcinoma of the lower alveolus. Am J Otolaryngol. 1999 Sep-Oct; 20(5):267-72.

190. Ayad T, Guertin L, Soulieres D, Belair M, Temam S, Nguyen-Tan PF. Controversies in the management of retromolar trigone carcinoma. Head Neck. 2009 Mar;31(3):398-405.

191. Dijkstra PU, Huisman PM, Roodenburg JL. Criteria for trismus in head and neck oncology. Int J Oral Maxillofac Surg. 2006 Apr; 35(4):337-42.

192. Garnett MJ, Nohl FS, Barclay SC. Management of patients with reduced oral aperture and mandibular hypomobility (trismus) and implications for operative dentistry. Br Dent J. 2008 Feb;204(3): 125-31.

193. Scott B, Butterworth C, Lowe D, Rogers SN. Factors associated with restricted mouth opening and its relationship to health-related quality of life in patients attending a maxillofacial oncology clinic. Oral Oncol. 2008 May;44(5):430-8.

194. Verdonck-de Leeuw IM, van Bleek WJ, Leemans CR, de Bree R. Employment and return to work in head and neck cancer survivors. Oral Oncol. 2010 Jan;46(1):56-60.

195. Cohen EG, Deschler DG, Walsh K, Hayden RE. Early use of a mechanical stretching device to improve mandibular mobility after composite resection: a pilot study. Arch Phys Med Rehabil. 2005 Jul;86(7):1416-9.

196. Lee R, Slevin N, Musgrove B, Swindell R, Molassiotis A. Prediction of post-treatment trismus in head and neck cancer patients. Br J Oral Maxillofac Surg. 2012 Jun;50(4):328-32.

197. Tsai CC, Wu SL, Lin SL, Ko SY, ChiangWF, Yang JW. Reducing trismus after surgery and radiotherapy in oral cancer patients: results of alternative operation versus traditional operation. J Oral Maxil- 
lofac Surg. 2016 May;74(5):1072-83.

198. Dijkstra PU, KalkWW, Roodenburg JL. Trismus in head and neck oncology: a systematic review. Oral Oncol. 2004 Oct;40(9):879-89.

199. Dias FL, Lima RA, Kligerman J, Farias TP, Soares JR, Manfro G, et al. Relevance of skip metastases for squamous cell carcinoma of the oral tongue and the floor of the mouth. Otolaryngol Head Neck Surg. 2006 Mar;134(3):460-5.

200. Jerjes W, Upile T, Petrie A, Riskalla A, Hamdoon Z, Vourvachis M, et al. Clinicopathological parameters, recurrence, locoregional and distant metastasis in 115 T1-T2 oral squamous cell carcinoma patients. Head Neck Oncol. 2010 Apr;2:9.

201. Fasunla AJ, Greene BH, Timmesfeld N, Wiegand S, Werner JA, Sesterhenn AM. A meta-analysis of the randomized controlled trials on elective neck dissection versus therapeutic neck dissection in oral cavity cancers with clinically node-negative neck. Oral Oncol. 2011 May;47(5):320-4.

202. Keski-Santti H,Atula T, Tornwall J, Koivunen P, Makitie A. Elective neck treatment versus observation in patients with T1/T2 N0 squamous cell carcinoma of oral tongue. Oral Oncol. 2006 Jan;42(1): 96-101.

203. Okura M, Aikawa T, Sawai NY, Iida S, Kogo M. Decision analysis and treatment threshold in a management for the N0 neck of the oral cavity carcinoma. Oral Oncol. 2009 Oct;45(10):908-11.

204. Po Wing Yuen A, Lam KY, Lam LK, Ho CM, Wong A, Chow TL, et al. Prognostic factors of clinically stage I and II oral tongue carcinoma: a comparative study of stage, thickness, shape, growth pattern, invasive front malignancy grading, Martinez-Gimeno score, and pathologic features. Head Neck. 2002 Jun;24(6):513-20.

205. Fakih AR, Rao RS, Borges AM, Patel AR. Elective versus therapeutic neck dissection in early carcinoma of the oral tongue. Am J Surg. 1989 Oct;158(4):309-13.

206. Rodrigo JP, Shah JP, Silver CE, Medina JE, Takes RP, Robbins KT, et al. Management of the clinically negative neck in early-stage head and neck cancers after transoral resection. Head Neck. 2011 Aug;33(8):1210-9.

207. Asakage T, Yokose T, Mukai K, Tsugane S, Tsubono Y, Asai M, et al. Tumor thickness predicts cervical metastasis in patients with stage I/II carcinoma of the tongue. Cancer. 1998 Apr;82(8):1443-8.

208. Kurokawa H, Yamashita Y,Takeda S, Zhang M, Fukuyama H,Takahashi T. Risk factors for late cervical lymph node metastases in patients with stage I or II carcinoma of the tongue. Head Neck. 2002 Aug;24(8):731-6.

209. Kligerman J, Lima RA, Soares JR, Prado L, Dias FL, Freitas EQ, et al. Supraomohyoid neck dissection in the treatment of T1/T2 squamous cell carcinoma of oral cavity. Am J Surg. 1994 Nov;168(5): 391-4.

210. Brazilian Head and Neck Cancer Study Group. Results of a prospective trial on elective modified radical classical versus supraomohyoid neck dissection in the management of oral squamous carcinoma.Am J Surg. 1998 Nov;176(5):422-7.

211. Chone CT, Silva AR, Crespo AN, Schlupp WR. Regional tumor recurrence after supraomohyoid neck dissection. Arch Otolaryngol Head Neck Surg. 2003 Jan;129(1):54-8.

212. Hao SP,Tsang NM. The role of supraomohyoid neck dissection in patients of oral cavity carcinoma. Oral Oncol. 2002 Apr;38(3):30912.

213. Pitman KT, Johnson JT, Myers EN. Effectiveness of selective neck dissection for management of the clinically negative neck. Arch Otolaryngol Head Neck Surg. 1997 Sep;123(9):917-22.

214. Byers RM. Modified neck dissection: a study of 967 cases from 1970 to 1980. Am J Surg. 1985 Oct;150(4):414-21.

215. LiW, Xu Z, Liu F, Huang S, DaiW, Sun C.Vascularized free forearm flap versus free anterolateral thigh perforator flaps for reconstruction in patients with head and neck cancer: assessment of quality of life. Head Neck. 2013 Dec;35(12):1808-13.

216. Guo CB, Feng Z, Zhang JG, Peng X, Cai ZG, Mao C, et al. Supraomohyoid neck dissection and modified radical neck dissection for clinically node-negative oral squamous cell carcinoma: a prospective study of prognosis, complications and quality of life. J Craniomaxillofac Surg. 2014 Dec;42(8):1885-90.

217. Kou Y, Zhao T, Huang S, Liu J, Duan W, Wang Y, et al. Cervical level IIb metastases in squamous cell carcinoma of the oral cavity: a systematic review and meta-analysis. Onco Targets Ther. 2017 Sep;10: 4475-83.

218. Lea J, Bachar G, Sawka AM, Lakra DC, Gilbert RW, Irish JC, et al. Metastases to level IIb in squamous cell carcinoma of the oral cavity: a systematic review and meta-analysis. Head Neck. 2010 Feb; 32(2):184-90.

219. Pantvaidya GH, Pal P, Vaidya AD, Pai PS, D’Cruz AK. Prospective study of 583 neck dissections in oral cancers: implications for clinical practice. Head Neck. 2014 Oct;36(10):1503-7.

220. Bhattacharya A, Adwani D, Adwani N, Sharma V. Is it worthy? Removal of level IIB nodes during selective neck dissection (I-III) for oral carcinomas. Ann Maxillofac Surg. 2015 Jan-Jun;5(1):20-5.

221. DiNardo LJ. Lymphatics of the submandibular space: an anatomic, clinical, and pathologic study with applications to floor-of-mouth carcinoma. Laryngoscope. 1998 Feb;108(2):206-14.

222. Lim YC, Kim JW, Koh YW, Kim K, Kim HJ, Kim KM, et al. Perivascular-submandibular lymph node metastasis in squamous cell carcinoma of the tongue and floor of mouth. Eur J Surg Oncol. 2004 Aug;30(6):692-8.

223. Agarwal SK,Arora SK, Kumar G, Sarin D. Isolated perifacial lymph node metastasis in oral squamous cell carcinoma with clinically node-negative neck. Laryngoscope. 2016 Oct;126(10):2252-6.

224. Paleri V, Rees G, Arullendran P, Shoaib T, Krishman S. Sentinel node biopsy in squamous cell cancer of the oral cavity and oral pharynx: a diagnostic meta-analysis. Head Neck. 2005 Sep;27(9): $739-47$.

225. Civantos FJ, Zitsch RP, Schuller DE, Agrawal A, Smith RB, Nason R, et al. Sentinel lymph node biopsy accurately stages the regional lymph nodes for T1-T2 oral squamous cell carcinomas: results of a prospective multi-institutional trial. J Clin Oncol. 2010 Mar;28(8): 1395-400.

226. Murer K, Huber GF, Haile SR, Stoeckli SJ. Comparison of morbidity between sentinel node biopsy and elective neck dissection for treatment of the $n 0$ neck in patients with oral squamous cell carcinoma. Head Neck. 2011 Sep;33(9):1260-4.

227. Schiefke F, Akdemir M, Weber A, Akdemir D, Singer S, Frerich B. Function, postoperative morbidity, and quality of life after cervical sentinel node biopsy and after selective neck dissection. Head Neck. 2009 Apr;31(4):503-12.

228. Fielding LP, Fenoglio-Preiser CM, Freedman LS. The future of prognostic factors in outcome prediction for patients with cancer. Cancer. 1992 Nov;70(9):2367-77.

229. Leemans CR, Tiwari R, Nauta JJ, van derWaal I, Snow GB. Regional lymph node involvement and its significance in the development of distant metastases in head and neck carcinoma. Cancer. 1993 Jan;71(2):452-6.

230. Lindberg R. Distribution of cervical lymph node metastases from squamous cell carcinoma of the upper respiratory and digestive tracts. Cancer. 1972 Jun;29(6):1446-9.

231. Johnson JT, Myers EN, Bedetti CD, Barnes EL, Schramm VL Jr, Thearle PB. Cervical lymph node metastases: incidence and implications of extracapsular carcinoma. Arch Otolaryngol. 1985 Aug; 111(8):534-7.

232. Liao CT, Hsueh C, Lee LY, Lin CY, Fan KH, Wang HM, et al. Neck dissection field and lymph node density predict prognosis in patients with oral cavity cancer and pathological node metastases 
treated with adjuvant therapy. Oral Oncol. 2012 Apr;48(4):329-36.

233. Ong W, Zhao R, Lui B, Tan W, Ebrahimi A, Clark JR, et al. Prognostic significance of lymph node density in squamous cell carcinoma of the tongue. Head Neck. 2016 Apr;38 Suppl 1:E859-66.

234. Ho CM, Lam KH,WeiWI, LauWF. Treatment of neck nodes in oral cancer. Surg Oncol. 1992 Feb;1(1):73-8.

235. Shah JP, Candela FC, Poddar AK. The patterns of cervical lymph node metastases from squamous carcinoma of the oral cavity. Cancer. 1990 Jul;66(1):109-13.

236. Davidson BJ, Kulkarny V, Delacure MD, Shah JP. Posterior triangle metastases of squamous cell carcinoma of the upper aerodigestive tract.Am J Surg. 1993 Oct;166(4):395-8.

237. Andersen PE, Warren F, Spiro J, Burningham A, Wong R, Wax MK, et al. Results of selective neck dissection in management of the node-positive neck. Arch Otolaryngol Head Neck Surg. 2002 Oct; 128(10):1180-4.

238. Byers RM, Wolf PF, Ballantyne AJ. Rationale for elective modified neck dissection. Head Neck Surg. 1988 Jan-Feb;10(3):160-7.

239. Kerrebijn JD, Freeman JL, Irish JC, Witterick IJ, Brown DH, Rotstein LE, et al. Supraomohyoid neck dissection. Is it diagnostic or therapeutic? Head Neck. 1999 Jan;21(1):39-42.

240. Kolli VR, Datta RV, Orner JB, Hicks WL Jr, Loree TR. The role of supraomohyoid neck dissection in patients with positive nodes. Arch Otolaryngol Head Neck Surg. 2000 Mar;126(3):413-6.

241. Santos AB, Cernea CR, Inoue M, Ferraz AR. Selective neck dissection for node-positive necks in patients with head and neck squamous cell carcinoma: a word of caution. Arch Otolaryngol Head Neck Surg. 2006 Jan;132(1):79-81.

242. Koo BS, Lim YC, Lee JS, Choi EC. Management of contralateral N0 neck in oral cavity squamous cell carcinoma. Head Neck. 2006 Oct;28(10):896-901.

243. Habib M, Murgasen J, Gao K, Ashford B, Shannon K, Ebrahimi A, et al. Contralateral neck failure in lateralized oral squamous cell carcinoma. ANZ J Surg. 2016 Mar;86(3):188-92.

244. Kurita H, Koike T, Narikawa JN, Sakai H, Nakatsuka A, Uehara S, et al. Clinical predictors for contralateral neck lymph node metastasis from unilateral squamous cell carcinoma in the oral cavity. Oral Oncol. 2004 Oct;40(9):898-903.

245. Liao CT, Huang SF, Chen IH, Chang JT, Wang HM, Ng SH, et al. Risk stratification of patients with oral cavity squamous cell carcinoma and contralateral neck recurrence following radical surgery. Ann Surg Oncol. 2009 Jan;16(1):159-70.

246. Ragbir M, Brown JS, Mehanna H. Reconstructive considerations in head and neck surgical oncology: United Kingdom National Multidisciplinary Guidelines. J Laryngol Otol. 2016 May;130(S2):S191-7.

247. Kao SS, Peters MD, Krishnan SG, Ooi EH. Swallowing outcomes following primary surgical resection and primary free flap reconstruction for oral and oropharyngeal squamous cell carcinomas: a systematic review. Laryngoscope. 2016 Jul;126(7):1572-80.

248. Lam L, Samman N. Speech and swallowing following tongue cancer surgery and free flap reconstruction: a systematic review. Oral Oncol. 2013 Jun;49(6):507-24.

249. Hsiao HT, Leu YS, Lin CC. Primary closure versus radial forearm flap reconstruction after hemiglossectomy: functional assessment of swallowing and speech. Ann Plast Surg. 2002 Dec;49(6):612-6.

250. Hsiao HT, Leu YS, Chang SH, Lee JT. Swallowing function in patients who underwent hemiglossectomy: comparison of primary closure and free radial forearm flap reconstruction with videofluoroscopy. Ann Plast Surg. 2003 May;50(5):450-5.

251. Uwiera T, Seikaly H, Rieger J, Chau J, Harris JR. Functional outcomes after hemiglossectomy and reconstruction with a bilobed radial forearm free flap. J Otolaryngol. 2004 Dec;33(6):356-9.

252. Riemann M, Knipfer C, Rohde M, Adler W, Schuster M, Noeth E, et al. Oral squamous cell carcinoma of the tongue: prospective and objective speech evaluation of patients undergoing surgical therapy. Head Neck. 2016 Jul;38(7):993-1001.

253. Hanasono MM, Matros E, Disa JJ. Important aspects of head and neck reconstruction. Plast Reconstr Surg. 2014 Dec;134(6):968e980e.

254. Dziegielewski PT, Ho ML, Rieger J, Singh P, Langille M, Harris JR, et al. Total glossectomy with laryngeal preservation and free flap reconstruction: objective functional outcomes and systematic review of the literature. Laryngoscope. 2013 Jan;123(1):140-5.

255. Manrique OJ, Leland HA, Langevin CJ,Wong A, Carey JN, Ciudad $\mathrm{P}$, et al. Optimizing outcomes following total and subtotal tongue reconstruction: a systematic review of the contemporary literature. J Reconstr Microsurg. 2017 Feb;33(2):103-11.

256. Yanai C, Kikutani T, Adachi M,Thoren H, Suzuki M, Iizuka T. Functional outcome after total and subtotal glossectomy with free flap reconstruction. Head Neck. 2008 Jul;30(7):909-18.

257. AyadT, Xie L. Facial artery musculomucosal flap in head and neck reconstruction: a systematic review. Head Neck. 2015 Sep;37(9): 1375-86.

258. Chien CY, Hwang CF, Chuang HC, Jeng SF, Su CY. Comparison of radial forearm free flap, pedicled buccal fat pad flap and split-thickness skin graft in reconstruction of buccal mucosal defect. Oral Oncol. 2005 Aug;41(7):694-7.

259. Chuang HC, Su CY, Jeng SF, Chien CY. Anterior lateral thigh flap for buccal mucosal defect after resection of buccal cancer. Otolaryngol Head Neck Surg. 2007 Oct;137(4):632-5.

260. Fang QG, Li ZN, Zhang X, Liu FY, Xu ZF, Sun CF. Clinical reliability of radial forearm free flap in repair of buccal defects. World J Surg Oncol. 2013 Jan;11:26.

261. Savant DN, Patel SG, Deshmukh SP, Gujarati R, Bhathena HM, Kavarana NM. Folded free radial forearm flap for reconstruction of full-thickness defects of the cheek. Head Neck. 1995 Jul-Aug;17(4): 293-6.

262. Liu F, Wang L, Pang S, Kan Q. Reconstruction of full-thickness buccal defects with folded radial forearm flaps: a retrospective clinical study. Medicine (Baltimore). 2017 Aug;96(32):e7344.

263. Brown JS, Barry C, Ho M, Shaw R. A new classification for mandibular defects after oncological resection. Lancet Oncol. 2016 Jan;17(1):e23-30.

264. Wang KH, Inman JC, Hayden RE. Modern concepts in mandibular reconstruction in oral and oropharyngeal cancer. Curr Opin Otolaryngol Head Neck Surg. 2011Apr;19(2):119-24.

265. Moubayed SP, L'Heureux-Lebeau B, Christopoulos A, Sampalis JS, Letourneau-Guillon L, Bissada E, et al. Osteocutaneous free flaps for mandibular reconstruction: systematic review of their frequency of use and a preliminary quality of life comparison. J Laryngol Otol. 2014 Dec;128(12):1034-43.

266. Zavalishina L, Karra N, Zaid WS, El-Hakim M. Quality of life assessment in patients after mandibular resection and free fibula flap reconstruction. J Oral Maxillofac Surg. 2014 Aug;72(8):1616-26.

267. Okura M, Isomura ET, Iida S, Kogo M. Long-term outcome and factors influencing bridging plates for mandibular reconstruction. Oral Oncol. 2005 Sep;41(8):791-8.

268. Miyamoto I, Yamashita Y, Yamamoto N, Nogami S, Yamauchi K, Yoshiga $\mathrm{D}$, et al. Evaluation of mandibular reconstruction with particulate cancellous bone marrow and titanium mesh after mandibular resection due to tumor surgery. Implant Dent. 2014 Apr;23(2):10815.

269. van Gemert J, Holtslag I, van der Bilt A, Merkx M, Koole R, Van Cann E. Health-related quality of life after segmental resection of the lateral mandible: free fibula flap versus plate reconstruction. J Craniomaxillofac Surg. 2015 Jun;43(5):658-62.

270. Seitz O, Harth M, Ghanaati S, Lehnert T, Vogl TJ, Sader R, et al. Secondary mandibular reconstruction after oral squamous cell car- 
cinoma resection: clinical reevaluation of transport disk distraction osteogenesis. J Craniofac Surg. 2010 Jan;21(1):59-63.

271. Wang JJ, Chen J, Ping FY,Yan Fg. Double-step transport distraction osteogenesis in the reconstruction of unilateral large mandibular defects after tumour resection using internal distraction devices. Int J Oral Maxillofac Surg. 2012 May;41(5):587-95.

272. Kontio R. Update on mandibular reconstruction: computer-aided design, imaging, stem cells and future applications. Curr Opin Otolaryngol Head Neck Surg. 2014 Aug;22(4):307-15.

273. Hayden RE, Mullin DP, Patel AK. Reconstruction of the segmental mandibular defect: current state of the art. Curr Opin Otolaryngol Head Neck Surg. 2012 Aug;20(4):231-6.

274. Han HH, Kim HY, Lee JY. The pros and cons of computer-aided surgery for segmental mandibular reconstruction after oncological surgery. Arch Craniofac Surg. 2017 Sep;18(3):149-54.

275. Yoshimura H, Matsuda S, Ohba S, Minegishi Y, Nakai K, Fujieda S, et al. Stereolithographic model-assisted reconstruction of the mandibular condyle with a vascularized fibular flap following hemimandibulectomy: evaluation of morphological and functional outcomes. Oncol Lett. 2017 Nov;14(5):5471-83.

276. Ciocca L, Mazzoni S, Fantini M, Persiani F, Baldissara P, Marchetti $\mathrm{C}$, et al. A CAD/CAM-prototyped anatomical condylar prosthesis connected to a custom-made bone plate to support a fibula free flap. Med Biol Eng Comput. 2012 Jul;50(7):743-9.

277. Antony AK, Chen WF, Kolokythas A, Weimer KA, Cohen MN. Use of virtual surgery and stereolithography-guided osteotomy for mandibular reconstruction with the free fibula. Plast Reconstr Surg. 2011 Nov;128(5):1080-4.

278. Joshi A, Calman F, O'Connell M, Jeannon JP, Pracy P, Simo R. Current trends in the follow-up of head and neck cancer patients in the UK. Clin Oncol (R Coll Radiol). 2010 Mar;22(2):114-8.

279. Digonnet A, Hamoir M, Andry G, Haigentz M Jr, Takes RP, Silver $\mathrm{CE}$, et al. Post-therapeutic surveillance strategies in head and neck squamous cell carcinoma. Eur Arch Otorhinolaryngol. 2013 May; 270(5):1569-80.

280. Haas I, Hauser U, Ganzer U.The dilemma of follow-up in head and neck cancer patients. Eur Arch Otorhinolaryngol. 2001 May;258(4): 177-83.

281. Collins R, Flynn A, Melville A, Richardson R, Eastwood A. Effective health care: management of head and neck cancers. Qual Saf Health Care. 2005 Apr;14(2):144-8.

282. Morton RP, Hay KD, Macann A. On completion of curative treatment of head and neck cancer: why follow up? Curr Opin Otolaryngol Head Neck Surg. 2004 Apr;12(2):142-6.

283. Boysen M, Lovdal O, Tausjo J, Winther F. The value of follow-up in patients treated for squamous cell carcinoma of the head and neck. Eur J Cancer. 1992;28(2-3):426-30.

284. Boysen M.Value of follow-up in patients treated for squamous cell carcinomas of the oral cavity and oropharynx. Recent Results Cancer Res. 1994;134:205-14.

285. Virgo KS, Paniello RC, Johnson FE. Costs of posttreatment surveillance for patients with upper aerodigestive tract cancer. Arch Otolaryngol Head Neck Surg. 1998 May;124(5):564-72.

286. van Agthoven M, van Ineveld BM, de Boer MF, Leemans CR, Knegt PP, Snow GB, et al. The costs of head and neck oncology: primary tumours, recurrent tumours and long-term follow-up. Eur J Cancer. 2001 Nov;37(17):2204-11.

287. British Association of Head and Neck Oncologists. Practice care guidance for clinicians participating in the management of head and neck cancer patients in the UK. Drawn up by a Consensus Group of Practising Clinicians. Eur J Surg Oncol. 2001 Jun;27 Suppl A:S117.

288. Marchant FE, Lowry LD, Moffitt JJ, Sabbagh R. Current national trends in the posttreatment follow-up of patients with squamous cell carcinoma of the head and neck. Am J Otolaryngol. 1993 MarApr;14(2):88-93.

289. Kothari P, Trinidade A, Hewitt RJ, Singh A, O’Flynn P. The followup of patients with head and neck cancer: an analysis of 1,039 patients. Eur Arch Otorhinolaryngol. 2011 Aug;268(8):1191-200.

290. Trinidade A, Kothari P,Andreou Z, Hewitt RJ, O'Flynn P. Follow-up in head and neck cancer: patients' perspective. Int J Health Care Qual Assur. 2012;25(2):145-9.

291. Schwartz DL, Barker J Jr, Chansky K, Yueh B, Raminfar L, Drago P, et al. Postradiotherapy surveillance practice for head and neck squamous cell carcinoma: too much for too little? Head Neck. 2003 Dec; 25(12):990-9.

292. Ul-Hassan F, Simo R, Guerrero-Urbano T, Oakley R, Jeannon JP, Cook GJ. Can (18)F-FDG PET/CT reliably assess response to primary treatment of head and neck cancer? Clin Nucl Med. 2013 Apr;38(4):263-5.

293. Isles MG, McConkey C, Mehanna HM. A systematic review and meta-analysis of the role of positron emission tomography in the follow up of head and neck squamous cell carcinoma following radiotherapy or chemoradiotherapy. Clin Otolaryngol. 2008 Jun; 33(3):210-22.

294. de Visscher AV, Manni JJ. Routine long-term follow-up in patients treated with curative intent for squamous cell carcinoma of the larynx, pharynx, and oral cavity. Does it make sense? Arch Otolaryngol Head Neck Surg. 1994 Sep;120(9):934-9.

295. Warner GC, Cox GJ. Evaluation of chest radiography versus chest computed tomography in screening for pulmonary malignancy in advanced head and neck cancer. J Otolaryngol. 2003 Apr;32(2): 107-9.

296. Steinkamp HJ, Maurer J, Cornehl M, Knobber D, Hettwer H, Felix R. Recurrent cervical lymphadenopathy: differential diagnosis with color-duplex sonography. Eur Arch Otorhinolaryngol. 1994;251(7): 404-9.

297. Westhofen M. Ultrasound B-scans in the follow-up of head and neck tumors. Head Neck Surg. 1987 May-Jun;9(5):272-8.

298. Ahuja A, Leung SF, Ying M, Metreweli C. Echography of metastatic nodes treated by radiotherapy. J Laryngol Otol. 1999 Nov;113(11): 993-8.

299. O’Meara WP, Thiringer JK, Johnstone PA. Follow-up of head and neck cancer patients post-radiotherapy. Radiother Oncol. 2003 Mar; 66(3):323-6.

300. Lapela M, Eigtved A, Jyrkkio S, Grenman R, Kurki T, Lindholm P, et al. Experience in qualitative and quantitative FDG PET in follow-up of patients with suspected recurrence from head and neck cancer. Eur J Cancer. 2000 May;36(7):858-67.

301. Manikantan K, Khode S, Dwivedi RC, Palav R, Nutting CM, RhysEvans $P$, et al. Making sense of post-treatment surveillance in head and neck cancer: when and what of follow-up. Cancer Treat Rev. 2009 Dec;35(8):744-53.

302. Gold KA, Kim ES. Role of molecular markers and gene profiling in head and neck cancers. Curr Opin Oncol. 2009 May;21(3):206-11.

303. Braakhuis BJ, Brakenhoff RH, Leemans CR. Gene expression profiling in head and neck squamous cell carcinoma. Curr Opin Otolaryngol Head Neck Surg. 2010 Apr;18(2):67-71.

304. Sinard RJ, Tobin EJ, Mazzaferri EL, Hodgson SE, Young DC, Kunz AL, et al. Hypothyroidism after treatment for nonthyroid head and neck cancer.Arch Otolaryngol Head Neck Surg. 2000 May;126(5): 652-7.

305. Colevas AD, Read R, Thornhill J, Adak S, Tishler R, Busse P, et al. Hypothyroidism incidence after multimodality treatment for stage III and IV squamous cell carcinomas of the head and neck. Int J Radiat Oncol Biol Phys. 2001 Nov;51(3):599-604.

306. Posner MR, Ervin TJ, Miller D, Fabian RL, Norris CM Jr, Weichselbaum RR, et al. Incidence of hypothyroidism following multimo- 
dality treatment for advanced squamous cell cancer of the head and neck. Laryngoscope. 1984 Apr;94(4):451-54.

307. Tell R, Lundell G, Nilsson B, Sjodin H, Lewin F, Lewensohn R. Longterm incidence of hypothyroidism after radiotherapy in patients with head-and-neck cancer. Int J Radiat Oncol Biol Phys. 2004 Oct; 60(2):395-400.

308. Francis DO, Weymuller EA Jr, Parvathaneni U, Merati AL, Yueh B. Dysphagia, stricture, and pneumonia in head and neck cancer patients: does treatment modality matter? Ann Otol Rhinol Laryngol. 2010 Jun;119(6):391-7.

309. Murphy BA, Gilbert J. Dysphagia in head and neck cancer patients treated with radiation: assessment, sequelae, and rehabilitation. Semin Radiat Oncol. 2009 Jan;19(1):35-42.

310. Crary MA, Carnaby GD, LaGorio LA, Carvajal PJ. Functional and physiological outcomes from an exercise-based dysphagia therapy: a pilot investigation of the McNeill Dysphagia Therapy Program. Arch Phys Med Rehabil. 2012 Jul;93(7):1173-8.

311. Lan Y, Ohkubo M, Berretin-Felix G, Sia I, Carnaby-Mann GD, Crary MA. Normalization of temporal aspects of swallowing physiology after the McNeill dysphagia therapy program. Ann Otol Rhinol Laryngol. 2012 Aug;121(8):525-32.

312. Crary MA, Carnaby Mann GD, Groher ME, Helseth E. Functional benefits of dysphagia therapy using adjunctive sEMG biofeedback. Dysphagia. 2004 Summer;19(3):160-4.

313. Shaker R, Easterling C, Kern M, NitschkeT, Massey B, Daniels S, et al. Rehabilitation of swallowing by exercise in tube-fed patients with pharyngeal dysphagia secondary to abnormal UES opening. Gastroenterology. 2002 May;122(5):1314-21.

314. Logemann JA, Pauloski BR, Rademaker AW, Lazarus CL, Gaziano J, Stachowiak L, et al. Swallowing disorders in the first year after radiation and chemoradiation. Head Neck. 2008 Feb;30(2):148-58.

315. Tuomi L, Andrell P, Finizia C. Effects of voice rehabilitation after radiation therapy for laryngeal cancer: a randomized controlled study. Int J Radiat Oncol Biol Phys. 2014 Aug;89(5):964-72.

316. van Gogh CD, Verdonck-de Leeuw IM, Langendijk JA, Kuik DJ, Mahieu HF. Long-term efficacy of voice therapy in patients with voice problems after treatment of early glottic cancer. JVoice. 2012 May;26(3):398-401.

317. Xi S. Effectiveness of voice rehabilitation on vocalisation in postlaryngectomy patients: a systematic review. Int J Evid Based Healthc. 2010 Dec;8(4):256-8.

318. Marunick M,Tselios N. The efficacy of palatal augmentation prostheses for speech and swallowing in patients undergoing glossectomy: a review of the literature. J Prosthet Dent. 2004 Jan;91(1):6774.

319. McNeely ML, Parliament M, Courneya KS, Seikaly H, Jha N, Scrimger $\mathrm{R}$, et al. A pilot study of a randomized controlled trial to evaluate the effects of progressive resistance exercise training on shoulder dysfunction caused by spinal accessory neurapraxia/neurectomy in head and neck cancer survivors. Head Neck. 2004 Jun;26(6):51830.

320. McNeely ML, Parliament MB, Seikaly H, Jha N, Magee DJ, Haykowsky MJ, et al. Effect of exercise on upper extremity pain and dysfunction in head and neck cancer survivors: a randomized controlled trial. Cancer. 2008 Jul;113(1):214-22.

321. Carvalho AP, Vital FM, Soares BG. Exercise interventions for shoulder dysfunction in patients treated for head and neck cancer. Cochrane Database Syst Rev. 2012 Apr;(4):CD008693.

322. Lauchlan DT, McCaul JA, McCarron T, Patil S, McManners J, McGarva J.An exploratory trial of preventative rehabilitation on shoulder disability and quality of life in patients following neck dissection surgery. Eur J Cancer Care (Engl). 2011 Jan;20(1):113-22.

323. Rock CL, Doyle C, Demark-Wahnefried W, Meyerhardt J, Courneya KS, Schwartz AL, et al. Nutrition and physical activity guide- lines for cancer survivors. CA Cancer J Clin. 2012 Jul-Aug:62(4): 243-74.

324. Hashibe M, Hunt J, Wei M, Buys S, Gren L, Lee YC. Tobacco, alcohol, body mass index, physical activity, and the risk of head and neck cancer in the prostate, lung, colorectal, and ovarian (PLCO) cohort. Head Neck. 2013 Jul;35(7):914-22.

325. Dijkstra PU, van Wilgen PC, Buijs RP, Brendeke W, de Goede CJ, Kerst A, et al. Incidence of shoulder pain after neck dissection: a clinical explorative study for risk factors. Head Neck. 2001 Nov; 23(11):947-53.

326. Samuel SR, Maiya GA, Babu AS, Vidyasagar MS. Effect of exercise training on functional capacity \& quality of life in head \& neck cancer patients receiving chemoradiotherapy. Indian J Med Res. 2013 Mar;137(3):515-20.

327. Nekhlyudov L, Lacchetti C, Davis NB, Garvey TQ, Goldstein DP, Nunnink JC, et al. Head and neck cancer survivorship care guideline: American Society of Clinical Oncology clinical practice guideline endorsement of the American Cancer Society guideline. J Clin Oncol. 2017 May;35(14):1606-21.

328. Blot WJ, McLaughlin JK, Winn DM, Austin DF, Greenberg RS, Preston-Martin S, et al. Smoking and drinking in relation to oral and pharyngeal cancer. Cancer Res. 1988 Jun;48(11):3282-7.

329. Freedman ND, Schatzkin A, Leitzmann MF, Hollenbeck AR, Abnet CC. Alcohol and head and neck cancer risk in a prospective study. Br J Cancer. 2007 May;96(9):1469-74.

330. Alcohol drinking. IARCWorking Group, Lyon, 13-20 October 1987. IARC Monogr Eval Carcinog Risks Hum. 1988;44:1-378.

331. IARC Working Group on the Evaluation of Carcinogenic Risks to Humans. Alcohol consumption and ethyl carbamate. IARC Monogr Eval Carcinog Risks Hum. 2010;96:3-1383.

332. Morris LG, Sikora AG, Hayes RB, Patel SG, Ganly I. Anatomic sites at elevated risk of second primary cancer after an index head and neck cancer. Cancer Causes Control. 2011 May;22(5):671-9.

333. Howren MB, Christensen AJ, Karnell LH, Funk GF. Psychological factors associated with head and neck cancer treatment and survivorship: evidence and opportunities for behavioral medicine. J Consult Clin Psychol. 2013 Apr;81(2):299-317.

334. Nayan S, Gupta MK, Strychowsky JE, Sommer DD. Smoking cessation interventions and cessation rates in the oncology population: an updated systematic review and meta-analysis. Otolaryngol Head Neck Surg. 2013 Aug;149(2):200-11.

335. Siegel RL, Jacobs EJ, Newton CC, Feskanich D, Freedman ND, Prentice RL, et al. Deaths due to cigarette smoking for 12 smoking-related cancers in the United States. JAMA Intern Med. 2015 Sep; 175(9):1574-6.

336. IARC Working Group on the Evaluation of Carcinogenic Risks to Humans. Personal habits and indoor combustions. Volume 100 E. A review of human carcinogens. IARC Monogr Eval Carcinog Risks Hum. 2012;100(Pt E):1-538.

337. Ostroff JS, Jacobsen PB, Moadel AB, Spiro RH, Shah JP, Strong $\mathrm{EW}$, et al. Prevalence and predictors of continued tobacco use after treatment of patients with head and neck cancer. Cancer. 1995 Jan;75(2):569-76.

338. Gritz ER, Nisenbaum R, Elashoff RE, Holmes EC. Smoking behavior following diagnosis in patients with stage I non-small cell lung cancer. Cancer Causes Control. 1991 Mar;2(2):105-12.

339. Dresler CM, Bailey M, Roper CR, Patterson GA, Cooper JD. Smoking cessation and lung cancer resection. Chest. 1996 Nov;110(5): 1199-202.

340. Walker MS, Larsen RJ, Zona DM, Govindan R, Fisher EB. Smoking urges and relapse among lung cancer patients: findings from a preliminary retrospective study. Prev Med. 2004 Sep;39(3):449-57.

341. Parsons A, Daley A, Begh R, Aveyard P. Influence of smoking cessation after diagnosis of early stage lung cancer on prognosis: sys- 
tematic review of observational studies with meta-analysis. BMJ. 2010 Jan;340:b5569.

342. Kawahara M, Ushijima S, Kamimori T, Kodama N, Ogawara M, Matsui K, et al. Second primary tumours in more than 2-year disease-free survivors of small-cell lung cancer in Japan: the role of smoking cessation. Br J Cancer. 1998 Aug;78(3):409-12.

343. Do KA, Johnson MM, Doherty DA, Lee JJ, Wu XF, Dong Q, et al. Second primary tumors in patients with upper aerodigestive tract cancers: joint effects of smoking and alcohol (United States). Cancer Causes Control. 2003 Mar;14(2):131-8.

344. Browman GP,Wong G, Hodson I, Sathya J, Russell R, McAlpine L, et al. Influence of cigarette smoking on the efficacy of radiation therapy in head and neck cancer. N Engl J Med. 1993 Jan;328(3): 159-63.

345. Zhang J, Kamdar O, Le W, Rosen GD, Upadhyay D. Nicotine induces resistance to chemotherapy by modulating mitochondrial signaling in lung cancer. Am J Respir Cell Mol Biol. 2009 Feb;40(2): 135-46.

346. Zevallos JP, Mallen MJ, Lam CY, Karam-Hage M, Blalock J, Wetter DW, et al. Complications of radiotherapy in laryngopharyngeal cancer: effects of a prospective smoking cessation program. Cancer. 2009 Oct;115(19):4636-44.

347. Moller AM, PedersenT,Villebro N, Schnaberich A, Haas M,Tonnesen R.A study of the impact of long-term tobacco smoking on postoperative intensive care admission. Anaesthesia. 2003 Jan;58(1):55-9.

348. Jerjes W, Upile T, Radhi H, Petrie A, Abiola J, Adams A, et al. The effect of tobacco and alcohol and their reduction/cessation on mortality in oral cancer patients: short communication. Head Neck Oncol. 2012 Mar;4:6.

349. Epstein JB, Guneri P, Barasch A. Appropriate and necessary oral care for people with cancer: guidance to obtain the right oral and dental care at the right time. Support Care Cancer. 2014 Jul;22(7): 1981-8.

350. Epstein JB, Thariat J, Bensadoun RJ, Barasch A, Murphy BA, Kolnick L, et al. Oral complications of cancer and cancer therapy: from cancer treatment to survivorship. CA Cancer J Clin. 2012 Nov-Dec; 62(6):400-22.

351. DeSantis CE, Lin CC, Mariotto AB, Siegel RL, Stein KD, Kramer JL, et al. Cancer treatment and survivorship statistics, 2014. CA Cancer J Clin. 2014 Jul-Aug;64(4):252-71.

352. Siegel RL, Miller KD, Jemal A. Cancer statistics, 2015. CA Cancer J Clin. 2015 Jan-Feb;65(1):5-29.

353. Simard S, Thewes B, Humphris G, Dixon M, Hayden C, Mireskandari S, et al. Fear of cancer recurrence in adult cancer survivors: a systematic review of quantitative studies. J Cancer Surviv. 2013 Sep;7(3):300-22.

354. Boyes AW, Girgis A, Zucca AC, Lecathelinais C. Anxiety and depression among long-term survivors of cancer in Australia: results of a population-based survey. Comment. Med J Aust. 2009 Sep; 191(5):295.

355. Hoffman KE, McCarthy EP, Recklitis CJ, Ng AK. Psychological distress in long-term survivors of adult-onset cancer: results from a national survey. Arch Intern Med. 2009 Jul;169(14):1274-81.

356. Mitchell AJ, Ferguson DW, Gill J, Paul J, Symonds P. Depression and anxiety in long-term cancer survivors compared with spouses and healthy controls: a systematic review and meta-analysis. Lancet Oncol. 2013 Jul;14(8):721-32.

357. Buchmann L, Conlee J, Hunt J, Agarwal J, White S. Psychosocial distress is prevalent in head and neck cancer patients. Laryngoscope. 2013 Jun;123(6):1424-9.

358. Funk GF, Karnell LH, Christensen AJ. Long-term health-related quality of life in survivors of head and neck cancer. Arch Otolaryngol Head Neck Surg. 2012 Feb;138(2):123-33.

359. Posluszny DM, Dougall AL, Johnson JT, Argiris A, Ferris RL, Baum
A, et al. Posttraumatic stress disorder symptoms in newly diagnosed patients with head and neck cancer and their partners. Head Neck. 2015 Sep;37(9):1282-9.

360. LydiattWM, Moran J, BurkeWJ.A review of depression in the head and neck cancer patient. Clin Adv Hematol Oncol. 2009 Jun;7(6): 397-403.

361. Devins GM, Payne AY, Lebel S, Mah K, Lee RN, Irish J, et al. The burden of stress in head and neck cancer. Psychooncology. 2013 Mar;22(3):668-76.

362. Andersen BL, Rowland JH, Somerfield MR. Screening, assessment, and care of anxiety and depressive symptoms in adults with cancer: an American Society of Clinical Oncology Guideline adaptation. J Oncol Pract. 2015 Mar;11(2):133-4.

363. Gonzalez-Garcia R. The role of salvage surgery in oral squamous cell carcinoma. Plast Aesthet Res. 2016;3:189-96.

364. Schwartz GJ, Mehta RH, Wenig BL, Shaligram C, Portugal LG. Salvage treatment for recurrent squamous cell carcinoma of the oral cavity. Head Neck. 2000 Jan;22(1):34-41.

365. Kowalski LP. Results of salvage treatment of the neck in patients with oral cancer. Arch Otolaryngol Head Neck Surg. 2002 Jan; 128(1):58-62.

366. Lin YC, Hsiao JR, Tsai ST. Salvage surgery as the primary treatment for recurrent oral squamous cell carcinoma. Oral Oncol. 2004 Feb; 40(2):183-9.

367. Liao CT, Chang JT, Wang HM, Ng SH, Hsueh C, Lee LY, et al. Salvage therapy in relapsed squamous cell carcinoma of the oral cavity: how and when? Cancer. 2008 Jan;112(1):94-103.

368. Agra IM, Carvalho AL, Ulbrich FS, de Campos OD, Martins EP, Magrin J, et al. Prognostic factors in salvage surgery for recurrent oral and oropharyngeal cancer. Head Neck. 2006 Feb;28(2):107-13.

369. Brown JS, Blackburn TK, Woolgar JA, Lowe D, Errington RD, Vaughan ED, et al. A comparison of outcomes for patients with oral squamous cell carcinoma at intermediate risk of recurrence treated by surgery alone or with post-operative radiotherapy. Oral Oncol. 2007 Sep;43(8):764-73.

370. Koo BS, Lim YC, Lee JS, Choi EC. Recurrence and salvage treatment of squamous cell carcinoma of the oral cavity. Oral Oncol. 2006 Sep;42(8):789-94.

371. Bataini JP. Radiotherapy in N0 head and neck cancer patients. Eur Arch Otorhinolaryngol. 1993;250(8):442-5.

372. Wei WI, Ferlito A, Rinaldo A, Gourin CG, Lowry J, Ho WK, et al. Management of the N0 neck: reference or preference. Oral Oncol. 2006 Feb;42(2):115-22.

373. Weiss MH, Harrison LB, Isaacs RS. Use of decision analysis in planning a management strategy for the stage N0 neck. Arch Otolaryngol Head Neck Surg. 1994 Jul;120(7):699-702.

374. Fakih AR, Rao RS, Patel AR. Prophylactic neck dissection in squamous cell carcinoma of oral tongue: a prospective randomized study. Semin Surg Oncol. 1989;5(5):327-30.

375. Ferlito A, Shaha AR, Rinaldo A. The incidence of lymph node micrometastases in patients pathologically staged N0 in cancer of oral cavity and oropharynx. Oral Oncol. 2002 Jan;38(1):3-5.

376. Jones AS, Tandon S, Helliwell TR, Husband DJ, Jones TM. Survival of patients with neck recurrence following radical neck dissection: utility of a second neck dissection? Head Neck. 2008 Nov;30(11): 1514-22.

377. Yao M, Roebuck JC, Holsinger FC, Myers JN. Elective neck dissection during salvage laryngectomy. Am J Otolaryngol. 2005 Nov-Dec; 26(6):388-92.

378. Yuen AP, Wei WI, Ho CM. Results of surgical salvage for radiation failures of laryngeal carcinoma. Otolaryngol Head Neck Surg. 1995 Mar;112(3):405-9.

379. Dagan R, Morris CG, Kirwan JM,Werning JW,Vaysberg M,Amdur $\mathrm{RJ}$, et al. Elective neck dissection during salvage surgery for locally 
recurrent head and neck squamous cell carcinoma after radiotherapy with elective nodal irradiation. Laryngoscope. 2010 May;120(5): 945-52.

380. Yirmibesoglu E, Fried D, Shores C, Rosenman J, Weissler M, Hackman $\mathrm{T}$, et al. Incidence of subclinical nodal disease at the time of salvage surgery for locally recurrent head and neck cancer initially treated with definitive radiation therapy. Am J Clin Oncol. 2013 Oct;36(5):475-80.

381. Solares CA, Fritz MA, Esclamado RM. Oncologic effectiveness of selective neck dissection in the N0 irradiated neck. Head Neck. 2005 May;27(5):415-20.

382. Lee DJ, Kwon KH, Chung EJ, Park IS, Kim JH, Rho YS. The role of elective neck dissection during salvage surgery in head and neck squamous cell carcinoma. Acta Otolaryngol. 2013 Aug;133(8):886-
92.

383. Wong LY,WeiWI, Lam LK, Yuen AP. Salvage of recurrent head and neck squamous cell carcinoma after primary curative surgery. Head Neck. 2003 Nov;25(11):953-9.

384. Sun LM, Leung SW, Su CY,Wang CJ.The relapse patterns and outcome of postoperative recurrent tongue cancer. J Oral Maxillofac Surg. 1997 Aug;55(8):827-31.

385. Gleich LL, Ryzenman J, Gluckman JL,Wilson KM, BarrettWL, Redmond KP. Recurrent advanced (T3 orT4) head and neck squamous cell carcinoma: is salvage possible? Arch Otolaryngol Head Neck Surg. 2004 Jan;130(1):35-8.

386. Ord RA, Kolokythas A, Reynolds MA. Surgical salvage for local and regional recurrence in oral cancer. J Oral Maxillofac Surg. 2006 Sep; 64(9):1409-14. 